\title{
Eva Schlinkmann
}

\section{Rekonstruktive Verfahren}

\subsection{Einleitung}

Die kommunikative Vergegenwärtigung von Vergangenheit ist eine allgegenwärtige Praktik in unserer alltäglichen Lebenswelt (vgl. Bergmann \& Luckmann 1995, 293-295) ${ }^{1}$. Dies betrifft öffentliche, institutionelle sowie private Bereiche wie z.B. die Rekonstruktion von Tathergängen vor Gericht (vgl. Meier zu Verl 2016), von Träumen in Therapiegesprächen (vgl. Gülich \& Hausendorf 2012; Hausendorf 2012a) oder von Klatsch- oder Beschwerdegeschichten am Esstisch einer Familie (vgl. Keppler 1995; Bergmann 1987; Günthner 2000). In diesem Beitrag werden rekonstruktive Verfahren in Pausengesprächen unter Theaterbesucher(inne)n analysiert. Aufgrund der zeitlichen Nachträglichkeit der Kommunikationssituation besteht für die Zuschauer(innen) die Notwendigkeit, ihre Kunsterfahrung während der Theateraufführung zu rekonstruieren, um auszuhandeln, was sie wahrgenommen haben und worauf sie sich beziehen (vgl. Linz, Hrncal \& Schlinkmann 2016, 536, 543). Der Beitrag geht der Frage nach, welche situations- und kontextspezifischen Merkmale und Verfahren Rekonstruktionen in Pausengesprächen im Theater auszeichnen. Gleichzeitig wird die „soziale Funktion“ (Klein \& Martínez 2009, 8; angelehnt an Gunkel 1906/2004) von Rekonstruktionen in Theaterpausengesprächen diskutiert.

Den theoretischen Rahmen der Untersuchung bilden die Konzepte des ,kommunikativen Haushalts' und der ,kommunikativen Gattung' nach Luckmann (1986) und Bergmann (1987) (vgl. Abschnitt 8.2.1). Zur spezifischeren Klassifizierung der kommunikativen rekonstruktiven Verfahren werden Arten und Subtypen der Rekonstruktion vorgestellt (vgl. Abschnitt 8.2.2). Anschließend verortet Abschnitt 8.2.3 die Pausengespräche in den situativen Kontexten der Kunst-/Publikums- und der geselligen Kommunikation. Auf der Basis der genannten Forschungsaspekte erfolgt dann eine Präsentation der Ergebnisse aus der Analyse des Datenkorpus zu Pausengesprächen im Theater, das im Hinblick auf folgende Fragen analysiert wurde:

- Welche Gegenstände rekonstruieren die Sprecher? Wie unterscheiden sich Subtypen von Rekonstruktionen? (vgl. Abschnitt 8.3.1)

- Wie steigen Sprecher in Rekonstruktionen ein? Wie betten sie dabei Rekonstruktionen in welche Kontexte ein? (vgl. Abschnitt 8.3.2)

1 Vgl. zum kommunikativen Gedächtnis Feilke (2014). 
- Wie entfalten sich Rekonstruktionen in ihrem Verlauf? Welche Funktionen und Darstellungsmodi prägen sie dabei (vgl. Abschnitt 8.3.3)?

_ Wie beenden Sprecher Rekonstruktionen (vgl. Abschnitt 8.3.4)?

Zum Schluss wird eine Zusammenfassung der rekonstruktiven Verfahren, Rekonstruktionsarten und -funktionen gegeben, die Pausengespräche im Theater auszeichnen (vgl. Abschnitt 8.5).

Um die Analyseergebnisse zu illustrieren, werden im vorliegenden Beitrag 11 ausgewählte Auszüge aus 6 Gesprächen vorgestellt. Die ausgewählten Gespräche zeichnen sich einerseits durch ihre Reichhaltigkeit an Rekonstruktionen aus. Andererseits beinhalten sie Rekonstruktionspraktiken, die als exemplarisch für das gesamte Datenkorpus im Hinblick auf die darin vorkommenden Rekonstruktionen im spezifischen Kontext der Theaterpausengespräche gelten können.

\subsection{Rekonstruktive Verfahren im Kontext}

Als theoretische Grundlage der Analyse in Abschnitt 8.4 dient der Bezugsrahmen der kommunikativen Gattungen, der grundlegend auf den Untersuchungen von Luckmann (1986) \& Bergmann (1987) basiert. Innerhalb dieses Rahmens erläutert Abschnitt 8.2.1 die theoretischen Konzepte des kommunikativen Haushalts, der kommunikativen Gattung, des ,sozialen Ereignisses‘ und der (Analyse-)Struktur kommunikativer Gattungen. Darauf aufbauend entwickelt Abschnitt 8.2.2 ein allgemeines Konzept von rekonstruktiven Verfahren und beschreibt einige für die anschließende Untersuchung relevante Subtypen. Die im Beitrag untersuchten rekonstruktiven Verfahren in Theaterpausengesprächen lassen sich kontextuell in die Bereiche der Publikumskommunikation, hier als Teil der Kunstkommunikation, sowie der geselligen Kommunikation einordnen (vgl. Abschnitt 8.2.3).

\subsubsection{Kommunikative Gattungen im kommunikativen Haushalt}

Das gesamte kommunikative Repertoire, das einer bestimmten Sprechergruppe zur Verfügung steht, bezeichnet Luckmann $(1986,1988)$ als den kommunikativen Haushalt einer Gesellschaft oder einer gesellschaftlichen Gruppierung (z.B. der Theaterbesucher(innen)) (vgl. auch Ayaß 2011). Luckmann (1988, 284) ergänzt, der kommunikative Haushalt sei „die Gesamtmenge der kommunikativen Vorgänge, die auf Bestand und Wandel einer Gesellschaft einwirken“. Dieser 
beinhaltet einerseits musterhaft verfestigte kommunikative Formen und andererseits freie und ,spontane' Formen (vgl. Ayaß 2011; Luckmann 1986). Letztere bringen die Sprecher je nach Situation, Intention und Kontext jeweils in situ vollkommen frei und flexibel spontan hervor (vgl. Bergmann 1987, 35-42, Günthner \& Knoblauch 1994, 696-702). Keppler (1995, 52) nennt diese spontaneren Gesprächsabschnitte und -phasen die „Gelenkstellen“ eines Gesprächs oder einer kommunikativen Gattung. Diese freieren Elemente ermöglichen oft den Übergang von einem Strukturelement eines Musters zum nächsten oder den Wechsel zwischen zwei verfestigten Mustern innerhalb eines Gesprächs. Anhand der kommunikativen Formen, die eine spezifische Gesellschaft zu einer bestimmten Zeit realisiert, lassen sich Rückschlüsse über das Relevanzsystem (Werte, Normen, Tabus etc.) dieser Gesellschaft ziehen (vgl. Ayaß 2011; Luckmann 1986). Demnach ist jeder kommunikative Haushalt höchst kultur- und epochenspezifisch und in seinen Elementen und Ausprägungen einem ständigen Wandel unterlegen (vgl. Ayaß 2011; Luckmann 1986). Die musterhaft verfestigten kommunikativen Formen innerhalb des kommunikativen Haushalts werden von Luckmann, Bergmann, Günthner \& Knoblauch, Keppler und Ayaß als ,kommunikative Gattungen“ bezeichnet.

Bereits Bakhtin $(1986,79)$ entwickelte das Konzept der ,speech genres', auf dem der Gattungsbegriff aufbaut. Zur dessen Relevanz schreibt er: „if speech genres did not exist [...], speech communication would be almost impossible“. Günthner \& König $(2016,177)$ definieren kommunikative Gattungen basierend auf den Gattungskonzepten von Gunkel (1906/2004), Hymes (1972), Vološinov (1929/1975), Bakhtin (1986), Luckmann (1986), sowie Günthner \& Knoblauch (1994) als ,[rekurrente kulturell verfestigte] allägliche kommunikative Muster, an denen sich Sprecher/innen und Rezipient/innen bei der Produktion und Rezeption kommunikativen Handelns orientieren." ${ }^{2}$ Ergänzend stellt Ayaß (2011, 278-279) heraus, dass kommunikative Gattungen kommunikative Vorgänge (z.B. einen Gesprächsausschnitt) bezeichnen, die „in ihrem Ablauf ein hohes Maß an Gleichförmigkeit“ aufweisen und „als Routinen, Regeln oder Rituale“ beschrieben werden können. Demnach gibt eine kommunikative Gattung durch gesellschaftlich verankerte Konventionen Formvorgaben, Leitlinien und Ordnungsschemata bezüglich der Frage vor, ,wer wann [mit wem] wie“ (vgl. Ayaß 2011, 279) kommuniziert. Konstitutiv für alle kommunikativen Gattungen sind, so Günthner \& König (2016) sowie Ayaß (2011), als Teil der musterhaften Verfestigungen ein relativ klar erkennbarer Anfang und ein Ende. Weiterhin werden unterschiedliche Gattungen durch unterschiedliche Bestim-

2 Vgl. ausführlicher zum Gattungskonzept Günthner (2014). 
mungsmerkmale im Sinne von Merkmalskombinationen charakterisiert, die auf allen sprachlichen Ebenen angesiedelt sein können - sei es beispielsweise eine spezifische Intonation, eine bestimmte Wortwahl, eine feste Sequenzabfolge oder eine spezielle Rollenverteilung der Kommunikationsteilnehmer. Nicht zuletzt unterscheiden sich unterschiedliche Gattungen im Verfestigungsgrad, der von sehr starr bis zu relativ unverbindlich reichen kann, sowie in ihrer Komplexität (vgl. Günthner \& Knoblauch 1996; Keppler 1995; Abb. 17).

An den daraus entstehenden spezifischen Merkmalskombinationen orientieren sich die Mitglieder einer Gesellschaft in „wiederkehrende[n] soziale[n] Situationen“ (Ayaß 2011, 279), wie z.B. beim Klatsch über einen gemeinsamen Nachbarn. Durch die prominente Gattung des Klatsches (vgl. Bergmann 1987) werden die Sprecher laut Ayaß (vgl. 2011, 278) in einer entsprechenden sozialen Situation von Entscheidungsdruck entlastet und empfinden Verhaltenssicherheit in der Interpretation des Hervorgebrachten und darin, was sie jeweils selbst hervorbringen. Diese „soziale Funktion“ (Klein \& Martínez 2009, 8) beschreibt schon Gunkel $(1906 / 2004,57)$ als „Sitz im Leben [...], aus dem Inhalt und Form erst verstanden werden können“. Die so tradierten „gesellschaftliche[n] Wissensbestände“ (Keppler 1995, 18) über Gattungen sind jedem Gesellschaftsmitglied in seiner Anwendung (nicht jedoch in seiner Theorie) bekannt, wie Keppler am Beispiel kommunikativer Gattungen bei Familientischgesprächen aufzeigt. Bakhtin (1986, 79) perspektiviert die Verwendung von ,speech genres“ aus der praktisch-konkreten Sprecher- und Hörerperspektive, indem er schreibt:

We learn to cast our speech in generic forms and, when hearing others' speech, we guess its genre from the very first words; we predict a certain length [...] and a certain compositional structure; we foresee the end; that is, from the very beginning we have a sense of the speech whole [...].

Wissenssoziologisch betrachtet wird nach Luckmann (1986, 195-200) durch Gattungen die Struktur aufgezeigt, in der gesellschaftliches (alltagspraktisches) Wissen (Ereignisse, Sachverhalte, Erfahrungen) intersubjektiv vermittelt, thematisiert, bewältigt und tradiert und somit Wirklichkeit erzeugt wird. Dieser Sicht liegt die Grundannahme der ethnomethodologischen Konversationsanalyse einer „Vollzugswirklichkeit“ (vgl. Bergmann 1981, 10-12; Berger \& Luckmann 1969/2012) zugrunde.

Untersucht wurden bisher sowohl alltägliche, verbreitete Formen wie die Alltagserzählung (vgl. Gülich 20083), die Belehrung, der Streit, die Diskussion (zu allen vgl. Keppler 1995), der Witz (vgl. Kotthoff 2011), das Frotzeln (vgl.

3 Vgl. dazu auch ausführlicher: Gülich (1980); Keppler (1995); Quasthoff (2001). 
Keppler 1995; Günthner 2000) oder der Klatsch (vgl. Bergmann 1987) als auch sehr spezifische Ausprägungen wie die Konversionserzählung (vgl. Ulmer 1988) oder das Sich-Mokieren und Jammern in Umweltgruppen (vgl. Christmann 1999 und 1999a). Jede Gattung erfüllt eine bestimmte kommunikative Aufgabe bzw. einen Bedarf in einer spezifischen sozialen Situation. Ein Beispiel stellt der „Vergemeinschaftungsmechanismus“ (Bergmann 1987a, 814) von Klatsch dar.

Die Relevanz von kommunikativen Gattungen lässt sich auch an den Konsequenzen, die die Nichtbeachtung von Gattungskonventionen nach sich zieht, erkennen. So stellt Bergmann $(1987,36)$ fest, dass die Nichtbeachtung zu „schmerzhaften Karambolagen“ im Sinne negativer sozialer Konsequenzen führe. Demnach könnte z.B. das Klatschen über eine Person ohne vorher die Klatschbereitschaft aller Gesprächsteilnehmer abzuklären (vgl. „Prä-Sequenz“; Bergmann 1987, 114) den Ruf des Klatschenden schädigen.

Unter den Überbegriff der kommunikativen Gattungen lassen sich sowohl große kommunikative Gattungen als auch ,kleine' kommunikative Gattungen ${ }^{5}$ fassen. Laut Ayaß $(2011,285)$ sind letztere weniger komplex, flexibler und weniger umfangreich als große kommunikative Gattungen. Außerdem unterscheiden sie sich von großen kommunikativen Gattungen durch ihren geringeren Komplexitäts- und Verfestigungsgrad sowie ihren geringeren Umfang und ihre größere Funktionsflexibilität. Darüber hinaus werden sie häufig in größere Muster und Gattungen eingebettet (vgl. Günthner \& Knoblauch 1994). So werden beispielsweise Alltagserzählungen (vgl. Keppler 1995; Quasthoff 2001), Klatsch (vgl. Bergmann 1987) und Sich-Mokieren in Umweltgruppen (vgl. Christmann 1999a) als große kommunikative Gattungen eingeordnet, wohingegen Frotzeln, Vorwürfe, (zu beiden vgl. Günthner 2000), Sprichwörter, Komplimente (vgl. zu beiden Ayaß 2011) oder Belehrungen (vgl. Keppler 1995) als kleine kommunikative Gattungen klassifiziert werden. Allerdings gestaltet sich der Übergang zwischen großen und kleinen kommunikativen Gattungen fließend (vgl. Günthner 2000).

Bestimmte Gattungen lassen sich im Rahmen spezifischer sozialer Ereignisse und sozialer Milieus finden. Letztere werden von jeweils spezifischen kommunikativen Haushalten geprägt. Die konstituierenden Eigenschaften eines

4 Vgl. auch Ayaß (2011); Bergmann (1987); Günthner (2014); Günthner \& König (2016).

5 Während Bakhtin $(1986,72)$ von „secondary speech genres“ (im Kontrast zu „primary speech genres“) spricht, heißen sie bei Luckmann (1988) und bei Bergmann (1987) „Kleinformen“ oder „Minimalgenres“ (vgl. Kotthoff 2011; Keppler 1995), bei Günthner \& Knoblauch (1994) „Kleinund Kleinstformen“ und bei Ayaß (2011) und Günthner (2000) „Kleine Formen“. Da sie ein fast deckungsgleiches Konzept bezeichnen, wird im Folgenden zusammenfassend der Terminus ,kleine Gattungen` verwendet. 
sozialen Milieus bestehen laut Keppler (1995, 23, 51-52) in relativ festen Sozialbeziehungen, gewohnheitsmäßigen Orten, synchronisierten Zeitbudgets und typischen sozialen Veranstaltungen. Beispiele für soziale Milieus sind Familien, Stammtische, Freundeskreise, Frauengruppen, Studierendencliquen, Vereine oder Theatergruppen. Diese sozialen Gruppen werden in der Regel durch jeweils spezifische soziale Veranstaltungen oder Ereignisse charakterisiert, wie z.B. das Familientischgespräch, bestimmte Meetings, Sprechstunden (vgl. Keppler 1995) oder das Theaterpausengespräch, sowie durch spezifische Gruppenstile. Dabei stellt ein soziales Ereignis einen strukturierten und formalisierten Handlungszusammenhang dar, der durch einen fixen zeitlichen und räumlichen Rahmen sowie typische Gesprächsformen (z.B. kommunikative Gattungen), einen typischen Gesprächsverlauf und typische Teilnehmerrollen kulturell geprägt wird (vgl. Ayaß 2011).

In Abschnitt 8.4 werden 11 Ausschnitte aus Theaterpausengesprächen (im Sinne sozialer Ereignisse) diverser sozialer Milieus von Theaterbesucher(innen) analysiert. Um dem nachzugehen, soll zunächst erläutert werden, wie sich nun einzelne kommunikative Gattungen im Rahmen bestimmter sozialer Ereignisse (wie des Theaterpausengesprächs) und spezifischer sozialer Milieus analytisch beschreiben lassen.

Zur Beschreibung der Merkmale einzelner kommunikativer Gattungen (im Rahmen bestimmter sozialer Ereignisse wie dem Theaterpausengespräch und spezifischer sozialer Milieus) und der Analyse ihrer Funktion wurde die Gattungsanalyse entwickelt. Methodisch beruht die Gattungsanalyse auf den Konzepten zweier bzw. dreier synthetisch zusammenhängender Strukturebenen: Der ,Binnenstruktur', der ,Außenstruktur‘ und ggf. der ,situativen Realisierungsebene‘. Unter die Binnenstruktur fasst Luckmann $(1986)^{6}$ die konkreten kommunikativen Elemente, die Akteure verwenden, um die Basis für die kommunikative Gattung herzustellen. Diese materiale Basis kann aus sehr unterschiedlichen Elementen bestehen, die eine Vorauswahl aus allen möglichen kommunikativen ,Codes‘ einer Gesellschaft darstellen. Sie betreffen sprachliche Bereiche wie Phonologie, Prosodie, Semantik, Syntax, aber auch textuelle sowie parasprachliche und nonverbale Aspekte. Konkret betrifft die Binnenstruktur nach Luckmann (1986) also Elemente wie „rhetorische Mittel, Stilmittel aber auch Lautmelodien und andere prosodische Elemente, Wortwahl, Register usf.“ (Ayaß 2011, 280). Die zweite gattungsanalytische Ebene bezeichnet Luckmann (1986) als Außenstruktur der Gattung, die den sozio-kulturellen Kontext be-

6 Vgl. auch Ayaß (2011); Bergmann (1987); Günthner (2006); Günthner \& Knoblauch (1994); Günthner \& König (2016); Keppler (2006) und Luckmann (1988; 2002). 
schreibt, u.a. das kommunikative Milieu, die kommunikative Situation, die Sprecherrollen und die wechselseitigen Beziehungen der Handelnden. Konkrete Ausprägungen hängen beispielsweise mit Alter, Geschlecht und Status der Kommunizierenden zusammen (vgl. Günthner 2006).

Günthner \& Knoblauch (1994) ergänzen das Gattungsanalysemodell von Luckmann um eine dritte durch die ethnomethodologische Konversationsanalyse beeinflusste Ebene: Die situative Realisierungsebene (vgl. „Dialogstruktur“, Androutsopoulos \& Schmidt 2002, 50; „Interaktionsebene“, Günthner 2000, 16). Sie basiert auf dem realisierten strukturellen, interaktiven, sequenziellen Ablauf der jeweiligen Gattung und legt den Fokus auf die Dialogizität von Gattungen aufgrund der Beteiligung von mehreren Akteuren. Dabei werden Bereiche wie spezifische sequenzielle Muster, konversationelle Merkmale, interaktive Organisationsstrategien und Beteiligungsformate sequenzanalytisch untersucht. Beispiele für konversationelle Merkmale einer Gattung beziehen sich auf musterhafte Redezugabfolgen, Einschub-, Prä- und Postsequenzen sowie Paarsequenzen, aber auch auf die längerfristige Gesprächsorganisation (vgl. Günthner \& Knoblauch 1994, 708; Keppler 2006). Zusammenfassend besteht das Ziel der Gattungsanalyse im Auffinden und Beschreiben von sprachlich-kommunikativen Mustern und Musterkombinationen auf den beschriebenen Ebenen. Eine Gruppe kommunikativer Verfahren (inklusive kommunikativer Gattungen), die im Kontext von Pausengesprächen im Theater besonders relevant ist, sind die rekonstruktiven Verfahren. Deshalb werden diese im Folgenden aus der Gesamtheit aller kommunikativen Formen, die den kommunikativen Haushalt ausmachen, herausgegriffen. In Abschnitt 8.2 werden rekonstruktive Verfahren zunächst beschrieben und anschließend anhand von Datenmaterial untersucht (Abschnitt 8.4).

\subsubsection{Rekonstruktive Verfahren}

Social events are essentially transitory [...], i.e. they occur, they are gone and irrevocably become part of the past. [...] And so, past events, ,gone forever', are reconstructed. (Bergmann \& Luckmann 1995, 293)

Eine Art der kommunikativen Verfahren, die in jeder Gesellschaft existieren und hier als Subgruppe herausgegriffen werden sollen, sind die rekonstruktiven Verfahren. Diese bezeichnen die Gesamtheit an sprachlich-kommunikativen Verfahren, derer sich Sprecher einer Gesellschaft bedienen, um bereits vergangene Erfahrungen, Ereignisse und Handlungen im Gespräch zu vergegenwärtigen und zu reproduzieren (vgl. Günthner 2000, 203; 2007; Gülich 2007; Gülich, 
Knerich \& Lindemann 2009). Eingängige Beispiele dafür stellen der Klatsch, z.B. die Rekonstruktion des verwerflichen Verhaltens eines gemeinsamen Bekannten, dar (vgl. Bergmann 1987), das Erzählen einer selbst erlebten Alltagsgeschichte (vgl. Gülich 2008), die Schilderung eines erlittenen Anfalls im Therapiegespräch (vgl. Gülich, Knerich \& Lindemann 2009) oder das Imitieren einer Person, z.B. eines als arrogant wahrgenommenen Arztes oder einer als einfältig empfundenen Verkäuferin (vgl. Günthner 2002).

Rekonstruktive Verfahren reichen von freien, spontanen kommunikativen Elementen, die aus wenigen Redezügen und Sequenzen bestehen, über musterhafte kleine kommunikative Gattungen bis zu den umfangreichen, komplexen rekonstruktiven Gattungen, die ganze Gesprächsabschnitte dominieren können. Somit repräsentieren rekonstruktive Verfahren einen Ausschnitt aus dem Gesamtkomplex des kommunikativen Haushalts, der alle kommunikativen Verfahren umfasst. Diejenigen rekonstruktiven Verfahren, die einen gewissen Grad an musterhafter Verfestigung und Komplexität aufweisen, lassen sich aus der Gesamtmenge der rekonstruktiven Verfahren als (kleine oder große) rekonstruktive Gattungen herausgreifen (vgl. Abb. 17).

Abbildung 17 stellt den Zusammenhang zwischen rekonstruktiven kommunikativen Verfahren und dem kommunikativen Haushalt einer Gesellschaft dar. Der Haushalt wird durch den äußeren Kreis dargestellt und beinhaltet alle möglichen kommunikativen Verfahren, derer sich die Sprecher einer Gesellschaft bedienen. Diese lassen sich in typische spontane kommunikative Formen (dargestellt durch den inneren dunkelgrauen Kreis), sowie kleine kommunikative Gattungen (dargestellt durch den mittleren hellgrauen Ring) und große kommunikative Gattungen (dargestellt durch den weißen äußeren Ring) gliedern. Wie die gestrichelten Linien symbolisieren, sind die Übergänge dabei fließend. Das prägnanteste Unterscheidungsmerkmal von spontanen Formen und kleinen und großen Gattungen besteht in ihrer Komplexität und Verfestigung, wie der schwarze Pfeil illustriert. Spontane kommunikative Formen sind weder musterhaft verfestigt noch komplex. Im Gegensatz dazu sind die Muster großer kommunikativer Gattungen stärker verfestigt und komplexer als die kleiner kommunikativer Gattungen. Rekonstruktive (kommunikative) Verfahren, als Gattungsfamilie, stellen nun einen Ausschnitt aus allen möglichen kommunikativen Verfahren des kommunikativen Haushalts dar. Entsprechend werden sie in der Abbildung als Keilform repräsentiert. Ebenso wie alle anderen kommunikativen Verfahren/ Formen lassen sie sich in spontane kommunikative Formen (innerer Kreis), verfestigte kleine kommunikative Gattungen (mittlerer Ring) und große kommunikative Gattungen (äußerer Ring) gliedern. Der Fokus dieses Kapitels liegt auf eben diesem Segment, also allen mehr oder weniger 
musterhaft verfestigten rekonstruktiven Verfahren (spontanen Formen, aber vor allem auch kleinen und großen kommunikativen Gattungen).

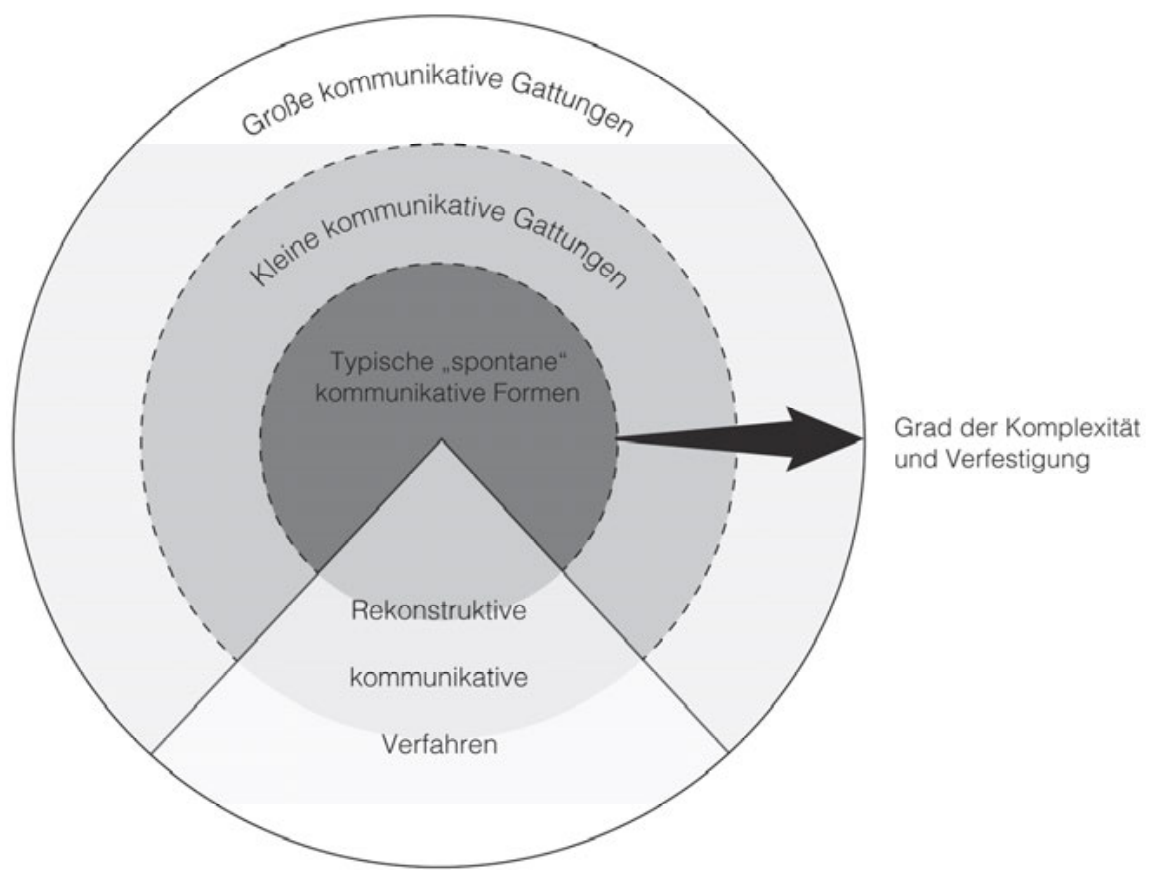

Abb. 17: Kommunikativer Haushalt und rekonstruktive Verfahren (eigene Darstellung angelehnt an Luckmann 1986)

Rekonstruktive Verfahren wurden bereits in diversen Kontexten untersucht. Dabei wurden einerseits relativ allgemeine, verbreitete Muster herausgearbeitet, wie z.B. die Erzählung/Geschichte (vgl. Ehlich 1980; Gülich 20087; Günthner 2005'; Kern, Morek \& Ohlhus 2012; Keppler 1995; Labov \& Waletzky 1967; Quasthoff 2001'; Schumann et al. 2015) mit den Subtypen Alltagsgeschichte (vgl. Keppler 1995; Gülich 2008 ${ }^{10}$ ), Beispielgeschichte (vgl. Keppler 1988); Beschwerdegeschichte (vgl. Günthner 2007¹), Klatsch (vgl. Bergmann 1987; Kepp-

7 Vgl. mit Schwerpunkt auf Mustern und Funktionen auch Gülich (1980).

8 Vgl. zu kurzen Erzählungen („Small stories“) auch Günthner (2012).

9 Vgl. ausführlicher auch Quasthoff (1980).

10 Vgl. mit Fokus auf narrative und szenische Rekonstruktion Gülich (2007).

11 Vgl. ausführlicher auch Günthner (2000). 
ler 1995) und Witz (vgl. Kotthoff 2011). Ebenso untersucht wurden die allgegenwärtigen Verfahren: ,Medienverweis‘/,Medienreferenz' und ,Medienrekonstruktion‘ (vgl. Keppler 1995; Ulmer \& Bergmann 1993), Verfahren der Vergangenheitsrekonstruktion im Familientischgespräch (vgl. Keppler 1995), Bericht (vgl. Kotthoff 2011) oder Lästern (vgl. Schubert 2009). Andererseits wurden eher (kontext-)spezifische rekonstruktive Verfahren beschrieben wie z.B. die Konversionserzählung (vgl. Ulmer 1988), Rekonstruktionen in Krankheitserzählungen (vgl. Deppermann \& Lucius-Hoene 2005; Gülich, Knerich \& Lindemann 2009²) und in Traumerzählungen (vgl. Gülich \& Hausendorf 2012; Hausendorf 2012) sowie das Sich-Mokieren in Umweltgruppen (vgl. Christmann 1999a). Ein besonderer Fokus im Bereich der rekonstruktiven Verfahren liegt weiterhin auf der sprachlichen Darstellungsweise der ,Reinszenierung'/des ,Reenactment“ (vgl. Bergmann 2000; Günthner 2000; Huynh 2016; Keppler 1995; Knipp 2016; Meier zu Verl 2016; Meiler 2016) und auf Redewiedergaben (vgl. Butterworth 2015; Buttny \& Cohen 2007; Clift 2007; Coulmas 1986; Couper-Kuhlen 2007; Günthner 2005 ${ }^{13}$; Holt 2007; Semino \& Short 2004; Tannen 1989/2007 ${ }^{14}$ ). Einige dieser für die Analyse besonders relevanten rekonstruktiven Verfahren werden im Folgenden vorgestellt und mit Blick auf ihre kontextspezifische Ausformung und Funktion ergänzt und weiterentwickelt.

Eine in der Erzählforschung bereits intensiv untersuchte rekonstruktive Gattungsfamilie besteht im Geschichten-Erzählen bzw. den Erzählungen. So weist Keppler (1995, 72-78) auf das kommunikative Verfahren des GeschichtenErzählens in Familientischgesprächen hin. Basierend auf Stahls (1977) ,personal narrative' definiert sie es durch folgende Merkmale: erzählt in der ersten Person; Erzähler ist Hauptakteur; Nacherzählen von Wissen aus erster Hand; persönlicher Charakter der Erzählung; idiosynkratische Erzählung. Des Weiteren beginnen Geschichten, laut Keppler, i.d.R. mit einer Einleitung (,story preface) in Form eines Erzählangebots und einer Annahme/Ablehnung (vgl. Sacks 1971), gefolgt von den Elementen der Orientierung (Ort, Zeit, Personen), der Komplikation (des Handlungsverlaufes), der (globalen) Evaluation (Markierung der erzählenswerten Qualität des Ereignisses), der Auflösung (des Handlungsknotens) im Sinne des Höhepunkts und schließlich der Coda (Herstellung der Verbindung zur Erzählzeit) (vgl. Quasthoff 2001, 1293). Ergänzend werden in der

12 Vgl. auch ausführlicher mit Fokus auf Schmerz-, Anfalls- und Krankheitsdarstellung Gülich (2003; 2003a; 2002).

13 Vgl. ausführlicher auch (2000) und mit Fokus auf weitere Formen und Funktionen Günthner (2002).

14 Vgl. in Bezug auf griechische und amerikanische Erzählungen auch Tannen (1986). 
weiteren Literatur, stark zusammengefasst, folgende konstitutive Merkmale für Erzählungen genannt: Das erzählte Ereignis muss in der Vergangenheit liegen, ,erzählenswert' sein (also ein für den Erzähler (!) unerwartetes oder ungewöhnliches Element enthalten, das interaktiv als solches relevant gesetzt wird; vgl. Gülich 2008), von menschlichen Figuren handeln und bestimmte formale Merkmale aufweisen (z.B. eine narrative Makrostruktur, narrative Tempora, bestimmte Konnektiva, evaluative und expressive Merkmale, direkte Rede und einen hohen Detaillierungsgrad) (vgl. Ehlich 1980; Gülich 2008; Gülich \& Lucius-Hoehne 2015; Günthner 2005; Kern, Morek \& Ohlhus 2012; Quasthoff 2001; Schumann et al. 2015).

Die Unterscheidung von Erzählungen nach ihrer Funktion reicht von „funktional“ oder „nicht-funktional“ (Gülich 1980, 335) über „kommunikative[...] und interaktive[...] Funktionen“ (Quasthoff 1980, 146) und „eher argumentativpersuasive“ oder „eher phatische Funktionen“ (Günthner 2000, 211) bis hin zur Differenzierung je nach spezifischem Gesprächskontext. Dies verdeutlicht die „Vielfältigkeit der narrativen Genres (Hervorh. im Original)“ (Quasthoff 2001, 1295) verdeutlicht.

Weiterhin charakterisiert Quasthoff (1980, 209-223) Erzählungen durch die Verwendung bestimmter Strukturierungsmittel, nämlich Verzögerungsphänomene (Wiederholungen; ,Fehlstarts‘, (gefüllte) Pausen) und Verknüpfungs- und Gliederungssignale z.B. zur Einleitung der Geschichte: metanarrative Äußerungen, Aufmacher (vgl. Labov 1972 „abstracts“), Nennung von Zeit und Ort im Sinne einer Orientierung oder als Schlusssignal: zusammenfassende/abkürzende Schlussankündigung durch Partikeln indizierte Expansionssequenzen. Außerdem betont Quasthoff $(2001,1294)$ den Tempuswechsel zwischen narrativen Tempora und dem szenischen oder historischen Präsens als typisches Element mündlicher Alltagserzählungen. Gülich \& Lucius-Hoene (2015) stellen weiterhin für die narrative Rekonstruktion von Kriegserlebnissen die Erinnerungsthematisierung (z.B. „,ich erinnere mich äh dass:“; Gülich \& Lucius-Hoene 2015, 144) zur Rahmung und Strukturierung der Geschichte, einen chronologischen Ablauf und eingebettete szenische Darstellungen fest.

Eine Unterart des Geschichten-Erzählens besteht im ,alltäglichen Erzählen“ bzw. in der ,Alltagserzählung‘, in der „der normale Alltag Gegenstand von Erzählungen ist“ (Gülich 2008, 403). Ergänzend zu den genannten Merkmalen von Erzählungen konstatiert die Autorin für Alltagserzählungen am Beispiel der Rekonstruktion einer Kriegsgeschichte u.a. die Verwendung von Anredeformen, Interjektionen und des ,szenischen Präsens،, das Imitieren von Stimme und Sprechweise (vgl. Reinszenierung), „eine sehr kleinschrittige und detaillierte Rekonstruktion von Handlungsabläufen“ (Gülich 2008, 413), rhetorische Fragen 
und die „Reaktualisierung der deiktischen Erlebnisperspektive und der früheren Wahrnehmungs- und Wissensbasis“ (Gülich 2008, 414), sowie die Evaluation der Pointe durch die Gesprächspartner.

Ein weiterer im Kontext von Pausengesprächen im Theater relevanter Subtyp von rekonstruktiven Verfahren besteht in sogenannten Medienrekonstruktionen (vgl. Ulmer \& Bergmann 1993) ${ }^{15}$. Ulmer \& Bergmann unterscheiden dabei unter diesem Überbegriff zwischen Medienrekonstruktionen und Medienverweisen. Demnach stellen Medienrekonstruktionen „eigenständige kommunikative Einheiten“ (Ulmer \& Bergmann 1993, 99) in einem Gespräch dar, in denen entweder ein gesamtes Medienereignis ${ }^{16}$ oder gewisse Teile eines Ereignisses, die der Geselligkeit des Gesprächs dienen, rekonstruiert werden. Medienrekonstruktionen sind weitaus umfangreicher als Medienverweise und werden im Gesprächsverlauf deutlich abgegrenzt (z.B. durch eine Gesprächspause vor der Rekonstruktion und durch einen klaren Anfang und ein klares Ende) (vgl. Ulmer \& Bergmann 1993, 88-90; 99).

Im Gegensatz dazu sind Medienverweise „kurze Bezugnahmen auf Medien oder Medienprodukte, die meist en passant erfolgen, oft ungenauer Art sind“ (Ulmer \& Bergmann 1993, 84) und in einen übergeordneten Gesprächszusammenhang (z.B. eine Diskussion oder Argumentation) eingebettet sind. Darüber hinaus grenzen sie sich dadurch von Medienrekonstruktionen ab, dass ein Medienverweis in der Regel nur von einem Sprecher vollzogen wird, während an einer Rekonstruktion meist alle Sprecher gemeinsam und weitgehend gleichberechtigt beteiligt sind. Nicht zuletzt erfolgt die Rekonstruktion im Rahmen eines Medienverweises zumeist fragmentarisch, selektiv und oft unpräzise. Denn hier wird nur der Teil/Aspekt eines Medienereignisses wiedergegeben, der für den übergeordneten Gesprächskontext (z.B. eine Diskussion oder Argumentation) und den weiteren Gesprächsverlauf relevant ist. Die allgemeine kommunikative Funktion von Medienverweisen (in Bezug auf die von Ulmer \& Bergmann untersuchten (Massen-)Medien wie Fernsehen und Radio) besteht in der Präsentation von relevanten Informationen und Neuigkeiten aus einer externen Wissensquelle. Neben dieser Funktion erfüllt jeder Medienverweis jedoch auch eine je nach Situation variierende interaktive Funktion, die relevanter sein kann als die reine Wissensvermittlung. So kann er beispielsweise der Autorisierung eines gewissen Standpunkts, der Verantwortungsdelegation in Bezug auf eine spezifische

15 Vgl. auch Keppler (1995); Bergmann (2000); Günthner (2000).

16 Als Medienereignis wird das ganzheitliche Rezeptionserlebnis eines Medienprodukts z.B. einer Fernsehsendung verstanden, angelehnt an die Anwendung des Terminus bei Ulmer \& Bergmann (1993) und die Definition eines sozialen Ereignisses nach Luckmann (1988). 
Meinung oder als defensive Technik dienen, um z.B. Argumente zu verteidigen. Ulmer \& Bergmann (1993) und Keppler (1995) ordnen dieses rekonstruktive Verfahren als kommunikative Kleinstform ein. Daraus ergibt sich folgende Gegenüberstellung:

Tab. 4: Gegenüberstellung von Medienverweis und -rekonstruktion (eigene Tabelle angelehnt an Ulmer \& Bergmann 1993 und Keppler 1995)

\section{Medienverweis}

kurze, beiläufige (fragmentarische), andeutungsweise Bezugnahme auf ein Medienereignis

\section{Medienrekonstruktion}

umfangreiche, ausführliche (ganzheitliche)

Rekonstruktion eines Medienereignisses

in übergeordnetem Gesprächszusammenhang eigenständige kommunikative Einheit

ein Sprecher

mehrere weitgehend gleichberechtigte

Sprecher

Doch kommen wir zurück zum komplexeren Verfahren der Medienrekonstruktion, die sich unter diversen Gesichtspunkten klassifizieren lässt. Eine Unterscheidung lässt sich an erster Stelle im Wissensstatus der Gesprächsteilnehmer festmachen. Um diesen interaktiv abzuklären, geht einer Medienrekonstruktion in der Regel eine Gesprächsphase der „Wissensabklärung“ (Ulmer \& Bergmann 1993, 90) voraus, in der ergründet wird, welchen Sprechern das zu rekonstruierende Medienereignis bekannt ist. Wird dabei eine Wissensasymmetrie festgestellt, so erfolgt eine Medienrekonstruktion, die die ,unwissenden' Gesprächsteilnehmer über das Ereignis informieren soll (,informierende Medienrekonstruktion“, Ulmer \& Bergmann 1993, 90-93). Konsequent rekonstruieren die ,wissenden' Sprecher gemeinsam das gesamte Medienereignis in Form einer Nacherzählung, die die typischen Merkmale konversationeller Erzählungen aufweist (vgl. oben; z.B. ,story preface‘, Erzählaufforderung, Initiierungssequenz, chronologische Rekonstruktion des Ereignisses, abschließender Kommentar und Bewertung, Ratifizierung durch Zuhörer). Inhaltlich beziehen sich informierende Medienrekonstruktionen, laut Ulmer \& Bergmann, zumeist auf chronologisch ablaufende (fiktive oder reale) Ereignisse (vgl. bei Keppler 1995, 249: „wissensvermittelnde[...] Medienrekonstruktion“).

Natürlich kann in der Phase der Wissensabklärung auch ermittelt werden, dass alle Gesprächsteilnehmer das angesprochene Medienereignis kennen. Kommt es daraufhin zu einer Rekonstruktion, so dient die Medienrekonstrukti- 
on hauptsächlich der ,gemeinsamen Erinnerung‘ im Gespräch („kommemorierende Medienrekonstruktion“, Ulmer \& Bergmann 1993, 95). Dabei rekonstruieren alle Sprecher in gleichberechtigten Rollen selektiv Fragmente des Medienereignisses, die ihnen erwähnenswert erscheinen, z.B. weil sie besonders lustig, besonders provokant oder besonders aufwühlend sind. Diesbezüglich merkt Keppler $(1995,260)$ an,

daß Medieninhalte dann, wenn sie als eigenständige Themen in Unterhaltungen Eingang finden, nicht nur nacherzählt oder rekonstruiert werden, sondern daß dabei stets auch kommentiert und erklärt, interpretiert und bewertet, in Frage gestellt und heiliggesprochen wird.

Häufig besteht die kommunikative Funktion einer Medienrekonstruktion also z.B. in einem Meinungsvergleich, einer gemeinsamen Deutung oder Kritik des Medienereignisses und seiner Aspekte. Auf diese Weise wird das rekonstruierte Ereignis in jedem Fall ein „Bestandteil der gemeinsamen Erfahrungswelt“ (Ulmer \& Bergmann 1993, 98), der den Vergleich von Wertmaßstäben und Weltdeutungen der Sprecher ermöglicht und somit hochgradig gemeinschaftsstiftend ist. ${ }^{17}$ (Vgl. auch Keppler 1995, 242: „,kommemorative Medienrekonstruktionen“).

Ulmer \& Bergmann weisen jedoch ausdrücklich darauf hin, dass die genannten rekonstruktiven Verfahren nicht ausschließlich bei der Rekonstruktion von Medienereignissen angewandt werden, sondern ebenso für andere Inhalte wie z.B. die gemeinsame kommunikative Erinnerung an Urlaubserlebnisse oder Kindheitsepisoden (kommemorierende Rekonstruktion).

Abgesehen vom Umfang und der Art der Einbettung unterscheiden sich Rekonstruktionen auch in ihrer Darstellungsweise, die zwischen „szenischem Erzählen und Berichten“ (Quasthoff 2001, 1294) variiert ${ }^{18}$. Keppler (1995) sowie Ulmer \& Bergmann (1993) sprechen hier von Reinszenierungen im Kontrast zur berichtenden Darstellungsweise (vgl. Reinszenierung/Re-Enactments bei Bergmann 2000; Gülich 2007; Günthner 2000; Sidnell 2006; Replaying bei Goffman 1975; 1981). Bei Reinszenierungen geht es um eine „Wiederaufführung und Wiederbelebung“ (Keppler 1995, 248) der vergangenen Ereignisse. Kennzeichnend für diesen Modus sind z.B. wörtliche Zitate (Redewiedergabe; vgl. unten), Imitation (z.B. von Sprechweisen, Stimme oder Tonfall aber auch von non-verbalen Handlungen, Geräuschen oder Gesang), Lebhaftigkeit und Anschaulichkeit. Anhand dieses Nachspielens der Ereignisse sollen die Zuhörer letztere „in ge-

17 Für einen differenzierteren Überblick der funktionalen Rahmung vgl. Abschnitt 8.6.4.

18 Vgl. auch zum szenischen und berichtenden Erzählen: Labov \& Waletzky (1967); Rehbein (1984). 
wisser Weise nacherleben können“ (Bergmann 2000, 216). Häufig werden dabei komische Inhalte reinszeniert und von Lachen der Rezipienten begleitet sowie von seriellen Reinszenierungen gefolgt (vgl. Bergmann 2000, 216). Der Sinn solcher Reinszenierungen besteht, laut Bergmann (2000, 216), meist im gemeinsamen Vergnügen an einer „gemeinschaftsstiftenden Aktivität“.

Im Gegensatz dazu steht die berichtende Darstellung einer Rekonstruktion, die i.d.R. umfangreicher und inhaltlich komplexer aufgebaut ist (vgl. Ulmer \& Bergmann 1993, 94-95). Zentrale Merkmale des Berichtens, die im Kontext von Theaterpausengesprächen relevant sind und im Kontrast zur Reinszenierung stehen, umfassen die „Sachorientierung“ (Kotthoff 2011, 394), die „systematische Rekonstruktion“ von „relevanten Daten“ und den „Wahrheitsanspruch unter einem spezifischen Blickpunkt“ (Kotthoff 2011, 394). Strukturell äußert sich diese Orientierung z.B. in einem orientierenden „abstract“ (Labov 1972 363-364; vgl. Labov \& Waletzky 1967, 32) zu Beginn des Berichts und einer „Quintessenz“ (Kotthoff 2011, 396) am Schluss. Die gesamte berichtende Darstellung ist dabei sprachlich-kommunikativ von fehlenden „Dramatisierungsstrategien (wie Redewiedergabe oder Vorführen von Szenen), wenig Detaillierung, [fehlendem] Spannungsaufbau, dafür aber Beschreibungen“ (Kotthoff 2011, 395), sowie Knappheit (z.B. durch Ellipsen) und Informationsvermittlung mit Anspruch auf Neutralität und Faktizität geprägt (vgl. Rehbein 1984, 71).

Wie bereits angedeutet, ist ein typisches Merkmal der reinszenierenden Darstellungsweise von Rekonstruktionen die Redewiedergabe. Tannen (1989/2007, 102) definiert diese (,reported speech“) als „repeating one’s own or another's words within a discourse“. Ebenso beschreiben Engel (1988/1996), Götze, Hess-Lüttich \& Wahrig (2002) und Helbig \& Buscha (1972/2001) Redewiedergaben als „Wiedergabe tatsächlich stattgefundener Äußerungsakte“ (Butterworth 2015, 60). Bei dieser Definition handelt es sich laut Butterworth (2015, 59) jedoch um einen „unscharfe[n] Begriff“. Denn zahlreiche Untersuchungen belegen, dass eine enge Definition nicht zutreffend ist. So werden neben tatsächlich stattgefundenen Äußerungsakten z.B. auch erfundene, hypothetische, zukünftige oder mögliche Äußerungen ebenso wie Gedanken (vgl. Tannen 1989/2007, 112-128: „constructed dialogue“) auf dieselbe Weise wiedergegeben. Butterworth $(2015,64)$ kommt deshalb zu dem Schluss, dass Redewiedergaben als ein kommunikatives Verfahren aufzufassen seien, „mit dessen Hilfe Sprecher/innen kommunikative Situationen entwerfen und diese (Re-)Konstruktionen für den aktuellen Interaktionszusammenhang nutzen können“. Ohne hier auf die diversen Formen, Merkmale und Funktionen von Redewiedergaben im Detail einzugehen, lässt sich als weite Definition von Butterworth $(2015,108)$, die hier als Basis zugrunde gelegt wird, festhalten: „Der kommunikative Akt der 
Redewiedergabe (KA0) ist eine als solche gekennzeichnete Bezugnahme auf einen nicht-gegenwärtigen kommunikativen Akt (KA1)“. Relevant dabei sind die von den Sprechern vollzogene Dekontextualisierung vergangener kommunikativer Akte durch die Lösung aus ihrem ursprünglichen Kontext und ihre gleichzeitige Rekontextualisierung durch die Übertragung in die gesellschaftlichkommunikative Gegenwart, die die Sprecher vollziehen. Dabei lässt sich jede Redewiedergabe einordnen als Wiedergabe eines entweder mündlichen, schriftlichen oder mentalen sprachlichen Akts sowie eines Akts, der vollzogen wurde, noch zu vollziehen ist oder lediglich als vollziehbar dargestellt wird (kontrafaktisch oder virtuell) (Butterworth 2015, 102-109).

\subsubsection{Rekonstruktion im Kontext der Kunstkommunikation bzw. der geselligen Kommunikation}

Die vorangehend beschriebenen rekonstruktiven Verfahren werden zunächst von den Beteiligten in einen Kontext eingeordnet, z.B. den Kontext der Publikums- und Kunstkommunikation und/oder der geselligen Kommunikation. Zur Beantwortung der Frage, wie dies erfolgt, sollen im Folgenden diese beiden Kontexte von Rekonstruktionen vorgestellt werden, die sich jedoch nicht gegenseitig ausschließen, sondern als Pole eines Kontinuums mit einem Überschneidungsbereich zu betrachten sind (vgl. Kapitel 5, i.d.B.).

Eine mögliche Rahmung für rekonstruktive Verfahren in Pausengesprächen im Theater besteht in der Kunstkommunikation (vgl. auch Kapitel 6, i.d.B.). Hausendorf $\left(2012^{19}\right)$ beschreibt Kunstkommunikation als eigenständigen Kommunikationsbereich wie z.B. die Wirtschaftskommunikation oder die Gesundheitskommunikation. Diesen Bereich definieren Hausendorf \& Müller (2015, 435) als „Kommunikation über und mit Kunst“ (vgl. Hausendorf 2012; Filk \& Simon 2010). Weiterhin beschreiben Hausendorf \& Müller basierend auf Hausendorf (2011; 2012) die sprachlichen (oralen und literalen) Routinen und kommunikativen Muster, die Kunstkommunikation charakterisieren. Während Hausendorf dieses jedoch lediglich auf den „gesellschaftlichen Funktionsbereich der Bildenden Kunst“ (Hausendorf \& Müller 2015, 435) anwenden, bezieht die vorliegende Analyse das Schema auf die spezifische Kunstkommunikation der performativen Kunst des Theaters und entwickelt das Konzept dementsprechend weiter. Dabei wird Kunstkommunikation mit Hausendorf (2011; 2012) als Lösung bestimmter kommunikativer Aufgaben verstanden. Nimmt ein Sprecher

19 Vgl. zur Kunstkommunikation auch Hausendorf (2007; 2011). 
demnach ein potentielles Kunstwerk („Kunstverdacht“, Hausendorf \& Müller 2015, 436) wahr, so fühlt er sich einem Zugzwang ausgesetzt, auf dieses Bezug zu nehmen, es zu beschreiben, zu bewerten, zu erläutern oder zu deuten (vgl. Hausendorf 2011; 2012). Diese sprachlichen Handlungen beziehen sich nach Hausendorf \& Müller (2015) modellhaft auf eine jeweils spezifische Frage, die es $\mathrm{zu}$ beantworten gilt.

Die Antworten auf die Frage: „Was gibt es zu sehen (hören, tasten, schmecken, riechen usw.)?“ klassifiziert Hausendorf (2011; 2012, 101) im Kontext der bildenden Kunst als „Beschreiben“, während „Bewerten“ für den Autor das Beantworten der Frage: „Was ist davon zu halten?“ betrifft, „Erläutern“ die Antwort auf die Frage: „Was weiß man darüber?“ darstellt und die Frage: „Was steckt dahinter?“ den Fluchtpunkt des „Deuten[s]“ bildet. Die Erfüllung dieser Aufgaben erfolgt durch die Anwendung spezifischer semantisch-pragmatischer Mittel, die bestimmten Bedeutungsfeldern zugeordnet werden können. So können Kunstbetrachter(innen) ihre Bewertung eines Kunstwerks ausdrücken, indem sie sich zu den Themen Gefallen/Geschmack, Rang/Wert, Wirkung/Eindruck oder Qualität in Bezug auf das Werk äußern. Dagegen betrifft das Beschreiben die Bedeutungsfelder Materialität, Format, Formen und Sichtbarkeit, während das Erläutern sich sprachlicher Mittel zur Darstellung von Werk, Biographischem, Tradition oder Geltung bedient und das Deuten ein Kunstwerk in Bezug auf Intention, Symbol, Bedeutung und Aussage charakterisiert. ${ }^{20}$

Rekonstruktive Verfahren können im Kontext der genannten Aufgaben der Kunstkommunikation verwendet werden und somit u.a. eine fachliche Kommunikationsfunktion erfüllen. Darüber hinaus können Rekonstruktionen von Theaterzuschauer(inne)n während der Pause ebenso in einen geselligen und/oder gemeinschaftsstiftenden Kontext eingebettet sein ${ }^{21}$. So beschreibt Keppler (1995, 242) kommemorierende Medienrekonstruktionen in Familientischgesprächen, „bei denen die Rekonstruktionen weniger der Wissensvermittlung als dem Vergnügen der gemeinsamen Erinnerung“ und der „allgemeinen Erheiterung“ und Unterhaltung (Keppler 1995, 247) dienen. Hier geht es vor allem darum, ,alle an den erheiternden Episoden teilhaben und sie nunmehr gemeinsam auf sich wirken zu lassen“ (Keppler 1995 250). Ebenso beobachten Ulmer \& Bergmann

20 Hausendorf (2006; 2011; 2012) verbindet die Bearbeitung dieser Aufgaben und die dazugehörigen Mittel mit jeweils spezifischen sozialen Positionierungen, die hier jedoch aus Relevanzgründen nicht weiter ausgeführt werden.

21 Der gesellige Rahmen von Rekonstruktionen kann hier im Sinne eines ,homileiischen Diskurses‘ bei Ehlich \& Rehbein (1980), sowie der ,phatischen Kommunikation“ nach Malinowski (1923) und als ,Face Work‘ nach Goffman (1967) verstanden werden. 
(1993, 100) im selben Setting, dass kommemorierende Medienrekonstruktionen „weniger unter dem Zwang zu thematischer Relevanz“ stehen, „sondern eher mit dem Ziel, den Geselligkeitswert des Gesprächs zu erhöhen“verbunden werden. Keppler (1995, 221) kommt daher zu dem Schluss, dass die Rekonstruktion von Medienressourcen „für gesellige Unterhaltungen besonders geeignet sei“. Ähnlich stellen Ulmer \& Bergmann das Vorkommen von Medienrekonstruktionen und -verweisen in gesprächserhaltenden Kontexten fest: Medien sind thematische Ressourcen, ,auf die die Sprecher vorzugsweise dann zurückgreifen, wenn das Gespräch zu verebben droht oder bereits zum Erliegen gekommen ist“ (Ulmer \& Bergmann 1993, 89). Und nicht zuletzt weist Keppler (1995, 258) innerhalb von Familientischgesprächen auf einen gemeinschaftsstiftenden Kontext für Medienrekonstruktionen und -verweise hin: „die Rekonstruktion medialer Erzeugnisse steht im Dienst der Konstruktion gemeinsamer Einstellungen zu den betreffenden Produkten sowie den Themen, die sie exponieren“.

Alle genannten Kontexte ${ }^{22}$ von Rekonstruktionen schließen sich nicht gegenseitig aus, sondern können sich ergänzen und überschneiden. Im nächsten Abschnitt wird an authentischem Datenmaterial ${ }^{23}$ aufgezeigt, wie die konkrete sprachliche Umsetzung von unterschiedlichen rekonstruktiven Verfahren (vgl. Abschnitt 8.2) und ihrer Einbettung in verschiedene Kontexte von Sprechern gestaltet wird. Dabei liegt der Fokus auf dem Kontext der Kunstkommunikation.

Auf der Grundlage der Gesprächsdaten und der in diesem Kapitel dargelegten literaturbasierten Merkmale lässt sich ein Schema zur Klassifizierung/Typologisierung von Medienrekonstruktionen und Medienverweisen (im Sinne von Ulmer \& Bergmann 1993 und Keppler 1995) im spezifischen Kontext von Pausengesprächen im Theater (als soziales Ereignis im Sinne von Bergmann \& Luckmann 1995) entwerfen (vgl. Abb. 18). Als Überbegriff für alle diese rekonstruktiven Verfahren (wie Medienrekonstruktionen und -verweise) mit den in der Analyse zu erarbeitenden spezifischen musterhaften Merkmalen wird im Folgenden der Terminus ,Theaterrekonstruktionen“ verwendet.

22 Vgl. die Ebene der Kontexte in Abbildung 18.

23 Vgl. zur kritischen Auseinandersetzung mit dem Begriff Kapitel 4, i.d.B. 


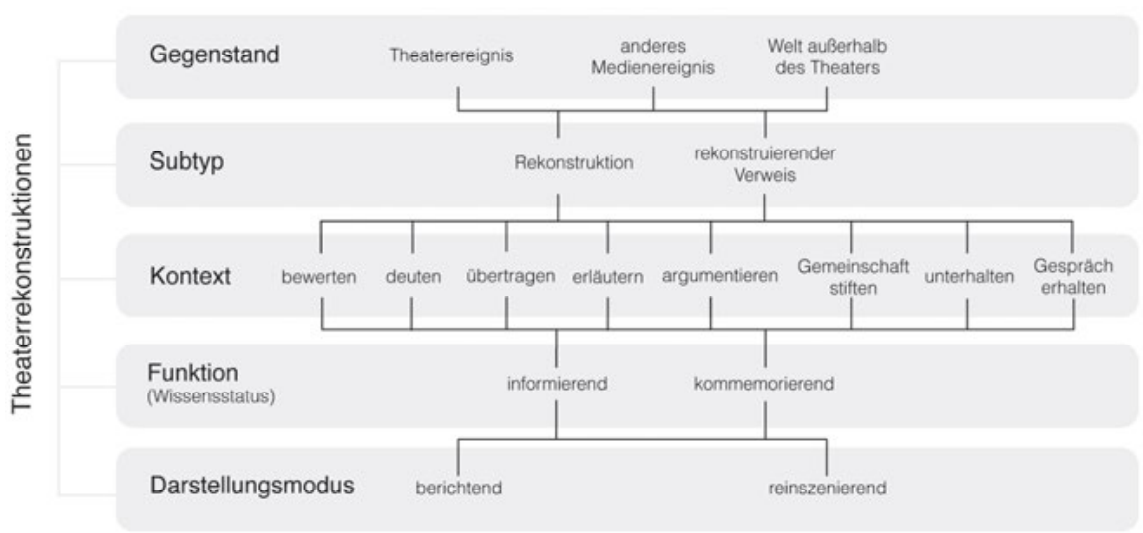

Abb. 18: Typologisierung von Theaterrekonstruktionen

Wie Abbildung 18 (eigene Abbildung) illustriert, unterscheiden sich Theaterrekonstruktionen zunächst hinsichtlich des Gegenstandes oder des Inhalts, den die Sprecher rekonstruieren (oberste Ebene: Gegenstand). Diese können sich auf das Theaterereignis, ein anderes Medienereignis oder auf die Welt außerhalb des Theaters beziehen. Das Theaterereignis soll dabei als Medienereignis (vgl. Abschnitt 8.2.1) im Sinne eines ganzheitlichen Rezeptionserlebnisses der Theaterinszenierung verstanden werden ${ }^{24}$. Es umfasst also nicht nur die eigentliche Theaterinszenierung auf der Bühne, sondern auch alle anderen Erlebnisse, die sich während des strukturierten und formalisierten Handlungszusammenhangs der Theateraufführung, der durch einen fixen zeitlichen Rahmen (Betreten des Theatersaals vor Inszenierungsbeginn und das Verlassen desselben nach dem Pausen- oder Schlussapplaus) begrenzt wird, ereignen. So werden z.B. auch Bezüge zu eigenen Gefühlen und Gedanken der Zuschauer(innen) während der Aufführung oder Beobachtungen zum Verhalten anderer Zuschauer(innen) oder zu sonstigen Geschehnissen im Theatersaal miteinbezogen. Von der Thematisierung des Theaterereignisses wird das Rekonstruieren anderer Medienprodukte und -ereignisse wie z.B. von Büchern, Filmen und Fernsehsendungen oder Opernaufführungen (und ggf. ihrer Rezeption im Sinne eines sozialen Ereignisses) differenziert. An dritter Stelle steht die Thematisierung der Welt außerhalb des Theaters, also z.B. von Alltagserlebnissen. Diese werden jedoch eingegrenzt auf Inhalte, die angeregt durch die Theaterinszenierung

24 Vgl. die Anwendung des Terminus bei Ulmer \& Bergmann (1993) und die Definition eines sozialen Ereignisses nach Luckmann (1988). 
(z.B. bestimmte Themen daraus) in die Pausengespräche eingebettet werden. Alle genannten rekonstruktiven Thematisierungen des Theaterereignisses, anderer Medienereignisse oder der Welt außerhalb des Theaters lassen sich unabhängig von ihrem Inhalt wiederum unterscheiden bezüglich der Art der sprachlich-kommunikativen Realisierung im Sinne verschiedener Subtypen (zweite Ebene: Subtyp). Angelehnt an die Konzepte der Medienrekonstruktion und des Medienverweises bei Ulmer \& Bergmann (1993) wird hier basierend auf den Unterschieden bezüglich der Stellung im Gespräch, des Umfangs und der Sprecherbeteiligung zwischen Rekonstruktionen und rekonstruierenden Verweisen differenziert. ${ }^{25}$ Weiterhin sollen die hier zu betrachtenden Theaterrekonstruktionen klassifiziert werden in Bezug auf den Kontext, in den die Sprecher sie einbetten (Ebene drei: Kontext; vgl. Abschnitt 8.2.3). So können Rekonstruktionen z.B. im Kontext von Bewertungen, Deutungen oder Übertragungen (vgl. Abschnitt 8.3.2.2) kontextualisiert werden. Außerdem unterscheiden sich die so klassifizierten Rekonstruktionen bezüglich des Wissensstatus der Sprecher und der damit verbundenen Funktion (Ebene vier: Funktion) ${ }^{26}$. Die Funktion kann einerseits darin bestehen, unwissende Sprecher zu informieren oder sich kommemorierend an der gemeinsamen Erinnerung zu erfreuen. Nicht zuletzt grenzen sich Rekonstruktionen durch die Art ihrer Darstellung voneinander ab (Ebene fünf: Darstellungsmodus), die entweder tendenziell berichtend oder tendenziell reinszenierend sein kann. Anhand dieser Parameter werden die Rekonstruktionen im Folgenden beschrieben. Dabei wird nicht jede Rekonstruktion zwingend auf jeder Ebene eingeordnet, so dass auch Ebenen von Abbildung 18 übergangen werden können. Außerdem können sich einzelne Parameter auch nur auf einzelne Sequenzen oder Teilrekonstruktionen beziehen, so dass vollständige Rekonstruktionen in ihren Beschreibungsparametern changieren können.

\subsection{Rekonstruktion in Foyergesprächen im Theater}

In Abschnitt 8.2 wurde der theoretische und methodische Rahmen für die Analyse des Datenmaterials im Hinblick auf rekonstruktive Verfahren dargelegt. Dabei wurde die Relevanz rekonstruktiver Gattungen im kommunikativen

25 Da es sich bei allen hier behandelten Rekonstruktionen, um Rekonstruktionen in Bezug auf das Medium ,Theater' handelt, wird an dieser Stelle und im Folgenden auf die Spezifizierung Theaterrekonstruktion und Theaterverweis verzichtet.

26 Vgl. Kapitel 7, i.d.B. 
Haushalt einer Gesellschaft aufgezeigt. Weiterhin gab Abschnitt 8.2 Aufschluss über die Forschungslücke, die im Bereich der Kunstkommunikation hinsichtlich des Bereichs der performativen Künste besteht. Wenden wir uns nun der Analyse ebendieser Daten zu, um die übergeordneten Fragen zu beantworten: Welcher rekonstruktiver Verfahren bedienen sich Theaterzuschauer(innen) im Pausengespräch? Und lassen sich dabei mehr oder weniger musterhafte Verfestigungen oder rekonstruktive Gattungen finden? Diese Fragen sollen anhand folgender Teilaspekte behandelt werden: Welche Inhalte rekonstruieren die Theaterbesucher(innen) in der Pause? Und welche rekonstruktiven Subtypen werden dabei verwendet? (8.1) Wie steigen die Sprecher in Rekonstruktionen ein? Und in welchem Kontext finden Rekonstruktionen statt? (8.2) Wie entfalten die Zuschauer(innen) die Rekonstruktionen? Welchen Funktionen dienen die Rekonstruktionen dabei? Und welche Darstellungsweisen nutzen die Sprecher? (8.3)

Als Datengrundlage für dieses Kapitel dienen 11 Ausschnitte aus 6 Pausengespräche aus dem Projekt-Korpus, anhand derer sich die spezifischen Eigenschaften von Rekonstruktionen in Foyergesprächen im Theater besonders gut aufzeigen lassen. Es handelt sich um Pausengespräche bei Aufführungen der Stücke „Der Streik“ und „Brain and Beauty“, die im Schauspiel Köln aufgeführt wurden, sowie während der Stücke „Hamlet“ und „Der Hundertjährige, der aus dem Fenster stieg und verschwand“, die im Apollo-Theater Siegen inszeniert wurden. Die Sprechergruppen bestehen aus zwei bis drei Personen, die bis auf eine Ausnahme in relativ vertrauter Beziehung zueinander stehen. Es unterhalten sich jeweils eine dreiköpfige Familie, Mutter und Tochter, zwei Studienfreunde und ein junges Paar. Da es zu einer Interaktion zwischen zwei Sprechergruppen kommt, kommunizieren außerdem in einem der Gespräche zwei Sprecher miteinander, die sich erst seit dem Abend der Datenerhebung kennen. Die Sprecher unterscheiden sich sowohl hinsichtlich Alter (16-73 Jahre), Geschlecht, Beruf (z.B. Schüler(in), Student(in), Physiotherapeut(in), Informatiker(in) oder Dozent(in)) und Bildungsstand (Realschulabschluss bis Promotion) als auch in der Regelmäßigkeit ihrer Theaterbesuche (1-20 pro Jahr). 


\subsection{1 „dann kommt aber einer in SOcken daher ${ }^{627}$ - Gegenstände und Subtypen der Rekonstruktion}

Hinsichtlich der Frage, welche Inhalte die Sprecher während der Pause rekonstruieren, lassen sich in der Analyse des Datenkorpus drei grundsätzliche Tendenzen bezüglich der Rekonstruktionsgegenstände feststellen: Die Theaterbesucher(innen) beziehen sich in der Rekonstruktion auf die aktuelle Theatervorstellung, auf andere Medienerfahrungen (z.B. aus Oper, Fernsehen oder Büchern) oder auf die Welt außerhalb des Theaters. Im Folgenden werden die ersten beiden Fälle anhand zweier Gesprächsausschnitte (Ausschnitt 1 und 2) exemplifiziert. ${ }^{28}$ Bei Betrachtung der Rekonstruktionen im Datenmaterial fallen außerdem zwei Typen der Rekonstruktion auf, die sich u.a. bezüglich ihres Umfangs, ihrer Stellung im Gesprächszusammenhang und der Sprecherbeteiligung unterscheiden: Medienverweis und -rekonstruktion (vgl. Ulmer \& Bergmann 1993; Keppler 1995; Tabelle 4).

Der erste Ausschnitt stammt aus einem Pausengespräch während einer Aufführung der klassischen Shakespeare-Tragödie „Hamlet“, die von Prinz Hamlet handelt, der den Mord und Thronraub an seinem Vater König Hamlet rächen will. Moritz und Marco unterhalten sich zunächst über organisatorische Aspekte (Aufsuchen des WCs) und bewerten die Rollen, schauspielerische Leistung, das Bühnenbild, die Kostüme und die Beleuchtung der Theateraufführung, bevor sich folgender Gesprächsausschnitt ereignet:

Ausschnitt 1: „ich hab ernsthaft KOPFschmerz.“29

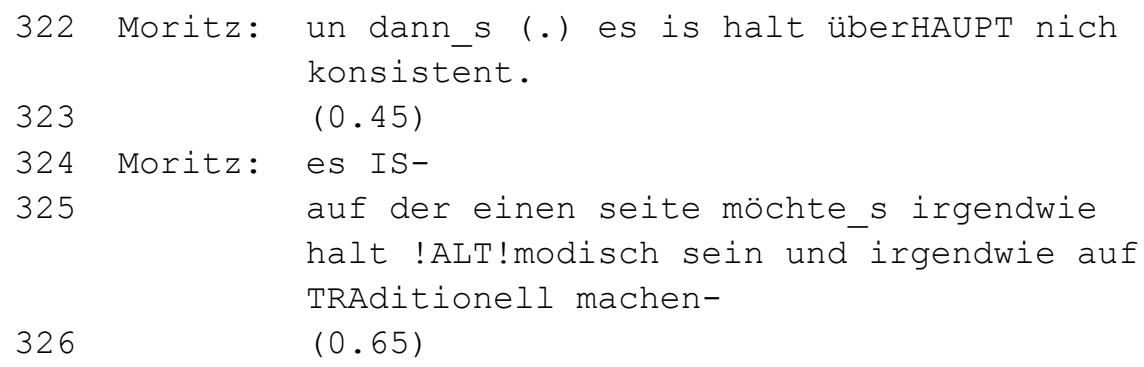

27 Siegen 14-11-14 Hamlet Gr.2.

28 Aus Relevanz- und Platzgründen wird auf die Rekonstruktion von Ereignissen außerhalb der Theatererfahrung nicht näher eingegangen.

29 Siegen 14-11-14 Hamlet Gr.2. 
327 Moritz: dann kommt aber einer [in SO]cken daher-

328 Marco:

329 Moritz: also AUCH$[j a-$ ]

330

$(0.47)$

331 Moritz: de gute GEIST-

332 Marco: oKEE ja:-

$333(0.22)$

334 Moritz: also !ICH! persönlich seh den geist halt nicht so LEIdend.

335 $(0.62)$

336 Moritz: KANN man machen.

MUSS man aber nich.

und-

339

(2.95)

340 Moritz: ja dann ham wa ma bischn was aus m HoRrorfilm abgeguckt-=deswegen zittert der geist die ganze zeit so? $(0.31)$

342 Moritz: dis dis s KLASsische dieses öh öh öh öh.

dieses BEATphasedings((spezielle Einstellung für DJ-Software, die Ton und Licht synchronisiert)) so PAbabababa: .

345 Marco: das find ich AUCH-

346 DAS das fand ich auch komisch.

$347 \quad(0.2)$

348 Moritz: so ! HO [:!.]

349 Marco: [ja. ]

$350 \quad(1.15)$

351 Marco: OhJEE:-

$352 \quad(0.64)$

353 Marco: so SCHLIMM fand_s du_s.

354 Moritz: ich fand_s ICH o (ich) also ganz ehrch. $355 \quad(0.39)$

356 Moritz: norMAlerweise-

357 würd_ich jetz GEHen. 
$\begin{array}{lll}358 \text { Marco: } & \text { ah ich find_s no erTRÄGlich. } \\ 359 & & (0.71)\end{array}$

Moritz beginnt in Zeile 322, indem er die gesamte Inszenierung rekonstruiert: „un dann_s (.) es is halt überHAUPT nich konsistent.“ Die identifizierende Bezugnahme (vgl. Hausendorf 2011; Kapitel 6, i.d.B.) auf das gesamte Stück erfolgt hier über das Relativpronomen „es“. Durch den Aufzählungsmarker „und dann“ (Z. 322) stellt der Sprecher den Zusammenhang zum übergeordneten argumentativen Gesprächsthema, nämlich der Bewertung der Aufführung her (vgl. Ulmer \& Bergmann 1993, 99). Im Gegensatz zu Medienrekonstruktionen in Alltagsgesprächen von Familien bei Ulmer \& Bergmann (1993) und Keppler (1995) wird das Medium, auf das sich der Sprecher bezieht, als externe Wissensquelle nicht explizit eingeführt. Moritz spezifiziert seine Gesamtrekonstruktion im Folgenden und exemplifiziert sie durch den rekonstruierenden Verweis auf ein Kostüm: „es IS- auf der einen seite möchte_s irgendwie halt !ALT!modisch sein und irgendwie auf TRAditionell machen- (0.65) dann kommt aber einer [in SO]cken daher-“ (Z. 324-327). Durch die hyperbolische, umgangssprachlichflapsige Reinszenierung ${ }^{30}$ „dann kommt aber einer [in SO]cken daher-“ ironisiert und stilisiert Moritz den Inszenierungsaspekt und die dargestellte Figur, wodurch der Unterhaltungswert der Rekonstruktion erhöht wird (vgl. Günthner 2012). Außerdem dient der Verweis auf die Kostümierung in Socken als Beispiel für die nicht ,altmodische“ und nicht ,traditionelle‘ Inszenierung und somit als Autorisierung von Moritz‘ Standpunkt (vgl. Ulmer \& Bergmann 1993, 88). Marco ratifiziert die Rekonstruktion überlappend in Zeile 328. Den simultan von Moritz geäußerten Verweis auf die Kostümierung behandeln beide Sprecher trotz seiner Ungenauigkeit („einer“; „,daher“) nicht als „explikationsbedürftig“ (Ulmer \& Bergmann 1993, 84).

Daraufhin (Z. 328-331) rekonstruiert Moritz indirekt die Inszenierung einer Rolle: „also AUCH- (0.47) de gute GEIST- also !ICH! persönlich seh den geist halt nicht so LEIdend." Er gibt auf diese Weise ein Beispiel für seinen vorherigen rekonstruierenden Verweis auf die gesamte Inszenierung (Z. 322-327). Durch die einleitende Formulierung „also $\mathrm{AUCH}$ - de gute GEIST-“ inklusive der anschließenden Minimalpause führt Moritz explizit das Thema seiner folgenden Ausführungen ein und grenzt die kommunikative Einheit so vom vorherigen Gesprächszusammenhang ab (vgl. Ulmer \& Bergmann 1993, 88). Der Ausdruck „de gute GEIST“, der den definiten Artikel der vermuten lässt, stellt den Bezug zur

30 Vgl. ausführlicher zu Reinszenierungen Abschnitt 8.3.3.2. 
Theateraufführung im Sinne der identifizierenden Bezugnahme her. Die Verwendung des definiten Artikels legt nahe, dass Moritz bei seinem Rezipienten „ein Wissen vom betreffenden Medienereignis“ (Ulmer \& Bergmann 1993, 95) voraussetzt (vgl. ebenso im Verlauf der Rekonstruktion die Verwendung der Ausdrücke so, die, dieses, das, es durch Moritz und Marco). ${ }^{31}$ Wie von Ulmer \& Bergmann (1993, 95) für kommemorierende Medienrekonstruktionen festgehalten, äußert Moritz mit „also !ICH! persönlich seh den geist halt nicht so LEIdend.“ (Z. 334) eine „erste individuelle Stellungnahme bereits in der Initiierungsphase“. Marco ratifiziert die Rekonstruktion konzedierend: „oKEE ja:-“ (Z. 332). Durch das deiktische „so“ wird in der Rekonstruktion der Bezug zur Darstellung des Geistes in der im Fokus liegenden Inszenierung hergestellt. Moritz begründet seinen konträren Darstellungsvorschlag durch den Allgemeinplatz „KANN man machen. MUSS man aber nich.“ (Z. 336-337). Anschließend fährt er mit der Rekonstruktion der Inszenierung des Geistes fort, indem er einen Inszenierungsaspekt bezüglich Musik und Beleuchtung thematisiert: „und- (2.95) ja dann ham_wa ma bischn was aus_m HORrorfilm abgeguckt-=deswegen zittert der geist die ganze zeit SO? (0.31) dis dis s KLASsische dieses öh öh öh öh. dieses BEATphasedings- so PAbabababa:.“ (Z. 339-344). In der Rekonstruktion der Rolle des Geistes und seiner Inszenierung verwendet Moritz an dieser Stelle (2015) eine Redewiedergabe nach Butterworth im Sinne der Wiedergabe eines vergangenen hypothetischen mündlichen kommunikativen Akts (,ja dann ham_wa ma bischn was aus_m HORrorfilm abgeguckt-“). Er vergegenwärtigt den fiktiven Gedankengang, den der Intendant oder Regisseur bei der Inszenierung des Geistes gehabt haben könnte. ${ }^{32}$ In den Zeilen 338-344 verweist Moritz im Sinne eines (rekonstruierenden) Medienverweises indirekt kurz, beiläufig und fragmentarisch auf eine Praxis aus einem anderen Medium, nämlich aus dem Horrorfilm. Dabei nennt er in Zeile 338-340 explizit das Medium, auf das er verweist, und ordnet den Medienverweis dem übergeordneten argumentativen Gesprächsthema unter, indem er ihn durch die Aufzählungsmarker „und- (2.95) ja dann“ einleitet: „ja dann ham_wa ma bischn was aus_m HORrorfilm abgeguckt-“. Er spezifiziert und begründet den rekonstruierenden Medienverweis, indem er den exakten Inszenierungsaspekt rekonstruiert, der seiner Meinung nach „abgeguckt“ wurde, nämlich eine Beleuchtungs- und Tontechnik aus dem Bereich des DJing: „=deswegen zittert der geist die ganze zeit SO? (0.31) dis dis $S$ KLASsische dieses öh öh öh öh. dieses BEATphasedings- so PAbabababa:." Diese anschauliche Reinszenierung stellt durch die deiktischen Mittel „SO?“, „dis dis

31 Vgl. im Detail zum komemmorierenden Darstellungsmodus Abschnitt 8.3.3.1.

32 Vgl. detaillierter zu Redewiedergaben Abschnitt 8.3.3.3. 
[...] dieses“ und „so“ den Bezug zur Aufführung her, deren Höhepunkt die akustische (und vermutlich simultan gestisch-körperliche) Reproduktion von nonverbalen Handlungen (vgl. Ulmer \& Bergmann 1993, 94): „PAbabababa:“ darstellt. ${ }^{33}$ Marco schließt die Rekonstruktion in Zeile 345-346 ab: „das find ich AUCH-DAS das fand ich auch komisch. "Trotz des von Moritz verwendeten Fachterminus „BEATphase[...]“ stellt Marco keine Nachfragen, sondern behandelt den kurzen Medienverweis als nicht explikationsbedürftig und abgeschlossen. In Zeile 348 fährt Moritz fort, indem er ironisierend und parodistisch die (erwünschte) Publikumsreaktion auf die Inszenierung des Geistes onomatopoetisch reinszeniert: „so !HO[:!.]“, was wiederum überlappend von Marco ratifiziert wird: „[ja.]“ (Z. 349).

Nach einer kurzen Pause inszeniert Marco sein Bedauern durch die zusammenfassende Rekonstruktion von Moritz“ Erleben der Inszenierung: „ohJEE:(0.64) so SCHLIMM fand_s du_s.“ (Z. 351-353) eingeleitet durch die Interjektion „ohJEE“. Moritz antwortet, indem er zur Rekonstruktion seines Erlebens der Aufführung ansetzt: „ich fand_s ICH o (ich) also ganz ehrch.“ (Z. 354). Nach mehreren Anakoluthen und Reformulierungen fasst er sein Erleben der Inszenierung zusammen, indem er konstatiert: „norMAlerweise- würd_ich jetz GEHen.“ (Z. 356-357). Durch diese Aussage, eine solche Vorstellung unter anderen Umständen (als den Erhebungsumständen) in der Pause zu verlassen, rekonstruiert er indirekt seinen Eindruck während der Inszenierung. Als Marco daraufhin im Zuge eines „Meinungsvergleich[s]“ (Ulmer \& Bergmann 1993, 95) seine eigene abweichende Wahrnehmung des Stücks rekonstruiert (,ah ich find_s no erTRÄGlich.“, Z. 358), spezifiziert Moritz hyperbolisch seine indirekte Rekonstruktion um den Aspekt der körperlichen Auswirkungen der Aufführungsrezeption auf ihn selbst: „, ich hab ernsthaft KOPFschmerz.“ (Z. 360).

In diesem Ausschnitt werden verschiedene Aspekte der gerade besuchten ersten Hälfte der Theatervorstellung rekonstruiert. Moritz vergegenwärtigt zunächst die gesamte Inszenierung (Z. 322-327), exemplifiziert anhand der Kostümierung einer Rolle (,dann kommt aber einer in SOcken daher-"). In direktem Anschluss (Z. 329-346) verschiebt sich der Rekonstruktionsfokus auf die Rolle und Inszenierung des Geistes (,de gute GEIST-“, Z. 331) bezüglich seiner emotionalen Darstellung und seiner Untermalung durch Licht und Ton, die ausführlich von beiden Sprechern rekonstruiert wird. Im Rahmen dieser Rekonstruktion verweist Moritz auf einen technischen Darstellungsaspekt, dessen Anwendung (laut Moritz) in einem anderen Medium verbreitet ist, nämlich die BeatphaseEinstellung in Horrorfilmen (Z. 340-344). Abschließend wechselt der Gegen-

33 Vgl. ausführlicher zu Reinszenierungen Abschnitt 8.3.3.2. 
stand der Rekonstruktion in Zeile 348-360 zum eigenen Erleben des Theaterstücks, das Marco und Moritz jeweils darstellen („ohJEE:- (0.64) so SCHLIMM fand_s du_s.“, Z. 351-353). Dabei wird der Bezug zum Hic et Nunc explizit wiederhergestellt, indem in Zeile 360 die (körperlichen) Konsequenzen des ,Stückerlebens “ thematisiert werden (,ich hab ernsthaft KOPFschmerz.“).

Der Ausschnitt verdeutlicht, wie die Sprecher im Kontext eines übergeordneten Gesprächszusammenhangs (hier eines Meinungsaustauschs über die Inszenierung) zwischen der Rekonstruktion verschiedener Aspekte des Theaterereignisses, die auf verschiedenen Ebenen angesiedelt sind, spielerisch wechseln. Der Übergang von der globalen Rekonstruktion der Inszenierung („es“) zu verschiedenen einzelnen Inszenierungsaspekten (Kostüme, Licht, Ton, schauspielerische Leistung) und schließlich zum eigenen Erleben der Aufführung wird nur minimal und teils implizit angezeigt durch „dann“, „,also AUCH-“, „ja dann“ und eine Pause gefolgt von „ohJEE:-“ und trotzdem nicht als problematisch thematisiert (vgl. Hrncal \& Gerwinski 2015; Kapitel 6 und 7, i.d.B.). Außerdem wird in die Rekonstruktion der Theaterinszenierung ein Verweis auf ein anderes Medienereignis eingewoben (Z. 340-343), das explizit benannt wird: „HORrorfilm“ (Z. 340). Der Verweis fungiert hier als „Autorisierung“ (Ulmer \& Bergmann 1993, 88) von Moritz‘ (abwertender) Rekonstruktion, wie an Marcos zustimmender Reaktion ablesbar wird.

Bezüglich der Frage, welche Subtypen von Rekonstruktionen der Ausschnitt aufweist, handelt es sich bei diesem Ausschnitt um eine Rekonstruktion im Sinne von Ulmer \& Bergmann (1993), die über einen längeren, klar abgegrenzten Gesprächsabschnitt das ,alleinige Thema“ (Ulmer \& Bergmann 1993, 88) darstellt. Zunächst rekonstruiert Moritz die gesamte Inszenierung. Darin eingebettet erwähnt der Sprecher in Zeile 327 im Sinne eines rekonstruierenden Verweises (vgl. Ulmer \& Bergmann 1993) das In-Socken-Laufen eines Darstellers. Dieses Detail zieht Moritz zur Begründung im Kontext der übergeordneten Argumentation bezüglich der Inkonsistenz der Inszenierung heran. In Zeile 329-347 verschiebt sich der Rekonstruktionsfokus auf die Darstellung des Geistes, die von beiden Sprechern im Sinne einer Rekonstruktion (vgl. Ulmer \& Bergmann 1993) ausführlich und als eigenständige kommunikative Einheit vergegenwärtigt wird. Sie lässt sich ebenfalls als Argument der übergeordneten rekonstruktiven Argumentation für die ,inkonsistente' Gesamtinszenierung unterordnen. In die Rekonstruktion des Geistes bettet Moritz in Zeile 340 einen Medienverweis auf ein Medium außerhalb des Theaters, nämlich das Genre des Horrorfilms, in Form einer Redewiedergabe ein: „ja dann ham_wa ma bischn was aus_m HORrorfilm abgeguckt-“. Außerdem veranschaulicht er die Inszenierung des Geistes durch eine Reinszenierung in Zeile 344: „so PAbabababa:.“ In 
der letzten Rekonstruktion thematisieren Marco und Moritz in Zeile 351-360 ausführlich und kooperativ das eigene Erleben der Inszenierung.

Zusammenfassend lässt sich anhand dieses Ausschnitts die ,Verschachtelung‘ sowohl eines übergeordneten rekonstruktiven Zusammenhangs (Argumentation für die inkonsistente, unerträgliche Inszenierung) im Sinne einer zusammenhängenden kommunikativen Einheit sowie einzelner untergeordneter Rekonstruktionen von Einzelaspekten der Inszenierung (ein Kostüm: Socken, eine Rolle: Geist, eine technische Einstellung: Beatphase, das eigene Erleben: Kopfschmerzen), als auch darin eingebetteter rekonstruktiver Verweise (auf die Gesamtdarstellung und den Horrorfilm) und einer reinszenierenden Redewiedergabe (Gedanken des Regisseurs/Dramaturgen) festhalten. Der gesamte Ausschnitt wird demnach in einem ,Modus' der Rekonstruktion mit fließenden Übergängen zwischen den einzelnen Phasen und Rekonstruktionstypen durchgeführt. Dieser rekonstruktive Modus erfüllt wiederum einen argumentativen (die Sprechermeinung stützenden, exemplifizierenden und autorisierenden) Sinn.

Zur Unterscheidung von Rekonstruktionen und rekonstruierenden Verweisen im Kontext von Theaterpausengesprächen ist festzuhalten, dass die übergeordnete Rekonstruktion „umfangreicher“ (Ulmer \& Bergmann 1993, 88) gestaltet ist. Bei näherer Betrachtung wird deutlich, dass diese sich in eine „Abfolge von kleinen Rekonstruktionsfragmenten“ (Ulmer \& Bergmann 1993, 97) gliedern lässt. Diese ,kleinen“ Rekonstruktionen unterscheiden sich in ihrer Einbettung in einen größeren rekonstruktiven Gesprächszusammenhang also nicht von rekonstruierenden Verweisen. Der Übergang von Rekonstruktionen zu Verweisen (in Bezug auf das Theaterereignis) gestaltet sich hier fließend. Weiterhin werden die Verweise, wie auch von Ulmer \& Bergmann (1993) und Keppler (1995) konstatiert, nur von Moritz geäußert, wohingegen sich Marco an der übergeordneten Rekonstruktion und ihren thematisch gegliederten kleineren Rekonstruktionen beteiligt - wenn auch minimal. Überdies unterscheidet sich die übergeordnete Rekonstruktion von den eingebetteten Verweisen dadurch, dass sie „weniger unter dem Zwang zu thematischer Relevanz“ steht, „sondern eher mit dem Ziel den Geselligkeitswert des Gesprächs zu erhöhen“ (Ulmer \& Bergmann 1993, 100) verbunden wird. Dementsprechend zeigen sich die Sprecher für beide Verweise den argumentativen Kontext klar an und die Rekonstruktion(en) werden von Reinszenierungen (z.B. einer Redewiedergabe), Übertreibungen, parodistischen Elementen und emotiven Ausdrücken (,so !HO:!.“; „ohJEE“; „KOPFschmerz“) geprägt.

Neben der Unterscheidung zwischen Rekonstruktion und Verweis in Theaterpausengesprächen zeigt dieser Ausschnitt die Relevanz einer weiteren Diffe- 
renzierung innerhalb der Verweise auf. Der erste Verweis „dann kommt aber einer in SOcken daher-“ (Z. 327) bezieht sich auf einen Aspekt innerhalb des Theaterereignisses. ,ja dann ham_wa ma bischn was aus_m HORrorfilm abgeguckt- “ (Z. 340-344) thematisiert demgegnüber ein anderes Medium. Aufgrund der situativ-örtlichen Einbettung des Gesprächs in das Foyer während der Pause des Theaterstücks sind die Bezugnahmen innerhalb des ersten Verweises sehr vage („dann“; „einer“; „,daher“), die mediale Wissensquelle wird nicht explizit genannt und keiner der Sprecher geht explizierend darauf ein. Im zweiten Verweis wird die externe Wissensquelle hingegen genannt und die zunächst vage Beschreibung des Aspekts wird im Folgenden vom selben Sprecher rekonstruierend spezifiziert: „=deswegen zittert der geist die ganze zeit SO? (0.31) dis dis $S$ KLASsische dieses öh öh öh öh. dieses BEATphasedings- so PAbabababa:.“ (Z. 340-344). Aufgrund dieser Differenz soll im Folgenden zwischen ,rekonstruierenden Theaterverweisen' im ersten Fall und ,rekonstruierenden Medienverweisen' im zweiten Fall unterschieden werden.

In Ausschnitt 1 war hauptsächlich das Medienereignis der Theateraufführung das übergeordnete Objekt der Rekonstruktion. Betrachten wir nun einen Ausschnitt, in dem ein Aspekt eines anderen Mediums rekonstruiert wird in seiner Realisierung. Der folgende Ausschnitt (2) entstammt dem Pausengespräch zwischen Alexander und Nicola, das sich in der Pause des ShakespeareStücks „Der Kaufmann von Venedig“ ereignet. Das Stück spielt im Venedig des 16. Jahrhundert und handelt hauptsächlich vom Kaufmann Antonio und seinem Freund Bassanio und den Themen Moral, Recht und Unrecht, dem Pochen auf das geschriebene Wort im Gesetz und der Doppelgesichtigkeit jeder Figur des Stücks. Dem Ausschnitt gehen einige Anmerkungen zur Umgebung und zur Getränkebeschaffung voraus sowie eine halbminütige kommemorierende bewertende Rekonstruktion der Inszenierung der Kästchen ${ }^{34}$ als bleiern, silbern und golden angemalte, sonst fast unbekleidete Frauen. Zuletzt bewertet Alexander diese als „INkonsequent" und äußert die Meinung, diese Umsetzung mache „überhaupt kein SINN.“

34 Bassanio muss sich im Stück zwischen drei Kästchen - einem bleiernen, einem silbernen und einem goldenen - richtig entscheiden, um die Hand seiner Angebeteten Portia zu gewinnen. 
Ausschnitt 2: „früher GAB_S wenigstens noch- n Obertitel- in der Oper-“35

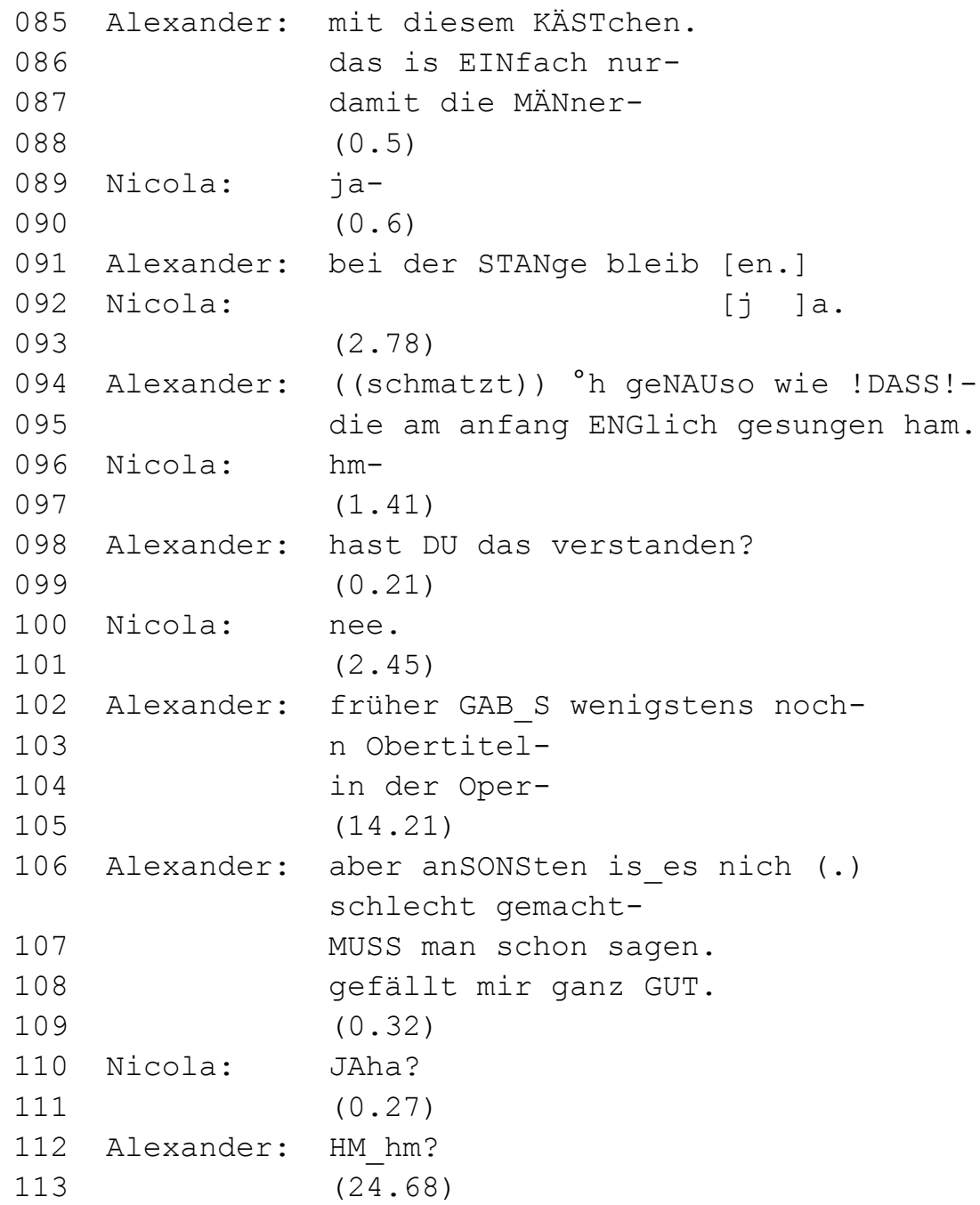

In Zeilen 85-93 fahren die Sprecher mit der bewertenden und deutenden Rekonstruktion der Inszenierung der Kästchen fort, indem Alexander über die Intention des Dramaturgen mutmaßt: „mit diesem KÄSTchen. das is EINfach nurdamit die MÄNner- (0.5) (0.6) bei der STANge bleiben.“. Nicola quittiert diese

35 Köln_14-06-15_Kaufmann_Gr.3. 
Interpretation in Zeile 89 und 92 durch ein zweifach geäußertes ,ja-“ bzw. ,ja.“ Nach einer längeren Pause rekonstruiert Alexander in Zeile 94 den Inszenierungsaspekt des englischsprachigen Gesangs zu Beginn des Stücks und fragt Nicola nach einer Pause, ob sie diese Entscheidung verstehen könne: „((schmatzt)) ${ }^{\circ} \mathrm{h}$ geNAUso wie !DASS!- die am anfang ENGlich gesungen ham. hast DU das verstanden?" (Z. 94-98), was von einem Hörersignal Nicolas begleitet wird („hm-“; Z. 96). Als Nicola verneint und es zu einer weiteren längeren Pause kommt, führt Alexander den rekonstruierenden komparativen Verweis auf die Oper an: „früher GAB_S wenigstens noch- $n$ Obertitel $^{36}$ - in der Oper-“. Dieser Verweis auf einen Inszenierungsaspekt eines anderen Mediums, der zur besseren Verständlichkeit der Handlung dient, ist hier in einen argumentativen Kontext eingebettet. Alexander zieht den Inszenierungsaspekt der Oper quasi als ,best (oder better) practice“ im Vergleich zur gerade besuchten Theateraufführung heran, um seine negativ bewertende Rekonstruktion $\mathrm{zu}$ autorisieren (vgl. Ulmer \& Bergmann 1993, 84-88). Der Einstieg in den Verweis ist dabei klar gekennzeichnet durch die Vergangenheitsmarker "früher" und „GAB_S“ (Z. 102). Im Anschluss an den rekonstruierenden Verweis entsteht eine Pause von 14 Sekunden, nach der Alexander in Zeile 106 die gesamte bisherige Inszenierung als „anSONSten“ „nich (.) schlecht gemacht-“ rekonstruiert. Dieser Ausschnitt dient stellvertretend für die Tendenz der Sprecher(innen), in den untersuchten Pausengesprächen Teilaspekte anderer Medienereignisse in einem argumentativen komparativen Kontext zu rekonstruieren.

Die beiden in diesem Kapitel untersuchten Gesprächsausschnitte illustrieren, wie in Pausengesprächen im Theater einerseits Elemente aus dem Erlebnis der Theaterinszenierung rekonstruiert werden. Dies erfolgt sowohl in Form ausführlicher, umfangreicher Rekonstruktionen durch beide Sprecher(innen) als auch in Form kurzer beiläufiger rekonstruierender Theaterverweise durch eine(n) Sprecher(in). Rekonstruktionen lassen sich wiederum in thematisch untergeordnete (Aspekt-)Rekonstruktionen gliedern und können den einbettenden Kontext für Verweise bilden. Rekonstruierende Verweise in Pausengesprächen sind demnach einem übergeordneten (kommunikativen z.B. argumentativen) Zusammenhang untergeordnet. Andererseits werden in den beiden Ausschnitten angeregt durch das Theatererlebnis Aspekte anderer Medienerfahrungen (Horrorfilm und Oper) zum Gegenstand gemacht. Dies geschieht als untergeordneter rekonstruierender Medienverweis in einem übergeordneten kommunikativen (z.B. argumentativen) Kontext.

36 Die Aussprache „Obertitel“ statt „Übertitel“ ist vermutlich einer Lautassimilation aufgrund der lokalen Nähe des Wortes „Oper“ zu verschulden. 


\subsection{2 „und? fandste war was NEUes? ${ }^{637}$ - Einstiege in Theaterrekonstruktionen}

Nachdem in Abschnitt 8.3.1 die möglichen Gegenstände von Rekonstruktionen und darauf aufbauend die verschiedenen Subtypen in ihren Ausprägungen dargestellt wurden, fokussiert dieser Abschnitt die Einstiege in Theaterrekonstruktionen. Die sprachlich-kommunikativen Einstiege in die Rekonstruktionen, die sich im Datenkorpus finden, eröffnen den Kontext, in den die Rekonstruktionen jeweils eingebettet sind (z.B. einen bewertenden, deutenden, erläuternden, argumentativen, gemeinschaftsstiftenden, unterhaltenden und/oder gesprächserhaltenden Kontext). Der Kontext einer Rekonstruktion kann sich in ihrem Verlauf (graduell) ändern und die unterschiedlichen Kontexte schließen sich nicht gegenseitig aus, sondern können sich innerhalb einer Rekonstruktion überschneiden oder ergänzen. Die Einstiege in Rekonstruktionen erfolgen im Datenkorpus meist am (unmittelbaren) Anfang eines Gesprächs, häufig auch während der Gesprächsmitte und in seltenen Fällen steigen die Sprecher am Gesprächsende (wieder) in die Rekonstruktion ein. Insgesamt werden deutende Rekonstruktionen in den häufigsten Fallen später im Gespräch eingeführt als bewertende Rekonstruktionen, so dass der Einstieg in die erste Rekonstruktion eines Gesprächs im Großteil der Rekonstruktionsfälle in einem bewertenden Kontext erfolgt. Nicht zuletzt unterscheiden sich die Einstiege in die Rekonstruktionen, je nach Rekonstruktionstyp, also abhängig davon, ob eine ausführliche Rekonstruktion bestimmter Episoden des Theaterereignisses, ein rekonstruierender Verweis in Bezugnahme auf das Theaterereignis oder in Bezugnahme auf andere Medien(ereignisse) eingeleitet wird. Die ersten Ausschnitte zeigen Einstiege in unterschiedliche Subtypen der Rekonstruktion, die einen bewertenden Kontext eröffnen.

\subsubsection{1 ${ }^{\circ}$ hh war nich so GANZ ä:h- ${ }^{\circ} \mathrm{h}{ }^{\circ} \mathrm{h}$ strinGENT irgendwie--"38 Rekonstruktion im Kontext des Bewertens}

Innerhalb der Gespräche des Datenkorpus fällt der Einstieg in einen Kontext besonders häufig auf: in den Kontext des Bewertens. ${ }^{39}$ Welche kommunikativen Merkmale zeichnen solche Einstiege in bewertende Rekonstruktionen aus?

Im folgenden Gespräch (Ausschnitt 3) unterhalten sich Monika und Emma nach dem Theaterstück „Brain and Beauty“ in der Pause bis zum Publikumsge-

37 Köln_14-04-22_BrainAndBeauty_Gr.2.

38 Köln_14-04-22_BrainAndBeauty_Gr.3.

39 Zum Bewerten in Theaterpausengesprächen vgl. Kapitel 7, i.d.B. 
spräch. Das Stück handelt von Schönheitsoperationen, basierend auf Erfahrungsberichten und Interviews mit Patient(inn)en und Ärzt(inn)en und arbeitet als Besonderheit stellenweise mit Schaufensterpuppen anstelle von Schauspieler(inne)n. Der Ausschnitt gibt den unmittelbaren Gesprächsbeginn nach dem Ende des Schlussapplauses wieder und die Sprecherinnen befinden sich noch im Theatersaal. Nach einer Präsequenz in Form von zwei kurzen Pausen, der Versicherung Monikas bezüglich der technischen Funktionalität ihres Aufnahmegerätes sowie einer gefüllten Pause setzt Emma zu einer ersten tentativen rekonstruktionseinleitenden Frage an.

Ausschnitt 3: „en bisschen komisch“40

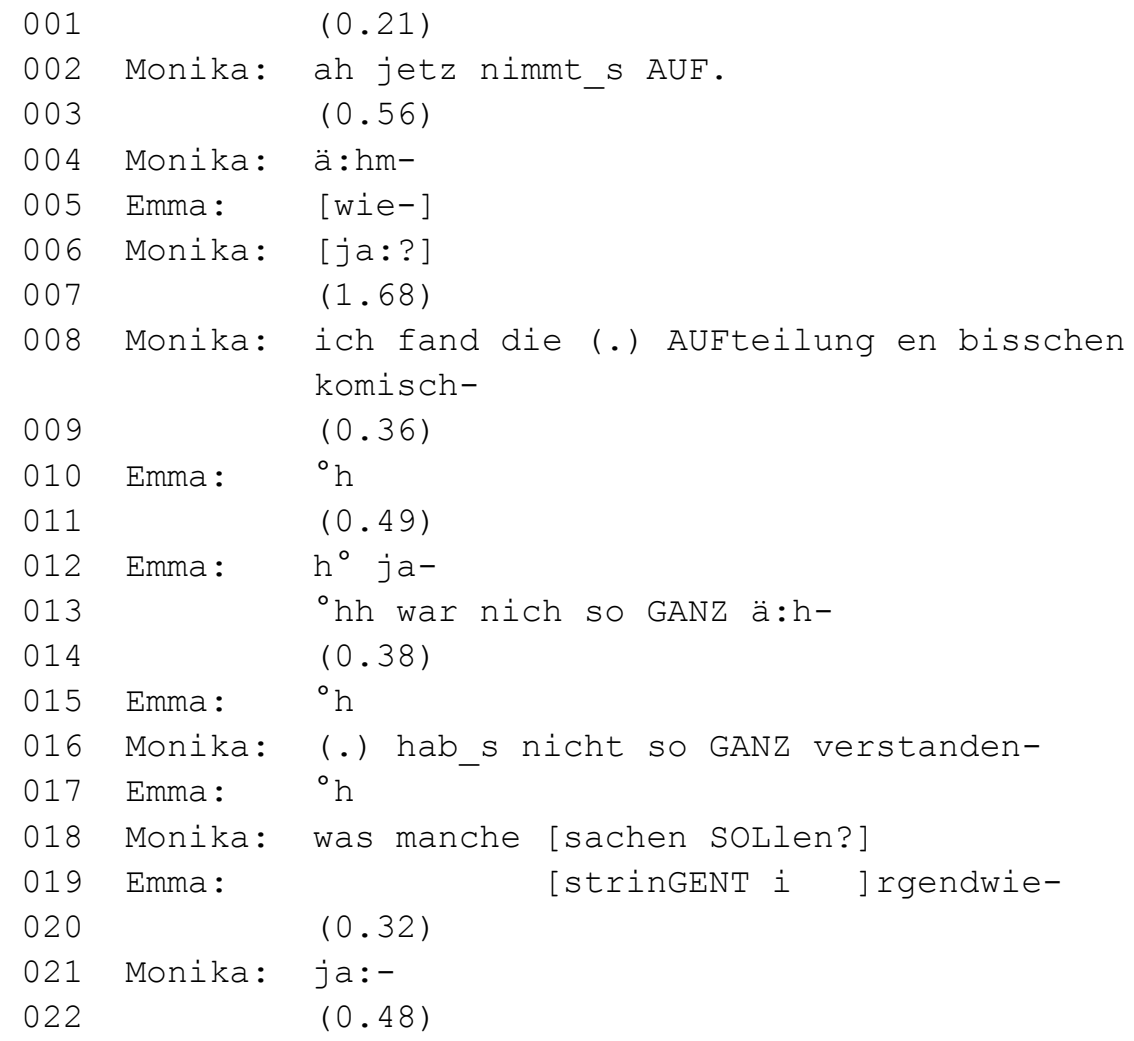

40 Köln_14-04-22_BrainAndBeauty_Gr.3. 


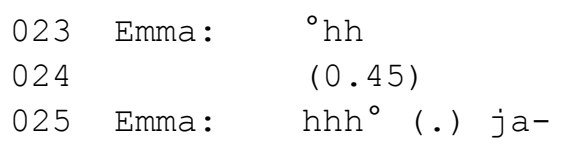

Auf Emmas abgebrochenen Frageansatz „wie-“ (Z. 5) reagiert Monika nach einer Pause mit einer Antizipation einer Aufforderung zur Rekonstruktion: ,ich fand die (.) AUFteilung en bisschen komisch-“ (Z. 8). Durch die identifizierende Bezugnahme „die (.) AUFteilung“ in Form einer definiten Nominalphrase fokussiert die Sprecherin einen (nicht weiter explizierten) Aufführungsaspekt und initiiert zugleich durch das verbum sentiendi „ich fand“ und das gehedgte evaluierende Adjektiv „en bisschen komisch“ eine bewertende Rekonstruktion (vgl. Hausendorf 2012, 115: „Darstellung des eigenen Gefallens“ und Hausendorf 2011, 523: „Darstellung von Subjektivität“ als Antwort auf die Frage, „was davon zu halten ist"). Nach mehreren (gefüllten) Pausen quittiert Emma die Rekonstruktion durch ein „ja:-“ (Z. 12). Die Sprecherinnen behandeln die vage Bezugnahme auf die Inszenierung hier als unproblematisch. In direktem Anschluss spezifiziert Emma die Rekonstruktion im Kontext des Bewertens expandierend und teils mit Monika überlappend um den Aspekt der Stringenz: „hh war nich so GANZ ä:h- strinGENT irgendwie-“ (Z.13, 19). Fast zeitgleich begründet Monika ihre bewertende Rekonstruktion, indem sie in Zeile 16 und 18 ausführt: „(.) hab_s nicht so GANZ verstanden- ${ }^{\circ} \mathrm{h}$ was manche sachen SOLlen?". Monika rekonstruiert ihr eigenes Erleben (im Sinne von Unverständnis) während der Theateraufführung, wobei der Bezug zur Theateraufführung wieder vage bleibt („manche sachen“). Durch die Rekonstruktion ihres Unverständnisses, die hier zunächst von Emma als Bewertung verstanden wird, eröffnet Monika gleichzeitig die Möglichkeit einer deutenden Rekonstruktion. Beide Sprecherinnen quittieren im Anschluss die gemeinsame Rekonstruktion wechselseitig durch ein „ja:-“ (Z. 21) bzw. „hhh ${ }^{\circ}$ (.) ja-“ (Z. 25). Daraufhin erfolgt eine fast vierminütige Rekonstruktion des eigenen Erlebens der Theateraufführung, der schauspielerischen Leistung, der Stückhandlung und der Intention des Intendanten/Regisseurs.

Zusammenfassend fällt bei der Untersuchung von Ausschnitt 3 zunächst auf, welch hohen Stellenwert Rekonstruktionen in Theaterpausengesprächen für die beiden Sprecherinnen haben: Lediglich ein abgebrochener Frageansatz („wie-“) wird von beiden Sprecherinnen als Einstieg in eine bewertende Rekonstruktion behandelt. In Bezug auf die eingangs gestellte Frage zum Einstieg in Rekonstruktionen zeigt Ausschnitt 3, wie die Sprecherinnen sich bereits dabei gegenseitig den bewertenden Kontext aufzeigen. Obwohl die Referenzen auf die Inszenierung sehr vage bleiben (,die (.) AUFteilung“; „““; „manche sachen“) 
machen sich Monika und Emma den bewertenden Kontext z.B. durch ein verbum sentiendi „ich fand“ oder evaluierende Adjektive („komisch“; „strinGENT“) deutlich. Im Sinne Kepplers (1995, 271) in Bezug auf Familientischgespräche scheint beim Einstieg in eine Rekonstruktion also weniger die inhaltliche Tiefe des Gesprächs im Vordergrund zu stehen, sondern vielmehr „die Tatsache, daß unter ihnen [den Sprecher(inne)n; ES] im Rahmen dieser sozialen Veranstaltung eine flexible, wenigstens halbwegs interessante Gesprächsführung möglich ist“. Dass Monika und Emma also übereinstimmen in ihren Annahmen über die kommunikativ-sprachlichen Merkmale eines Theaterpausengesprächs, wirkt wie ein „formales Band“ (Keppler 1995, 271) für die Unterhaltung. Weiterhin verdeutlicht der Ausschnitt den fließenden Übergang von einem bewertenden zu einem deutenden Rekonstruktionskontext (vgl. „(.) hab_s nicht so GANZ verstanden- ${ }^{\mathrm{h}} \mathrm{h}$ was manche sachen SOLlen?").

\subsubsection{2 „so einige TYpen (.) ham mich erinnert (.) an die gegenwart.“41 — Rekonstruktion im Kontext des Deutens}

Neben Einstiegen in Rekonstruktionen, die einen bewertenden Kontext eröffnen, fallen im Datenmaterial Einstiege in einen weiteren Kontext auf, die sich von den Einstiegen ins Bewerten unterscheiden. Welche Ausprägungen weisen diese Einstiege in deutende Rekonstruktionen auf? Ausschnitt 4 ereignet sich am unmittelbaren Anfang des Gesprächs zwischen Karl und Annalena während der Pause des Theaterstücks „Der Hundertjährige, der aus dem Fenster stieg und verschwand“. Das Stück basiert auf dem gleichnamigen Roman (Jonas Jonasson, 2009), der vom turbulenten Leben von Allan Karlson handelt, welcher an seinem hundertsten Geburtstag aus dem Altersheim flüchtet. In Zeitsprüngen erzählt das Stück von Allans aktueller abenteuerlicher Flucht und von vergangenen Episoden aus seinem Leben. Den Gesprächsausschnitt kennzeichnet eine besondere Gesprächssituation, da sich Karl und Annalena erst am Abend der Erhebung als Proband(inn)en verschiedener Teilnehmergruppen kennengelernt haben. Nach zwei Minuten Unterhaltung mit ihren eigenen Gruppen treffen die Sprecher beim Verlassen des Theatersaals aufeinander und beginnen ein separates Parallelgespräch.

41 Siegen 15-03-07 Hundertjährige Gr.1 Karl. 
Ausschnitt 4: „oder finden wir in der verGANGenheit- die GEgenwart?“42

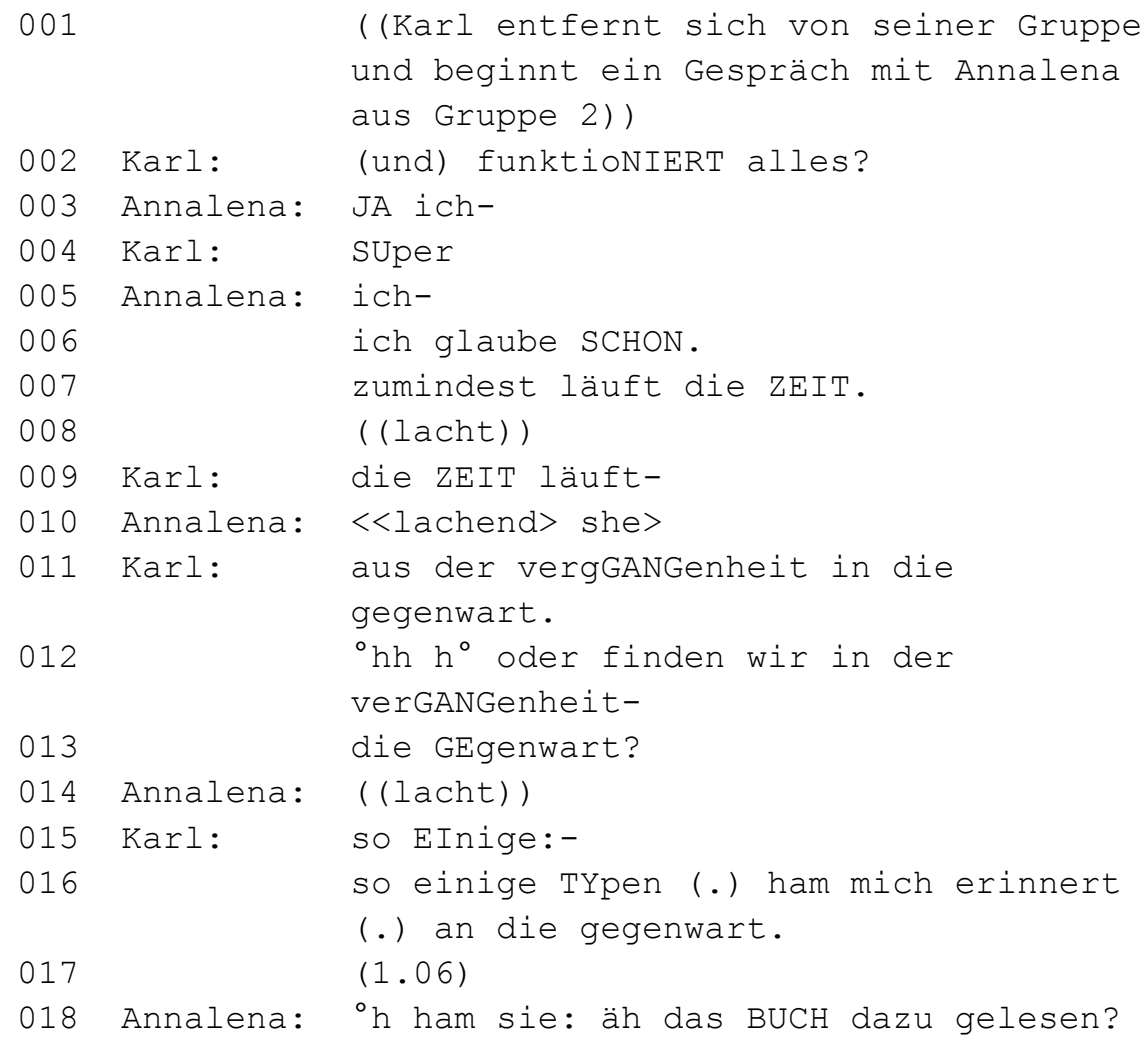

Karl initiiert das Gespräch, indem er Annalena nach dem Funktionieren ihres Aufnahmegerätes fragt. ${ }^{43}$ Diese kurze Vorlaufsequenz endet damit, dass Annalena in Zeile 7 ihre unsicher-zustimmende Antwort begründet durch den Hinweis auf die Aufnahmedauer, die auf dem Display des Aufnahmegerätes angezeigt wird (,zumindest läuft die ZEIT.“), und anschließend durch ein Lachen ihre Einstellung zu der eigenartigen Aufnahmesituation ausdrückt. Ihre Aussage zur Zeit nimmt Karl paraphrasierend auf und expandiert sie um eine tiefsinnige Perspektivierung auf die gesellschaftliche Ebene und die eigene Bezugswelt: „die ZEIT läuft- aus der vergGANGenheit in die gegenwart. ${ }^{\circ} \mathrm{hh} \mathrm{h}^{\circ}$ oder finden wir in der verGANGenheit- die GEgenwart?“ (Z. 9-13). Durch dieses Chan-

42 Siegen 15-03-07 Hundertjährige Gr.1. Karl.

43 Vgl. zur Thematisierung der Aufnahmesituation Kapitel 4, i.d.B. 
gieren zwischen den Ebenen der Gesprächssituation im Theater und der gesellschaftlichen Realität/Welt außerhalb des Theaters sowie zwischen den Rahmen der Aufnahmesituation (,die ZEIT läuft-“) und des Pausengesprächs rekontextualisiert Karl Annalenas ursprüngliche Aussage. Die vage Referenz „wir“ (Z. 12) in der rhetorischen Frage wird im weiteren Verlauf nicht als problematisch behandelt. Zwischen und nach Karls Redezügen lacht Annalena als Hörersignal.

Anschließend rekonstruiert Karl seine Gedanken während der Inszenierung: „,so EInige:- so einige TYpen (.) ham mich erinnert (.) an die gegenwart.“ (Z. 15-16), womit er die vorherigen Aussagen über die gesellschaftliche Realität als Deutungsversuche des Stücks rekontextualisiert. Die Referenz (im Sinne einer identifizierenden Bezugnahme; vgl. Hausendorf 2011) auf das gerade besuchte Theaterstück wird einerseits durch die deiktischen Ausdrücke „so EInige:- so einige TYpen“ und andererseits durch den Wechsel ins Perfekt (,ham mich erinnert“) hergestellt. Diese Begründung rahmt die beiden vorherigen Aussagen ( $Z$. 11-13) als Redewiedergaben im Sinne der Wiedergabe vergangener mentaler kommunikativer Akte (vgl. Butterworth 2015), also als Karls Gedanken während der Aufführung. Auf diese Weise eröffnet Karl eine Rekonstruktion in einem deutenden Kontext. Durch die vage „klassifizierende[ ] Referenz“ (Hausendorf 2012, 113) „so einige TYpen“ typisiert Karl die im Stück dargestellten Rollen und überträgt ihre Interpretation anschließend auf ,Typen` in der gesellschaftlichen Realität (,die gegenwart“).

Zeile 5-16 zusammenfassend gehen die Sprecher vom Hic et Nunc der gerade ablaufenden Aufnahme (Z. 2-8) einen deutenden Kontext eröffnend über zur indirekten Rekonstruktion der Aussage des Stücks (Z. 9-16) als Antwort auf die Frage: „Was steckt dahinter?“ (Hausendorf 2011, 522). Im Sinne des von Hausendorf $(2012,113)$ beschriebenen Deutens in Bezug auf Kunst weist Karl durch seine Umdeutung der ursprünglichen Aussage („die ZEIT läuft-“, Z. 9) auf „mögliche Intentionen des Künstlers“ (hier des Theaterregisseurs) und somit auf ein „Künstler-Agens“ (Hausendorf 2012, 522) hin und stellt so den Bezug zum Stück her ${ }^{44}$. Durch die steigende Intonation der umformulierten, partiell wiederholten Rekonstruktion (,oder finden wir in der verGANGenheit- die GEgenwart?“) betont der Sprecher - Hausendorf (2012, 114) entsprechend - die „Fraglichkeit der vorgetragenen Deutung“. Er sichert seine Interpretation auch im Folgenden nicht durch Wissen ab, sondern bleibt in der Rekonstruktion im Modus des „,unsicheren Für-Wahr-Haltens““ (Hausendorf 2012, 113 nach von Polenz 1988). Gleichermaßen finden sich in Zeile 11-16 einige (gefüllte) Pau-

44 Nach Hausendorf (2006; 2011; 2012) wendet Karl das Mittel/Bedeutungsfeld der Interpretation oder Aussage an, um die Aufgabe des Deutens zu erfüllen. 


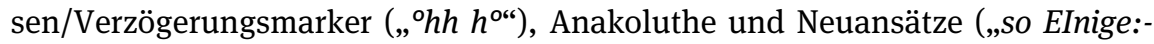
so einige TYpen"), die dem unsicheren, tentativen Charakter des Deutens entsprechen.

Nach einer längeren Pause stellt Annalena anschließend in Zeile 18 eine Rückfrage zu Karls Deutung, in der sie den neuen Aspekt der Literaturgrundlage fokussiert: „'h ham sie: äh das BUCH dazu gelesen?“. Sie löst sich teilweise aus dem unsicheren Modus des Deutens, indem sie mit der Rekonstruktion von möglichem Hintergrundwissen (vgl. Hausendorf 2012, 114) als potentielle Grundlage für Karls Deutung beginnt. Auf diese Weise zeigt sie ihr Verständnis von Karls Ausführungen als rekonstruierenden Deutungsversuch des Stücks an. Durch das deiktische Mittel „dazu“ referiert sie im Sinne einer identifizierenden Bezugnahme auf das Theaterstück. Dieser kurze fragmentarische Verweis auf ein anderes Medium (Buch), der kommunikativ in die deutende Rekonstruktion eingebettet ist, und im Anschluss von keinem der beiden Sprecher weiter expliziert wird, lässt sich als (deutender) Medienverweis einordnen. Er wird als potentielles Argument zur Begründung der Deutung relevant gesetzt. Daraufhin erfolgt eine vierminütige teils deutende, teils bewertende, teils erläuternde Rekonstruktion der Aussage des Spiels, des gesellschaftlichen Bezugs, des eigenen Erlebens, des Bezugs zur eigenen Lebenswelt, der schauspielerischen Leistung, der Handlung und des Bühnenbildes im Zusammenhang mit der Inszenierung.

Zusammenfassend zeichnet sich der vorliegende Einstieg in eine Rekonstruktion durch die unmittelbare Eröffnung eines deutenden Kontexts aus (,oder finden wir in der verGANGenheit- die GEgenwart?"). Dabei erfolgen sowohl die Deutung der Stückaussage als auch deren Begründung durch die eigene Wahrnehmung der Aufführung im Modus der (indirekten) Rekonstruktion. Die Sprecher setzen die deutende Rekonstruktion der Theaterinszenierung kommunikativ relevant und betten eine Redewiedergabe (,die ZEIT läuft- aus der vergGANGenheit in die gegenwart. ${ }^{\circ} h h^{\circ}$ oder finden wir in der verGANGenheit- die GEgenwart?") und einen Medienverweis („ $\mathrm{h}$ ham sie: äh das BUCH dazu gelesen?") in sie ein. Wie in der Ausstellungskommunikation in der bildenden Kunst (vgl. Hausendorf 2012; Hausendorf \& Müller 2016; Kindt 2016; vom Lehn \& Heath 2016) spricht dieser Ausschnitt dafür, dass im rekonstruktiven Modus in Theaterpausengesprächen neben dem Bewerten auch das Deuten relevant gesetzt wird.

Im Hinblick auf die eingangs gestellte Frage nach den Merkmalen von Einstiegen in deutende Rekonstruktionen fällt das Changieren der Sprecher zwischen den Ebenen der Stückhandlung, der eigenen Wahrnehmung der Inszenierung und der gesellschaftlichen Realität auf (z.B. durch den Tempuswechsel, 
die mehrdeutige Referenz von wir, die Umdeutung von die Zeit läuft oder das Übertragen der dargestellten Rollen auf gesellschaftliche Verhältnisse). Karl und Annalena interpretieren im Modus der Rekonstruktion die Intention der Aufführung und wechseln dabei ,von der Ebene der ästhetischen Erfahrung auf die Ebene der gesellschaftlichen Wirklichkeit“ (Linz, Hrncal \& Schlinkmann 2016, 544). Das rekonstruierende Deuten leitet auf diese Weise über zum „rekonstruierende[n] Übertragen“ (Linz, Hrncal \& Schlinkmann 2016, 536), auf das im nächsten Abschnitt eingegangen wird.

\subsubsection{3 „bekommen wir nich immer etwas VORgesetzt- (1.17) ${ }^{\circ} \mathrm{hh}$ vorgeREdet- vorge!SPIELT!“45 - Rekonstruktion im Kontext des Übertragens}

In den beiden vorherigen Abschnitten wurden Einstiege in Rekonstruktionen untersucht, die einen bewertenden und deutenden Kontext eröffnen. Abgesehen von diesen beiden Möglichkeiten trat im Datenkorpus eine dritte Art von Einstieg in einen anderen Kontext auf: den Kontext des Übertragens. Welche Merkmale zeichnen diese Einstiege in übertragende Rekonstruktionen aus? Zur Beantwortung dieser Frage sehen wir uns Ausschnitt 5 an, der sich in direktem Anschluss an Ausschnitt 4 ereignet. Nach einer ersten Deutung des Stücks „Der Hundertjährige, der aus dem Fenster stieg und verschwand“ unterhalten sich Karl und Annalena wie folgt weiter.

Ausschnitt 5: „beWEgungsabläufe“46

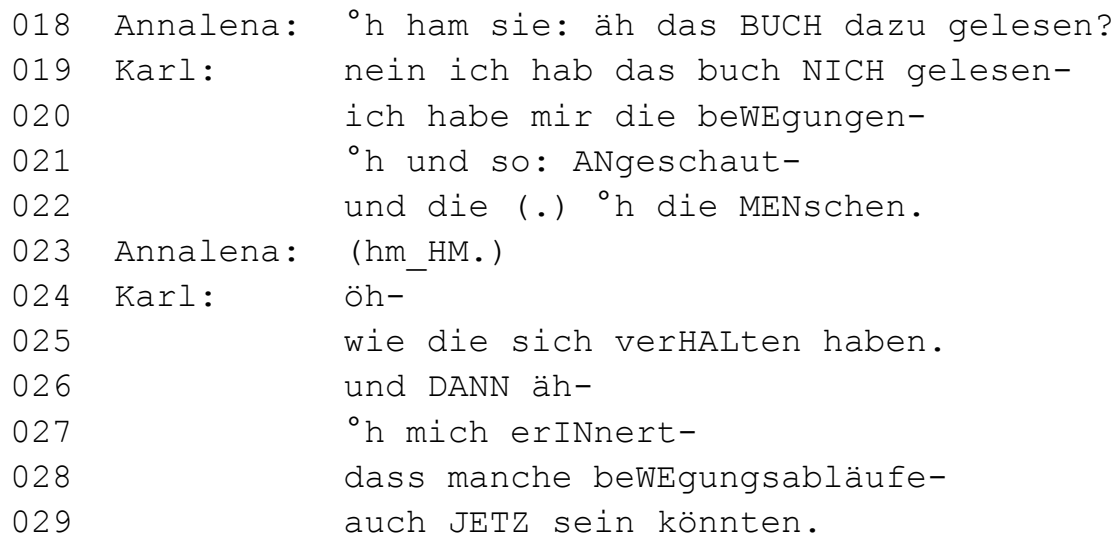

45 Siegen 15-03-07 Hundertjährige Gr.1. Karl. 46 Siegen 15-03-07 Hundertjährige Gr.1. Karl. 
030

031 Karl:

polItisch.

032

03

Annalena: ja.

034

035 Karl:

(.) (ja.)

036 Annalena:

${ }^{\circ} \mathrm{h}{ }^{\circ} \mathrm{hh}{ }^{\circ} \mathrm{h} \mathrm{h}{ }^{\circ}$

037 Karl:

(da MUSS_n-) [(vlleicht SEIN.)]

[wer vers ]wer

versteht den ANderen-

038

039

oder wer !WILL! den anderen verSTEHN.

Annalena:

040 Karl: UND öh- ${ }^{\circ} \mathrm{h}$ ((schmatzt))

041

042

043

$\mathrm{k}$ bekommen wir nich immer etwas

VORgesetzt-

(1.17)

044

'hh vorgeREdet-

vorge!SPIELT! von ANderen-

045

046

047

048

049

und sind überzeugt das is

hundertprozENtig.

${ }^{\circ} \mathrm{h} \mathrm{h}^{\circ}$ Aber e-

es regt an zum DENken.

$(0.38)$ hm_HM.

050 Annalena: ich hab auf jeden fall das BUCH gelesen-=

051

(un_auch) den FILM gesehn.

052

also es gibt da verschiedene

inszeNIErungen des theaterstücks.

053 Karl: hm_HM.

054 Annalena: geñAU.

Nach einer längeren Pause ratifiziert Annalenas anschließende Rückfrage zur Deutung in Zeile 18 „ „h ham sie: äh das BUCH dazu gelesen?“ die Deutungsversuche und setzt die Kenntnis der Literaturgrundlage zur Interpretation des Stücks relevant. Der deiktische, indexikalische Verweis „dazu“ setzt dabei die identifizierende Bezugnahme auf das Stück als Objekt der Rekonstruktion relevant. Gleichzeitig aktualisiert Annalena die Deutung um den Aspekt einer möglichen Begründung der Interpretation (auf der Grundlage der Literaturvorlage). Karl verneint jedoch echohaft repetierend (,nein ich hab das buch NICH gele- 
sen-“, Z. 19) und setzt mit „ich habe mir die beWEgungen- ${ }^{\circ} \mathrm{h}$ und so: ANgeschautund die (.) ${ }^{\circ} \mathrm{h}$ die MENschen." (Z. 20-21) statt der Romankenntnis die visuelle Wahrnehmung der „beWEgungen“ der Schauspieler(innen) als Begründung der Interpretation relevant, wodurch er seine Deutung bekräftigt und erläutert. Nachdem Annalena die Begründung quittiert („(hm_HM.)“, Z. 23), spezifiziert Karl die Rekonstruktion durch den elliptischen Relativsatz „öh- wie die sich verHALten haben.“ (Z. 25). Anschließend nimmt er seine anfängliche Redewiedergabe paraphrasierend, reformulierend und explizierend wieder auf, indem er ausführt: „und DANN äh- ${ }^{\circ} \mathrm{h}$ mich erINnert- dass manche beWEgungsabläufeauch JETZ sein könnten.“ (Z. 26-29), wodurch er einen Aktualitätsbezug herstellt. Nach einer zweiten längeren Pause expandiert Karl die Rekonstruktion um den Bedeutungsaspekt „poLItisch. ${ }^{\circ} h h^{\prime \prime}$ (Z. 31). Die Rekonstruktion der Bewegungen der Schauspieler(innen) wird von Karl auf mehreren zunehmend metaphorischen Ebenen kontextualisiert - von der körperlich-physiologischen Ebene der Stückhandlung (,beWEgungen“, Z. 20) über die stückbezogen globalinterpretierende Ebene der eigenen Deutung (,wie die sich verHALten haben.“, Z. 25 ; „,beWEgungsabläufe-“, Z. 28) bis hin zur Übertragung auf die gesellschaftspolitisch-interpretierende Ebene (,poLItisch. ${ }^{\circ} h h^{\prime}, \mathrm{Z}$. 31). Annalena quittiert diese Interpretation und Übertragung, indem sie in Zeile 33-34 mit ,ja. (.) (ja.)“ reagiert und setzt in Zeile $36 \mathrm{zu}$ einer tentativen Begründung an „da MUSS_n-) (vlleicht SEIN.)“. Diese wird jedoch in Zeile 37 von Karl zugunsten einer indirekten übertragenden Rekonstruktion der seines Erachtens durch das Stück vermittelten Intention in Bezug auf die gesellschaftliche Realität des menschlichen Miteinanders unterbrochen (,wer vers wer versteht den ANderenoder wer !WILL! den anderen verSTEHN.“). Nach einem kurzen non-verbalen Signal von Annalena expandiert er die indirekte übertragende Rekonstruktion durch die rhetorischen Fragen „UND öh- ${ }^{\circ} h$ ((schmatzt)) $k$ bekommen wir nich immer etwas VORgesetzt- (1.17) ${ }^{\circ}$ hh vorgeREdet- vorge!SPIELT! von ANderen- und sind überzeugt das is hundertproZENtig.“ (Z. 41-45). In diesem Redezug überträgt er die Aussage des Theaterstücks (seines Erachtens) auf die aktuelle, gesellschaftliche Realität (vgl. „wir“; „immer“). Durch das reformulierende, aktualisierende asyndetische Trikolon und seine (teils extrastarken) Fokusakzente (,VORgesetzt- (1.17) ${ }^{\circ}$ hh vorgeREdet- vorge!SPIELT!“) wird seine affektive Involviertheit deutlich und er setzt vor allem das ,Vorspielen' als Verbindung zwischen Theater und Gesellschaft relevant. In der expandierenden Postsequenz „' $h h^{\circ}$ Aber e- es regt an zum DENken. (0.38) hm_HM.“ (Z. 46-48) kontextualisiert er zusammenfassend die indirekt rekonstruierte Intention der Theaterinszenierung. Nach einer Pause initiiert er selbst die Ratifizierung, woraufhin wieder eine sehr lange Pause entsteht. Nach über sieben Sekunden rekontextua- 
lisiert Annalena schließlich wieder ihr Vorwissen zum Stück (die Literaturgrundlage und den auf dem Buch basierenden Film) als Deutungsgrundlage, indem sie entgegnet ,ich hab auf jeden fall das BUCH gelesen-=(un_auch) den FILM gesehn. also es gibt da verschiedene inszeNIErungen des theaterstücks." (Z. 50-52). Beide Sprecher ratifizieren diese Aussage und nach einer kurzen Pause wechselt der Fokus im anschließenden Gespräch zum allgemeinen Vergleich von Buchvorlagen und darauf basierenden Verfilmungen.

Hinsichtlich der Einstiege in alle genannten Kontexte fällt auf, dass die Rekonstruktion als eine der zentralen Aufgaben in allen Gesprächen permanent im Hintergrund mit zu leisten ist. In der Mehrheit der Gespräche des Korpus besteht die erste sprachliche Aktivität aus rekonstruktiven Handlungen, selbst auf abgebrochene Fragen (,[wie-]“) antworten die Sprecher rekonstruierend und auch wenn sich der Kontext ändert oder sich (vom Standpunkt dieses Kapitels aus gesehen) „Exkurse“ zu nicht-rekonstruktiven Inhalten ereignen, kehren die Sprecher immer wieder zu Rekonstruktionen zurück (vgl. Ausschnitte 10 und 11).

Die drei in Abschnitt 8.3.2 beschriebenen Ausschnitte illustrieren, wie Theaterbesucher(innen) in Pausengesprächen bereits beim Einstieg in Rekonstruktionen einen bestimmten Kontext eröffnen. So wurde anhand Ausschnitt 3 deutlich, wie sich die zwei Sprecherinnen mittels typischer verba sentiendi, evaluierender Adjektive und gegenseitiger Ratifizierungen einen bewertenden Kontext wechselseitig aufzeigen. Dabei kann die Tatsache, dass eine bewertende Rekonstruktion zustande kommt, relevanter sein als die Frage, worüber sich die Sprecher dabei unterhalten. Dahingegen zeigt Ausschnitt 4 einen Einstieg in eine deutende Rekonstruktion, der von einer Redewiedergabe der eigenen Gedanken während der Vorstellung (,so EInige:- so einige TYpen (.) ham mich erinnert (.) an die gegenwart.“), einer Typisierung einer Rollengruppe aus der Inszenierung (,so einige TYpen“) und einem hypothetisch-fragenden Unterton auf Seiten eines Sprechers geprägt wird. Die Gesprächspartnerin lacht zunächst als Hörersignal und zeigt ihr Verständnis der deutenden Rekonstruktion schließlich an, indem sie in Form eines eingebetteten deutenden Medienverweises („’h ham sie: äh das BUCH dazu gelesen?“) mögliches Hintergrundwissen (der Literaturgrundlage) zum Stück thematisiert. Neben diesen beiden Kontexten, die u.a. bereits von Hausendorf (2011; 2012) und Hausendorf \& Müller (2016a) als grundlegende Aufgaben der Kunstkommunikation in Ausstellungsgesprächen festgestellt wurden, beinhaltet Ausschnitt 5 den Einstieg in eine Rekonstruktion im Kontext des Übertragens. Diesen Kontext zeigen sich die beiden Sprecher an, indem sie in ihren Referenzen zwischen den Bezugsebenen der Inszenierung, der eigenen Deutung und der gesellschaftlichen Realität 
changieren (z.B. von „beWEgungen“ über „wie die sich verHALten haben.“ und „beWEgungsabläufe-“ bis hin $\mathrm{zu}$ „poLItisch. $\left.{ }^{\circ} h h^{\prime \prime}\right)$. Dabei begründen und explizieren sie die Übertragung wechselseitig und sind teilweise affektiv involviert (vgl. Stilmittel wie rhetorische Fragen und asyndetisches Trikolon). Anders als in den Beispielen zu bewertenden und deutenden Kontexten von Rekonstruktionen steigen nicht beide Sprecher gleichermaßen in die Rekonstruktion ein, sondern eine Sprecherin wechselt nach kurzer Zeit und minimaler Beteiligung aus dem übertragenden wieder zurück in den deutenden Kontext.

\subsubsection{Entfaltung von Rekonstruktionen}

Nachdem Abschnitt 8.3.2 die Einstiege von Theaterbesucher(inne)n in Rekonstruktionen in Pausengesprächen thematisierte, konzentriert sich dieser $\mathrm{Ab}$ schnitt auf die anschließende Entfaltung von Rekonstruktionen. Die zugrunde liegenden Pausengespräche legen zwei grundsätzliche Unterscheidungen nahe, die einerseits die Funktion von Rekonstruktionen in ihrer Entfaltung betreffen und andererseits ihre Darstellungsweise. Demzufolge beschreibt Abschnitt 8.3.3.1 die Entfaltung von Rekonstruktionen mit informierender Funktion im Kontrast zu derjenigen von Rekonstruktionen mit kommemorierender Funktion. Anschließend geht Abschnitt 8.3.3.2 auf die unterschiedlichen rekonstruktiven Verfahren im reinszenierenden Darstellungsmodus im Vergleich zum berichtenden Darstellungsmodus ein. Im Rahmen der reinszenierenden Darstellungsweise fällt in der Auseinandersetzung mit den Daten außerdem ein rekonstruktives Verfahren besonders auf, dem Abschnitt 8.3.3.3 gewidmet wird: die Redewiedergabe.

\subsubsection{1 „is dir die TAschenlampe aufgefallen?" ${ }^{47}$ - Informierend vs. kommemorierend}

Bezüglich des Wissensstatus der Sprecher lassen sich im Datenmaterial zwei Funktionen von Rekonstruktionen mit spezifischen rekonstruktiven Verfahren unterscheiden. Einerseits können Rekonstruktionen in Theaterpausengesprächen eine informierende Funktion haben, wenn es mindestens einen Sprecher gibt, dem der Rekonstruktionsinhalt nicht bekannt ist. Andererseits wohnt vielen Rekonstruktionen bezüglich der gerade besuchten und somit allen Sprechern bekannten Theaterinszenierung eine kommemorierende Funktion inne.

47 Siegen 14-11-14 Hamlet Gr.2. 
Wenden wir uns zunächst den Ausprägungen von Theaterrekonstruktionen mit informierender Funktion zu. Kommen wir dazu zurück zum Gespräch zwischen Marco und Moritz in der Pause des Theaterstücks „Hamlet“, aus dem in 8.1 bereits ein erster Ausschnitt betrachtet wurde. Der folgende Ausschnitt ereignet sich sechseinhalb Minuten nach dem ersten Ausschnitt, nachdem die Sprecher die schauspielerische und Inszenierungsleistung, humoristische Einlagen des Stücks, einige Rollen, das Bühnenbild und den Gesang rekonstruiert haben. Unmittelbar vor Beginn des Ausschnitts haben Marco und Moritz begonnen, sich in den Theatersaal zurück zu begeben und ihre Sitzplätze zu suchen:

Ausschnitt 6: „die TAschenlampe“48

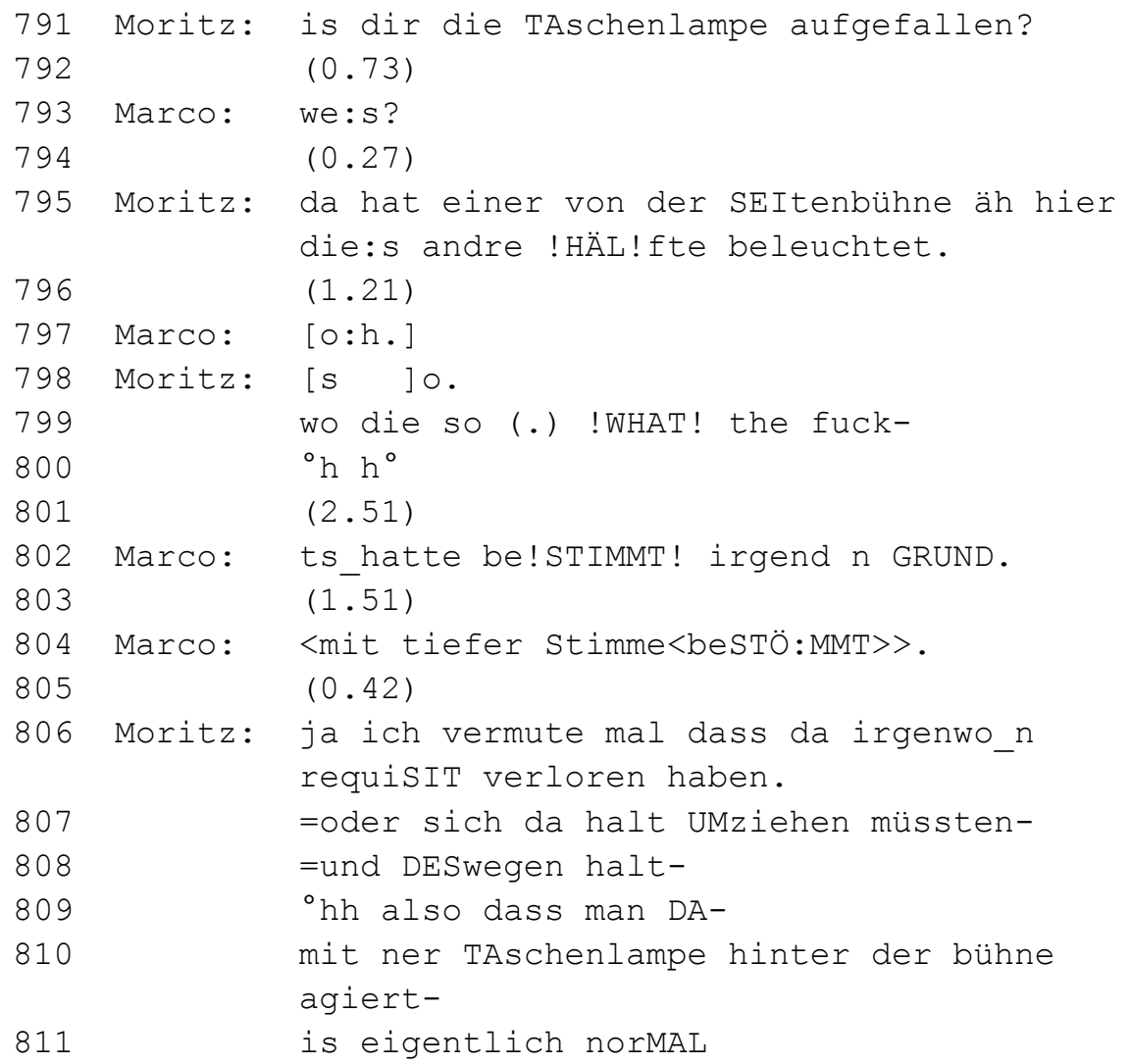

48 Siegen 14-11-14 Hamlet Gr.2. 


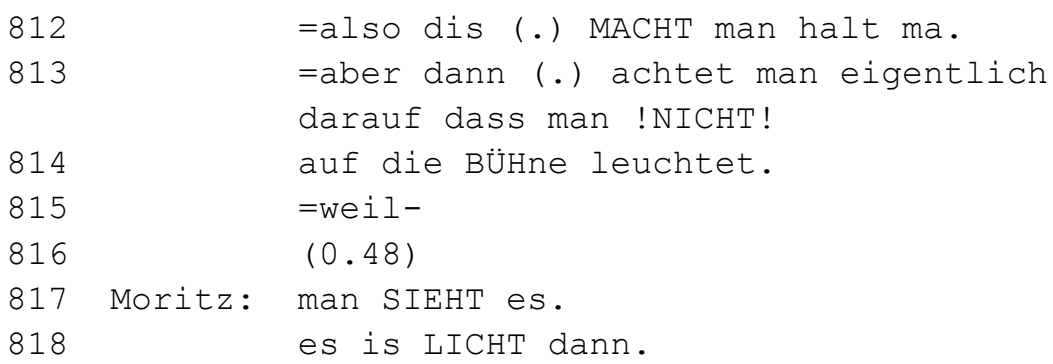

Moritz eröffnet in Zeile 791 die Rekonstruktion eines neuen Aufführungsaspekts, indem er Marco nach seiner Wahrnehmung eines Requisits fragt: „is dir die TAschenlampe aufgefallen?“. Auf diese Frage zur „explizite[n] Wissensabklärung“ (Keppler 1995, 249; vgl. Ulmer \& Bergmann 1993, 88-90) reagiert Marco nach einer kurzen Pause mit einer Gegenfrage („we:s?“, Z. 793). Nach einer weiteren kurzen Pause besteht Moritz' Antwort in der (lokalen, personalen und modalen) Explizierung des Aufführungsaspekts, wodurch er den Einsatz der Taschenlampe als Teil der Bühnenbeleuchtung rekontextualisiert: „da hat einer von der SEItenbühne äh hier die:s andre !HÄL!fte beleuchtet.“ (Z. 795). Anhand dieser Erklärung zeigt er sein Verständnis von Marcos vorheriger Gegenfrage und positioniert sich damit als „,unwissende[r]“ Gesprächsteilnehmer“, der zumindest diesen Aufführungsaspekt nicht (gut) kennt (vgl. Ulmer \& Bergmann 1993, 91) und gibt eine Erzählaufforderung (vgl. Ulmer \& Bergmann 1993, 92). Er versteht Marcos Nachfrage als Ausdruck eines gewissen „Interesse[s] am Thema“ (Keppler 1995, 249). Die zunächst vagen deiktischen Referenzen auf die Theaterinszenierung (,die TAschenlampe“, „da“ und „einer“) ergänzt er entsprechend Marcos ,Unwissenheit' an dieser Stelle um konkretere teils fachtechnische lokale Angaben: „von der SEItenbühne“ und „die:s andre !H ÄL!fte“. Die Wissensasymmetrie zwischen den beiden Sprechern wird nach einer längeren Pause partiell von Marco bestätigt, indem er in Zeile 797 die Partikel bzw. Interjektion des Erstaunens „o:h.“ als Reaktion auf eine ihm neue Information äußert. Im Ansatz überlappend setzt Moritz $\mathrm{zu}$ einer weiteren Explizierung der Rekonstruktion durch die temporale und modale Einordnung des Beleuchtungsaspekts an: „[s]o. wo die so (.)“ (Z. 798-799). Nach diesen beiden Ansätzen und der zweifachen Verwendung des Zögerungsmarkers „so“ bricht Moritz den Explizierungsversuch schließlich ab. Stattdessen rekonstruiert er in Zeile 799 nach einer Minimalpause seine eigene Reaktion auf die seitliche Beleuchtung durch die Taschenlampe während der Aufführung: „!WHAT! the fuck-“. Dazu verwendet er eine stark emotive Interjektion mit teils sehr starker Betonung und in englischer Sprache. Im Sinne von Butterworth (2015) expliziert er die Rekon- 
struktion in Form einer Redewiedergabe als Wiedergabe eines (eigenen) vollzogenen, mentalen kommunikativen Akts, also eines eigenen Gedankens. Diese wird gefolgt von zwei längeren (gefüllten) Pausen in den Zeilen 800-801. Daraufhin beantwortet Marco Moritz' implizite Frage (Was sollte das?) durch die Rekonstruktion der Intention des Regisseurs: „ts ${ }^{49}$ hatte be!STIMMT! irgend $n$ GRUND.“ (Z. 802). Als darauf eine Reaktion von Moritz ausbleibt (Z. 803), wiederholt Marco den bereits vorher stark betonten Heckenausdruck: „<mit tiefer Stimme<beSTÖ:MMT>>. “ Durch die tiefe Stimme und den langgezogenen umgangssprachlich modifizierten Vokal ironisiert Marco seine vorherige Aussage. An dieser Stelle positioniert er sich ansatzweise nicht nur als passiver, unwissender Zuhörer, sondern beteiligt sich durch die implizite Bewertung (in Form des ironisierenden Untertons) aktiv an der Rekonstruktion der Theaterinszenierung (vgl. Ulmer \& Bergmann 1993, 90). Wieder entsteht eine kurze Pause, woraufhin Moritz seine eigene implizite Frage durch die Rekonstruktion der Gründe für die Verwendung der Taschenlampe während der Inszenierung beantwortet und gleichzeitig Marcos vorherige Aussage expandierend expliziert: „ja ich vermute mal dass da irgenwo_n requiSIT verloren haben.=oder sich da halt UMziehen müssten-=und DESwegen halt-“ (Z. 806-808). Durch diese Reaktion auf Marcos vorherige Feststellung zeigt er sein Verständnis von Marcos „Kommentierung des Mediengeschehens“ (Ulmer \& Bergmann 1993, 93) als Ratifizierung der Rekonstruktion an, so dass die Erzähleinheit abgeschlossen werden kann (vgl. Ulmer \& Bergmann 1993, 93). Moritz‘ Äußerung beinhaltet vage Referenzen auf die Aufführung ( $d a$, irgendwo) sowie Allgemeingültigkeitsmarker (halt), was auf seine Anerkennung von Marcos partiell-wissender Rolle schließen lässt. Anschließend äußert Moritz eine auf Hintergrundwissen beruhende „Kommentierung des dargestellten Geschehens“ (Ulmer \& Bergmann 1993, 92): „ ohh also dass man DA- mit ner TAschenlampe hinter der bühne agiert- is eigentlich nor$M A L=$ also dis (.) MACHT man halt ma.=aber dann (.) achtet man eigentlich darauf dass man !NICHT! auf die BÜHne leuchtet. weil- (0.48) man SIEHT es. es is LICHT dann.“ (Z. 809-818). Eine anschließende Pause von zwei Sekunden sowie ein darauf folgender Themenwechsel ( $\mathrm{zu}$ einem anderen Beleuchtungsaspekt) verdeutlichen, dass beide Sprecher die Teilrekonstruktion mit Moritz‘ Kommentar als beendet betrachten (vgl. Ulmer \& Bergmann 1993, 92-93).

Bezüglich der Frage, welche Ausprägungen Rekonstruktionen in Theaterpausengesprächen mit informierender Funktion auszeichnen, illustriert Ausschnitt 6 folgende Ergebnisse: In Abgrenzung zu kommemorierenden Rekon-

49 „ts“ lässt in diesem Kontext die umgangssprachlich getilgte und verhärtete Version von „das“ vermuten. 
struktionen initiieren die Sprecher die vorliegende informierende Rekonstruktion durch eine Sequenz der expliziten Wissensabklärung, in deren Verlauf sich die beiden Sprecher zunächst als aktiver Erzähler und passiver Zuhörer positionieren. Dies stimmt mit den Erkenntnissen über informierende Medienrekonstruktionen von Ulmer \& Bergmann (1993) und Keppler (1995) überein, ebenso wie die darin enthaltene Erzählaufforderung („we:s?“). Die Wissensabklärung ist jedoch nicht nach der Initiierungssequenz beendet, sondern es folgt ein ständiger interaktiver Wahrnehmungsabgleich im Laufe der Rekonstruktion. Dabei handeln Marco und Moritz laufend ihre Rollen aus und passen ihre Beiträge sprachlich-kommunikativ daran an, z.B. durch vagere/konkretere Referenzierung der entsprechenden Aspekte der Theatervorstellung (von „die TAschenlampe“, „da“ und „einer“ über „von der SEItenbühne“ und „die:s andre !HÄL!fte“ zu „da“, „irgendwo“ und „,halt“ ) oder der bewertend ironisierenden Wiederholung einzelner Elemente („«mit tiefer Stimme<beSTÖ:MMT>>.“). Dementsprechend fehlt im Rahmen dieser informierenden Theaterrekonstruktion die „chronologisch strukturiert[e]“, ,in den Grundzügen vollständig und umfassend[e]“ (Ulmer \& Bergmann 1993, 91-92) Darstellung des Rekonstruktionsinhalts. Stattdessen fällt auch im Kontext der vorliegenden informierenden Rekonstruktion die Relevanz reinszenierender Verfahren wie Verstellen der Stimme und Redewiedergaben („!WHAT! the fuck-“.) auf. Zusätzlich zur Erheiterung (vgl. Keppler 1995) tragen diese Verfahren in Ausschnitt 6 zu einem negativ bewertenden und zynischen Unterton bei. U.a. deshalb lässt sich auch diese größtenteils informierende Theaterrekonstruktion eines Aufführungsaspekts als Teilrekonstruktion in den übergeordneten bewertenden argumentativen Rekonstruktionszusammenhang einordnen (vgl. Abschnitt 8.3.1). Schließlich stimmt die Rekonstruktion in den Beendigungsverfahren mit den von Bergmann \& Ulmer (1993) festgestellten Mechanismen der wechselseitigen Kommentierung des Rekonstruktionsgegenstandes überein.

Bei Betrachtung der Gespräche im Datenkorpus kristallisierte sich eine weitere Funktion von Rekonstruktionen bezüglich des Wissensstatus der Sprecher heraus: die kommemorierende Funktion. Welche Ausprägungen charakterisieren Rekonstruktionen mit dieser Funktion? Um diese Frage zu beantworten, sehen wir uns einen Ausschnitt aus dem Gespräch zwischen Ina und Finn an. Sie unterhalten sich in der Pause der Aufführung des Theaterstücks „Der Streik ${ }^{* 50}$, in dem es um die wirtschaftliche Entwicklung der USA in den 1950er Jahren geht. Vor dem Ausschnitt haben die beiden die Inszenierung bereits

50 Vgl. Kapitel 2.1.4.2., i.d.B. 
sieben Minuten lang gedeutet und bewertet, sich Getränke gekauft und sich anschließend auf den Außenbereich vor dem Theater begeben.

Ausschnitt 7: „TURbo [...] kapitaLISmus“51

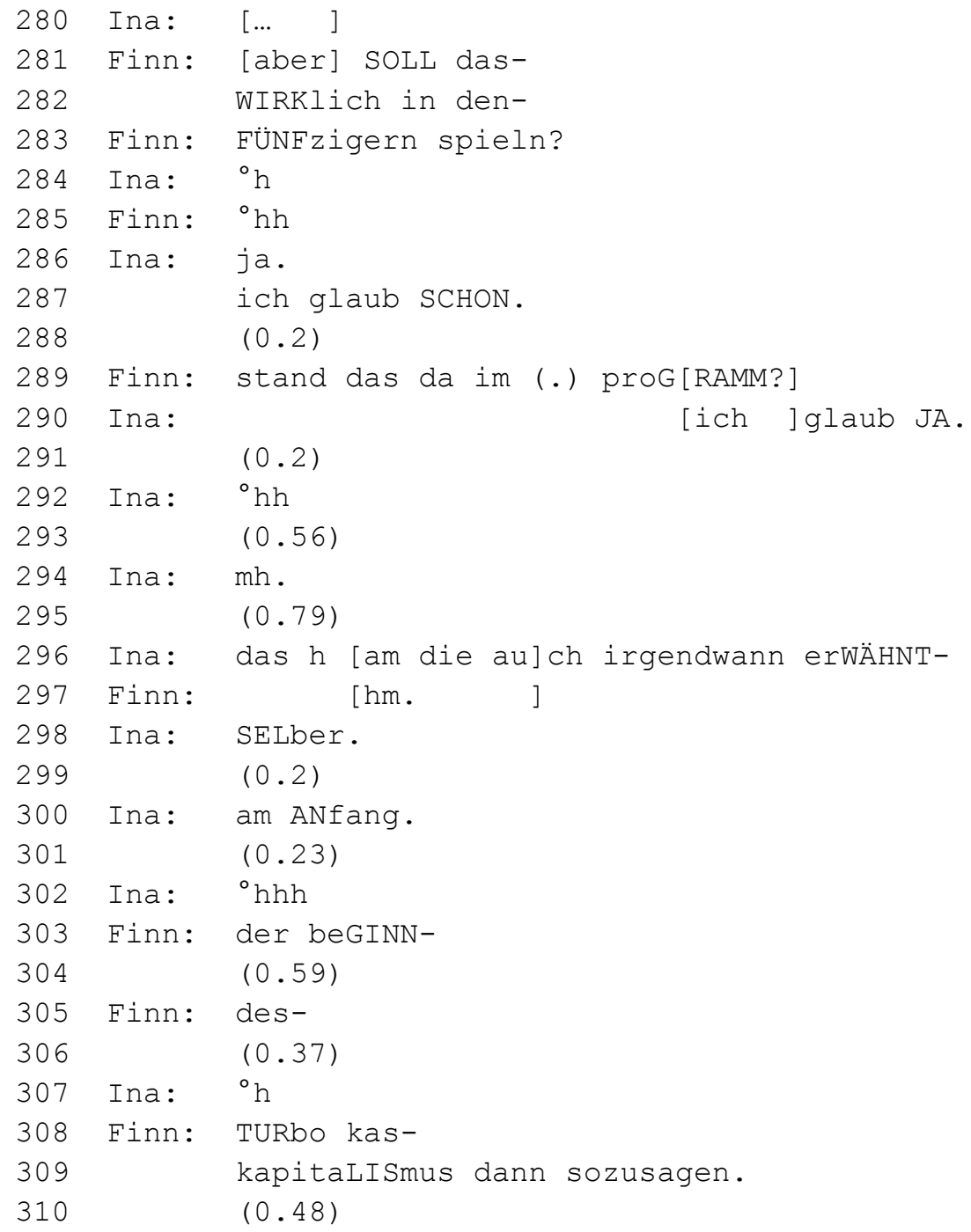

51 Köln_14-05-10_DerStreik_Gr.1. 


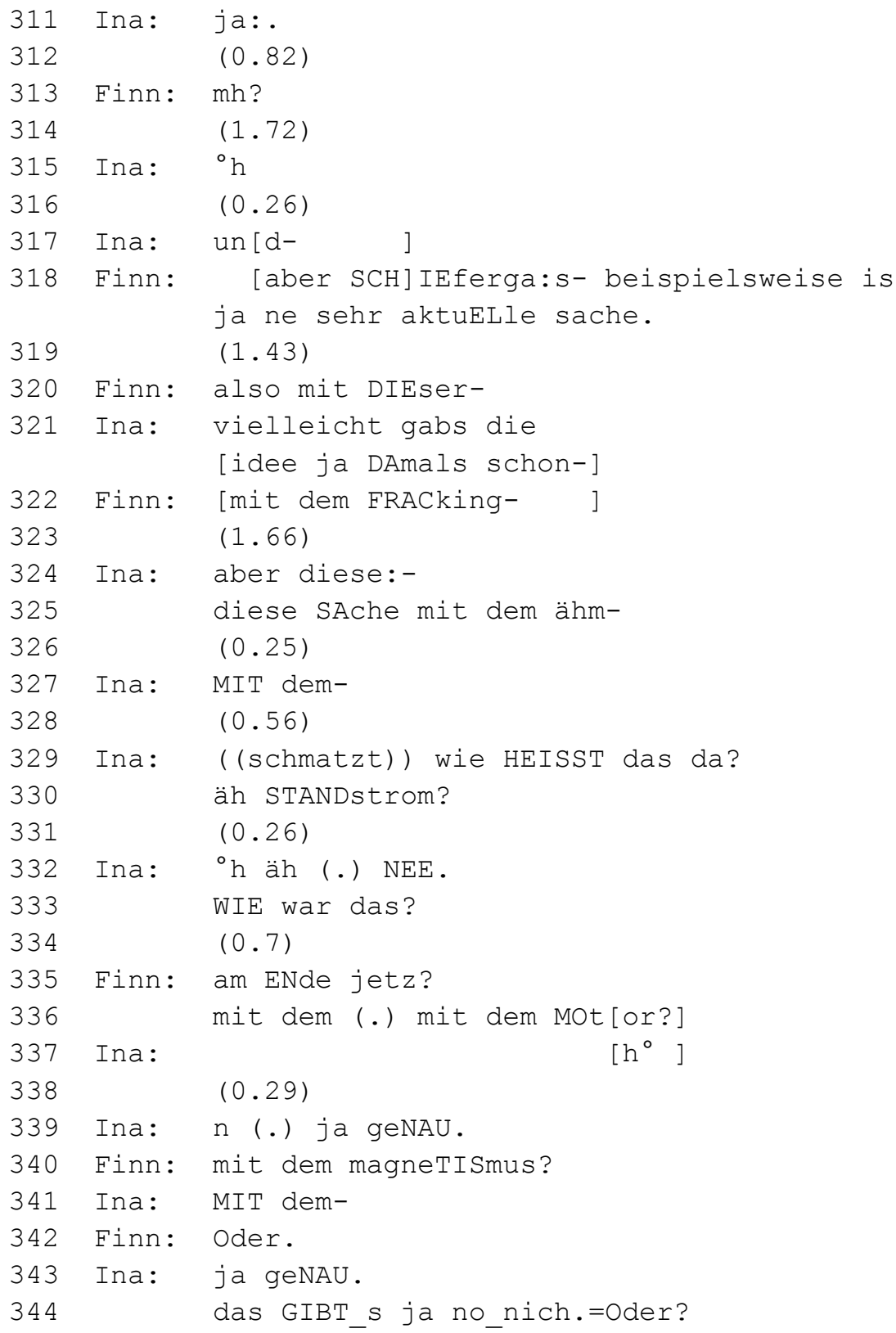




$\begin{array}{lll}345 & \text { Finn: } & (.) \text { nein. } \\ 346 & \text { Ina: } & h^{\circ} \\ 347 & & (0.21)\end{array}$

Zeile 280-317 zusammenfassend diskutieren Ina und Finn hier - initiiert durch Finn - die Frage, ob die Inszenierung „WIRKlich in den- FÜNFzigern spieln?“ soll. Im Kontext dieser Frage initiiert Finn in Zeile 318 die Rekonstruktion eines neuen Aspekts, indem er den Bezug zu Schiefergas, dessen Gewinnung im Stück thematisiert wurde, als „sehr aktuELle sache“ herstellt. Diese Lösung vom eigentlichen Mediengeschehen durch die Übertragung von „Inhalte[n] der Medienereignisse direkt auf andere Realitätsbereiche“ (nämlich hier die aktuelle Wirtschaftslage) halten schon Ulmer \& Bergmann $(1993,98)$ als typisches Element der kommemorierenden Funktion von Medienrekonstruktionen fest. Auf diese Weise argumentiert Finn gegen die Situierung der Stückhandlung in den 50er Jahren. Anhand der knappen Formulierung „,aber SCHIEferga:s-“, mit der er auf einen Aufführungsaspekt Bezug nimmt, zeigt er Ina an, dass er ihre Kenntnis des Aufführungsaspekts als „geteiltes Wissen“ (Keppler 1995, 236) voraussetzt. Nach einer Pause konkretisiert Finn expandierend in Zeile 320-322 seine Rekonstruktion: „also mit DIEser- mit dem FRACking“. Er wird dabei in Zeile 321 von einem Einwand von Ina unterbrochen, in dem sie den Aufführungsaspekt ,Schiefergasgewinnung durch Fracking' auf den Realitätsbereich der Technik der 50er Jahre überträgt: ,vielleicht gabs die idee ja DAmals schon-“. Dadurch argumentiert sie im Sinne eines „Meinungsaustausches“ (Ulmer \& Bergmann 1993, 95)52 für die Verortung des Stücks in den 50er Jahren. Diese Beteiligung an der deutenden/übertragenden Rekonstruktion zeigt ihre wissende Rolle an und lässt die Unterscheidung zwischen Produzent und Rezipient verschwimmen (vgl. Ulmer \& Bergmann 1993, 96; Keppler 1995, 244: „MitAutoren“). Im Anschluss an Finns Beitrag setzt Ina in Zeile 324 mit „aber diese (.) diese SAche mit dem ähm-“ zur Rekonstruktion eines weiteren Aufführungsaspekts im Rahmen der interpretativen temporalen Einordnung der Stückhandlung an. Die sprachliche Fassung des zu rekonstruierenden Aspekts gelingt ihr nicht ad hoc, so dass es im Folgenden zu einem erhöhten Formulierungsaufwand in Form von Selbstreparaturen (repetitiven Reformulierungen), Pausen und gefüllten Pausen kommt. In Zeile 329 initiiert sie schließlich die gemeinsame, interaktive Aushandlung des zu rekonstruierenden Aspekts durch die Fragen „((schmatzt)) wie heißt das DA? äh STANDstrom? ${ }^{\circ}$ äh (.) nee WIE war das?“. Dabei chnagiert sie durch den Tempuswechsel zwischen der Ebene der

52 Vgl. ebenso: „zur Verteidigung einer Meinung“(Keppler 1995, 225). 
wirtschaftlichen Realität (,wie heißt das DA?“) und der Ebene der Stückhandlung (,nee WIE war das?"). Finn reagiert auf diese Einforderung einer Benennung bzw. Erklärung in Zeile 335, indem er eine Sequenz zur Nachfrage bzw. Spezifizierung des fraglichen Rekonstruktionsaspekts initiiert: „am ende jetz (.) mit dem (.) mit dem MOtor? mit dem magneTISmus?=oder.“ Auch seine Beiträge sind von einem hohen Formulierungsaufwand und einem tentativen, fragenden Charakter beim Versuch der Rekonstruktion geprägt. Überlappend bestätigt Ina in Zeile 339 und 341 seine Interpretation des Aufführungsaspekts, ohne jedoch selbst zu einer begrifflichen Fassung zu kommen: „ja geNAU.“; „ MIT dem-“. Ohne dass eine(r) der beiden diese Leerstelle füllt, setzt Finn in Zeile 342 zur Formulierung einer Alternative an: „Oder.“ Daraufhin ratifiziert Ina Finns eingeschobenen Referenzierungsvorschlag zur Aushandlung der ,Sache mit dem Standstrom“: „ja geNAU.“ (Z. 343). Sie behandelt den Wahrnehmungsabgleich in der Einschubsequenz daraufhin als abgeschlossen, indem sie zurück zum Kontext des deutenden Meinungsvergleichs kommt: „das GIBT_s ja no_nich.=Oder?" (Z. 343). Den Bezug zum ausgehandelten Aufführungsaspekt stellt sie durch das deiktische „das“ her, welches auf ihre Annahme von Finns Vorwissen sowie den erfolgreichen Abschluss des Wahrnehmungsabgleichs schließen lässt. Sie überträgt die in der Inszenierung dargestellte ,Sache mit dem Motor und dem Magnetismus ' wiederum auf die gesellschaftliche Realität (vgl. Ulmer \& Bergmann 1993, 98). Schließlich quittiert Finn die deutende Rekonstruktion: „(.) nein.“ (Z. 345), und die anschließenden (gefüllten) Pausen weisen darauf hin, dass die Sprecher die Aspektrekonstruktion als abgeschlossen behandeln.

Zusammenfassend wird die vorliegende kommemorierende Rekonstruktion davon geprägt, dass die Sprecher in gemeinsamer interaktiver kooperativer Aushandlung „einzelne Aspekte des Medienereignisses“ (Ulmer \& Bergmann 1993, 95) „selektiv und fragmentarisch“ rekonstruieren: zum Einen „SCHIEferga:s-“ und zum Anderen „diese SAche mit dem ähm- äh STANDstrom?“ bzw. „MOtor?“ bzw. „magneTISmus?“. Ina und Finn rekonstruieren nur die Aspekte der Inszenierung, die ihnen im Kontext der Argumentation zur temporalen Einordnung und Deutung der Stückhandlung als besonders relevant erscheinen (vgl. Keppler 1995, 256). Dabei greifen sie zu „bewertenden und interpretierenden Kommentaren sowie wechselseitigen Kleinst-Belehrungen“ (Keppler 1995, 239) wie z.B. „aber SCHIEferga:s- beispielsweise is ja ne sehr aktuELle sache.“

Bezüglich der Frage nach den spezifischen kontextuellen Mustern von kommemorierenden Rekonstruktionen in Theaterpausengesprächen fällt zunächst die ständig mitlaufende interaktive Abklärung der Wissensvoraussetzungen im Sinne eines Wahrnehmungsabgleichs auf (vgl. konkretisierende, 
spezifizierende Reformulierungen, Einschubsequenz zur Nachfrage, Selbstreparaturen, (gefüllte) Pausen, tentativer, fragender Charakter, Frage-AntwortSequenzen). Einerseits setzen Ina und Finn Wissen (über die Aufführung) des jeweiligen Gesprächspartners voraus (vgl. definite und deiktische Referenzen: „das-“, „am ANfang.“, „DIEser-“, „die idee“, „mit dem FRACking-“, „diese:- “, „mit dem ähm-“", „MIT dem-“, „,das da?““, „das?“, „,am ENde jetz?“, „mit dem (.) mit dem MOtor?", „mit dem magneTISmus?", „MIT dem-“ und „das“), wodurch die kommemorierende Funktion u.a. im Kontrast zur informierenden steht. Andererseits handeln die Sprecher im Kontext der Deutung der Stückhandlung kommunikativ und kooperativ aus, was sie überhaupt wahrgenommen haben und ob ihre Wahrnehmung identisch ist. Außerdem zeichnet sich das kommemorierende Übertragen der Inszenierungsaspekte auf andere Realitätsbereiche durch ein spielerisches und teils zweideutiges und implizites Changieren zwischen den Ebenen der Theateraufführung und der gesellschaftlichen Realität aus („((schmatzt)) wie HEISST das da? äh STANDstrom? (0.26) äh (.) NEE. WIE war das?" und „am ENde jetz? mit dem (.) mit dem MOtor?“ [...] „das GIBT_s ja no_nich.=Oder?").

\subsubsection{2 "《<imitierend>TSQUEEZE〉 ma:l.“53 - Reinszenierend vs. berichtend}

Der nächste Ausschnitt (8) findet früher während desselben Gesprächs zwischen Finn und Ina statt. Vor dem Einsatz des Ausschnitts (8) haben die beiden Sprecher Inas Schwangerschaft und technische Aspekte der Aufnahmegeräte thematisiert und sind in eine kommemorierende bewertende Rekonstruktion eingestiegen. Dabei wurde die Verständlichkeit des Stücks negativ bewertend rekonstruiert:

Ausschnitt 8: „kommuNIStische zustände“554

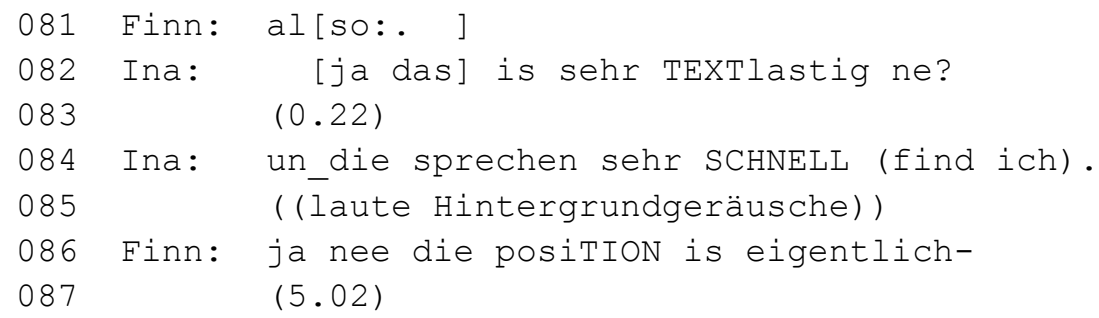

53 Köln 14-04-22 BrainAndBeauty Gr.3.

54 Köln_14-05-10_DerStreik_Gr.1. 
088 Finn: ALso.

$089 \quad(0.25)$

090 Finn: WER jetz hier (.) welche position?

$091 \quad(1.62)$

092

( (laute Hintergrundgeräusche))

$[\ldots]^{55}$

102 Finn: nee jetz äh also am ENde (.) (warn/wann) jetz hie:r (.) äh:-

$103(0.43)$

104 Finn: schon fast kommunIStische zustände?

$105 \quad(0.94)$

106 Finn: mit (.) das is alles PLANwirtschaft (.) und äh-

$107 \quad(0.55)$

108 Ina: jaJA-

109 Finn: alles GLEICHgeschaltet wird und so weiter oder?

$110 \quad(0.36)$

111 Finn: ALso.

$112 \quad(3.82)$

113 Ina: ich finde dass da auch (.) keine klare position bezogen werden kann.

114 =äh also $n$ n ! Ex!tra nich bezi bezogen wird weil-

$115 \quad{ }^{\circ} \mathrm{hh}$

$116 \quad(0.21)$

117 Finn: da wer [den nur so]

118 Ina: [äh:- ]

119 Finn: tenDENzen gezei[gt. ]

120 Ina: [nee j]a das wird

philosopHIERT halt sehr viel.=ne?

121 un_die charaktere WECHseln ja auch immer so_n bisschen ihre-

$122(0.58)$

55 An dieser Stelle erfolgt ein minimaler Exkurs auf ein paar Schuhe, das Teil des Bühnenbildes war und welches Ina im Raum entdeckt (Z. 93-101). Dieser Teil wurde hier aus Relevanzgründen gekürzt. 


\section{Ina: ihre MEInung . \\ $124 \quad(0.67)$ \\ 125 Ina: ${ }^{\circ} \mathrm{h}$}

Nach Finns Verzögerungssignal „also:““ führt Ina die bewertende Rekonstruktion in Zeile 82 weiter aus, indem sie den Inszenierungsaspekt des Textanteils des Stücks fokussiert: „ja das is sehr TEXTlastig ne?“. Diese Sequenz ergänzt sie nach einer kurzen Pause um die Rekonstruktion der schauspielerischen Leistung bezüglich der Sprechgeschwindigkeit, indem sie in Zeile 84 formuliert: „un_die sprechen sehr SCHNELL (find ich)“. So nimmt sie sowohl die kognitive als auch die auditive Verständlichkeit in den Fokus. Des Weiteren finden sich in ihrem Beitrag keine „Dramatisierungsstrategien“ (Kotthoff 2011, 395) oder Detaillierungen, sondern sie beschreibt die Inszenierungsaspekte relativ faktisch. Die weiterhin vagen rekonstruierenden Bezugnahmen „das“ und „die“ behandelt Finn im Folgenden als unproblematisch. Er verschiebt daraufhin den Fokus der Rekonstruktion auf die Intention des Regisseurs, genauer auf die (politischen) Positionen, die im Stück vertreten werden, wenn er verbalisiert: ,ja nee die posiTION is eigentlich- (5.02) ALso. (0.25) WER jetz hier (.) welche position?“ (Z. 86-90). Diese Einleitung der berichtenden Rekonstruktion behandeln die Sprecher im weiteren Verlauf als minimales „abstract“ (vgl. Kotthoff 201156). So expliziert Finn das angeschnittene Thema der Rekonstruktion in direktem Anschluss durch seine Formulierung in Zeile 102-111: „nee jetz äh also am ENde (.) (warn/wann) jetz hie:r (.) äh:- (0.43) schon fast kommuNIStische zustände? (0.94) mit (.) das is alles PLANwirtschaft (.) und äh- (0.55) alles GLEICHgeschaltet wird und so weiter oder? (0.36) ALso.“ Er exemplifiziert relativ knapp und elliptisch die vertretenen politischen Positionen durch die Verschiebung des Rekonstruktionsfokus auf den letzten Teil der bisher gesehenen Aufführung. Finn exemplifiziert und begründet seine Interpretation der gesellschaftspolitischen Positionierung der Stückhandlung (als kommunistisch) in Zeile 106 durch eine Redewiedergabe im Sinne der Wiedergabe eines (durch einen Schauspieler) vollzogenen mündlichen sprachlichen Akts (vgl. Butterworth 2015): „mit (.) das is alles PLANwirtschaft“. Ina quittiert diese während einer kurzen Pause in Zeile 108 durch das Hörersignal ,jaJA-“. Die beiden Sprecher behandeln die Redewiedergabe an dieser Stelle nicht als Mittel zur Dramatisierung oder Unterhaltung, sondern unter einem sachlichen „Wahrheitsanspruch“ (Kotthoff 2011, 394).

56 Angelehnt an Labov \& Waletzky (1976). 
Nach einer längeren Pause reagiert Ina teil-responsiv auf Finns Einforderung einer Bestätigung („oder?“), indem sie das Thema der Rekonstruktion erklärend auf die gesellschaftliche Ebene bezieht: „ich finde dass da auch (.) keine klare posiTION bezogen werden kann. =äh also $n n$ !EX!tra nich bezi bezogen wird weil- ${ }^{\circ} h h^{\prime \prime}($ Z. 113-115). Durch diese Formulierung überträgt sie das im Stück angesprochene Thema („da“ im Sinne von: In Bezug auf dieses Thema) auf die gesellschaftliche Realität, in der ihrer Meinung nach eine Positionierung bezüglich der Thematik nicht möglich ist. In schnellem Anschluss changiert sie wieder zwischen den Bezugsebenen zur Deutung des Stücks durch die spezifizierende deutende Rekonstruktion der Intention des Regisseurs: „äh also $n n$ !EX!tra nich bezi bezogen wird weil-“. In Zeile 117 f. nimmt Finn die interpretierende/übertragende Rekonstruktion der Stückhandlung reformulierend und spezifizierend wieder auf, indem er verbalisiert: „da werden nur so tenDENzen gezeigt.“. Durch das deiktische Lokaladverb da stellt er abermals die Referenz zur Stückhandlung her, die er rekonstruiert. Daraufhin begründet Ina ihre in 113-114 geäußerte Meinung, indem sie die Intention des Stücks und die Handlungen der Rollen rekonstruiert: „äh:- nee ja das wird philosoPHIERT halt sehr viel.=ne? un_die charaktere WECHseln ja auch immer so_n bisschen ihre- (0.58) ihre MEInung. “ (Z. 118-123). Anschließend behandeln die Sprecher die berichtende Rekonstruktion als abgeschlossen, wie an (gefüllten) Pausen und einem anschließenden Themawechsel $\mathrm{zu}$ organisatorischen Aspekten (Treffpunkt nach dem WC-Besuch) deutlich wird. Demnach zeigen sie sich wechselseitig an, dass sie die Aussagen (Tendenzen statt Positionen) in Zeile 113-119 als „Quintessenz“ (Kotthoff 2011, 396) der berichtenden Rekonstruktion verstehen. Im Kontrast zum Berichten in anderen Kontexten machen sie dabei Gebrauch von einer Redewiedergabe, die sie jedoch weniger als Dramatisierungsstrategie, sondern vielmehr als Beleg für den Wahrheitsanspruch einsetzen.

Ausschnitt 9 stammt aus dem Gespräch zwischen Emma und Monika in der Pause des Theaterstücks „Brain and Beauty“, dessen Einstieg bereits behandelt wurde. Nach dem Gesprächseinstieg thematisieren die Sprecherinnen die Interaktion der Schauspieler(innen) mit dem Publikum und die Erwähnung Prominenter im Stück, woraufhin sich folgender Ausschnitt ereignet: 


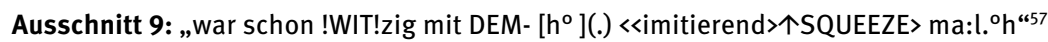

090 Emma: ${ }^{\circ} \mathrm{h}$ (.) war schon WITzig auch-

091

092

093 Monika: IRgendwie-

094 also [mit DEM.]

095

Emma :

$(0.23)$

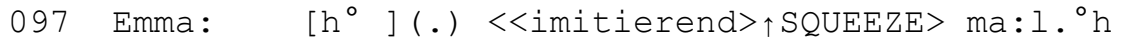

098 Monika: ( (lacht))

099 Emma: $\quad h^{\circ} h^{\circ}{ }^{\circ} \mathrm{hh}$

$100 \quad(0.26)$

101 Emma: ${ }^{\circ} \mathrm{h}$

102 Monika: ( (lacht))

103 Emma: $h^{\circ} h^{\circ}$

$104 \quad(0.44)$

105 Emma: ${ }^{\circ} \mathrm{h}$ aber ich hab die SONGS au nich so ganz-

$106 \quad(0.92)$

107 Emma: verSTANden-

108 wann DIE-

109 [wann DIE einge]spielt worden sind-

110 Monika: [HM_hm? ]

111 Emma: un waRUM dann?

112 Monika: BITte?

113 Emma: ${ }^{\circ}$ hh hab die !SONGS! nich so GANZ verstanden-

114 Monika: nee: .

115 Emma: weil waRUM die die ein gespielt worden sind?

116 Emma: und wann IMmer-

$117{ }^{\circ} \mathrm{h} \mathrm{h}^{\circ}{ }^{\circ} \mathrm{h}{ }^{\circ} \mathrm{h} \mathrm{h}^{\circ}$

$118 \quad(0.3)$

119 Emma: $\quad{ }^{\circ} \mathrm{h}{ }^{\circ} \mathrm{h} \mathrm{h}^{\circ}<<$ singend>BODdy is boss.>

120 ( (Song der Band 2Raumwohnung, der Teil der Inszenierung war))

57 Köln 14-04-22 BrainAndBeauty Gr.3. 
122 Monika: aber ich weiß auch nich so GANZ-

Emma steigt in Zeile 90 in die Rekonstruktion ein, indem sie den humoristischen Aspekt der Inszenierung rekonstruiert: „' (.) war schon WITzig auch-“, den sie gleichzeitig einschränkt („auch“). Das direkt anschließende „IRgendwie“ (Z. 91) schränkt die Rekonstruktion weiter ein, woraufhin Emma in Zeile 92 zur Spezifizierung durch die Fokussierung eines bestimmten Aufführungselements ansetzt (,also [mit DEM.]“). Überlappend fordert Monika durch die elliptische Nachfrage „mit?“ in Zeile 93 eine ebensolche ein, welche Emma daraufhin reformulierend einlöst: „war schon !WIT!zig mit DEM- $h^{\circ}$ (.) <<imitierend>个SQUEEZE> ma:l. ${ }^{\circ} h^{* 58}$ (Z. 97). Überlappend ratifiziert Monika Emmas Rekonstruktion: „ja.“ (Z. 96). In den Zeilen 92 und 97 leitet Emma durch einen elliptischen Relativsatz („mit $D E M^{\prime \prime}$ ) eine reinszenierende und stilisierende Redewiedergabe im Sinne der Wiedergabe eines vollzogenen mündlichen kommunikativen Akts einer Schauspielerin ein (vgl. Ulmer \& Bergmann 1993; Keppler 1995; Günthner 2005; Butterworth 2015). Diese Reinszenierung wird von Monika in Zeile 98 und 102 goutiert: „((lacht))“ (vgl. Günthner 2005). Es folgen außerdem in Zeile 99-104 mehrere (gefüllte) Pausen (in Form von Ein/Ausatmen). Daraufhin fährt Emma mit der Rekonstruktion ihrer eigenen Wahrnehmung der musikalischen Untermalung der Inszenierung fort: „ ${ }^{\circ} \mathrm{h}$ aber ich hab die SONGS au nich so ganz-verSTANden-“ (Z. 105-107). Sie spezifiziert ihre Verständnisprobleme, indem sie die Rekonstruktion ihrer Reflexion während der Vorstellung (im Sinne einer Rekontextualisierung unter Bezugnahme auf ihre Zuschauerrolle; vgl. Linz, Hrncal \& Schlinkmann 2016) auf den Aspekt des Zeitpunkts und der Begründung des Liedeinsatzes fokussiert: „wann DIEwann DIE eingespielt worden sind- un waRUM dann?“" (Z. 108-111) und somit modifiziert. Dabei rekonstruiert sie neben ihren eigenen Gedanken als Redewiedergabe im Sinne der Wiedergabe eines vergangenen mentalen kommunikativen Akts (vgl. Butterworth 2015) zugleich partiell die Intention des Regisseurs. In Zeile 110 und 112 verbalisiert Monika diesbezüglich teilweise überlappend akustische Verständnisprobleme: „hm_HM?“; „BITte?“. Daraufhin paraphrasiert Emma mit extrastarker Betonung, Heckenausdrücken und Repetition: „ " $h \mathrm{~h}$ hab die !SONGS! nich so GANZ verstanden- weil waRUM die die ein gespielt worden sind? und wann IMmer-“ (Z. 113-116). Bereits nach der ersten Intonations-

58 In einer Szene der Inszenierung fordert eine Schauspielerin einen Theatergast dazu auf, ihre Brust (mit Silikonbrustimplantat) anzufassen. 
einheit ratifiziert Monika diese Rekonstruktion: „nee.“ (Z. 113). Nach einer kurzen Sequenz (gefüllter) Pausen exemplifiziert Emma diese Songs in Form einer selbst-initiierten singenden Redewiedergabe: „<<singend $>$ BODdy is boss. >“ (Z. 119) (vgl. „Rekonstruktionsangebot“; Keppler 1995, 235), auf die sie keine Reaktion einfordert. Diese goutiert Monika lachend (Z. 122), während sie ihnen einen humoristischen Wert zuspricht: „is scho WITzig-“(Z. 121). Zuletzt geht sie wieder zur indirekten Rekonstruktion der Intention und eigenen Wahrnehmung über, indem sie ihre partielle Unwissenheit bezüglich der Interpretation/Bewertung verbalisiert: „aber ich weiß auch nich so GANZ-“ (Z. 123).

Zusammenfassend deutet Ausschnitt 9 auf den Stellenwert von Reinszenierungen (z.B. in Form von Geräuschimitationen oder (singenden) Redewiedergaben) in bewertenden Rekonstruktionen in Foyergesprächen hin. Sie können nach einer Bewertungshandlung auftauchen und die Bewertung demnach belegen oder illustrieren (vgl. Couper-Kuhlen 2007). Dabei können sie anstelle einer begrifflichen Fassung und eingeleitet durch elliptische Relativsätze angeführt werden (,war schon !WIT!zig mit DEM- $h^{\circ}$ (.) <<imitierend>个SQUEEZE> $m a: l .{ }^{\circ}{ }^{\prime}$ “, Z. 97). Außerdem können Reinszenierungen dazu dienen, „,die Gesprächsmühle am Laufen zu halten““ (Keppler 1995, 234), was auch durch ihre Serialität belegt werden kann (vgl. Ulmer \& Bergmann 1993). ${ }^{59}$ Nicht zuletzt zeigt sich der ästhetische Reiz von Theateraufführungen (z.B. im Kontrast zu bildender Kunst im Museum) darin, dass Reinszenierungen wie die untersuchten „vor allem [...] ihres Unterhaltungswertes willen“ (Keppler 1995, 234) und aus geselligem Vergnügen angebracht werden. Dies belegt auch das lachende Goutieren Monikas und Emmas eigenes Lachen in den beiden dargestellten Fällen (vgl. Günthner 2005).

\subsubsection{3 „oh ja ich HAB hie:r äh- (.) äh <<lachend>SCHElße〉 im gesicht implantiert" ${ }^{60}$ - Redewiedergaben}

Im Rahmen des in 3.3.2 beschriebenen reinszenierenden Darstellungsmodus von Theaterrekonstruktionen traten besonders häufig Redewiedergaben (als rekonstruktive Verfahren) innerhalb des Datenkorpus auf. In den beiden folgenden Ausschnitten wird der Frage nachgegangen, in welcher Form sich Redewiedergaben in Pausengesprächen im Theater manifestieren.

59 Neben den zwei hier aufgeführten Redewiedergaben verbalisiert Emma in den nächsten sieben Gesprächsminuten zwei weitere Male in identischer Form: „«<singend $>$ BODdy is boss $>$ “ (vgl. dazu Kapitel 2.1.4.1).

60 14-04-22 BrainAndBeauty Gr.2. 
Der folgende Ausschnitt entstammt dem Pausengespräch zwischen Irmgard und Cornelia, das sich zwischen dem Ende des Theaterstücks „Brain and Beauty“ und dem Beginn des anschließenden Publikumsgesprächs in der Theaterbar ereignet. Das Stück handelt von Schönheitsoperationen wie bereits in 3.1 und 3.2.1 erläutert wurde. Bevor der Ausschnitt beginnt, haben die Sprecherinnen amüsiert kurz Cornelias Selbstbedienung an Bonbons, die an einem Stehtisch ausliegen, thematisiert. Anschließend entstehen einige Gesprächspausen und Cornelia und Irmgard versichern sich kurz des Funktionierens der Aufnahmegeräte, woraufhin sich folgender Ausschnitt abspielt.

Ausschnitt 10: „«<lachend $>$ SCHEIße im gesicht implantiert“61

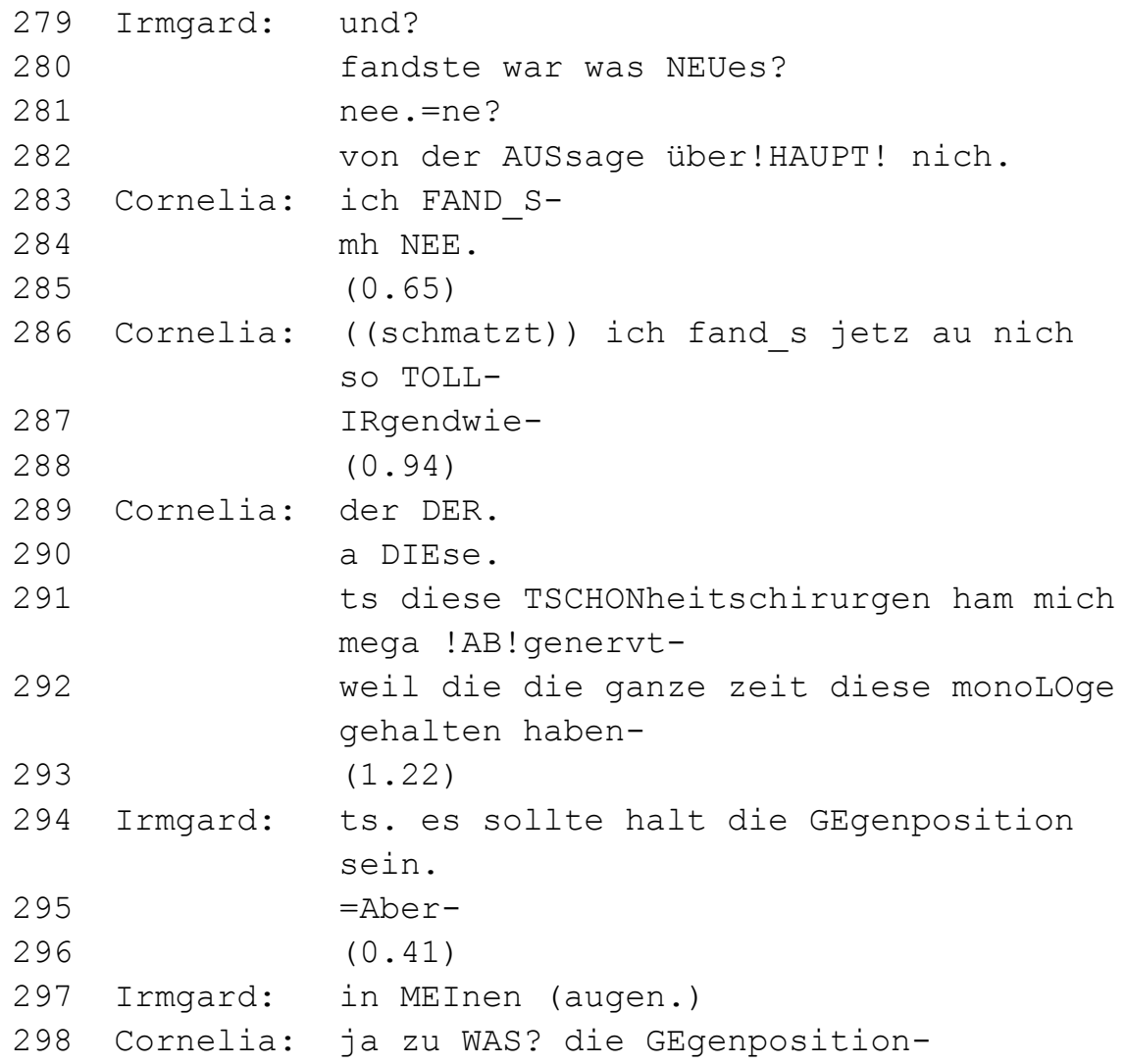

61 14-04-22 BrainAndBeauty Gr.2. 
299

300

301

302

303

304

305

306

307

308

309

310

311

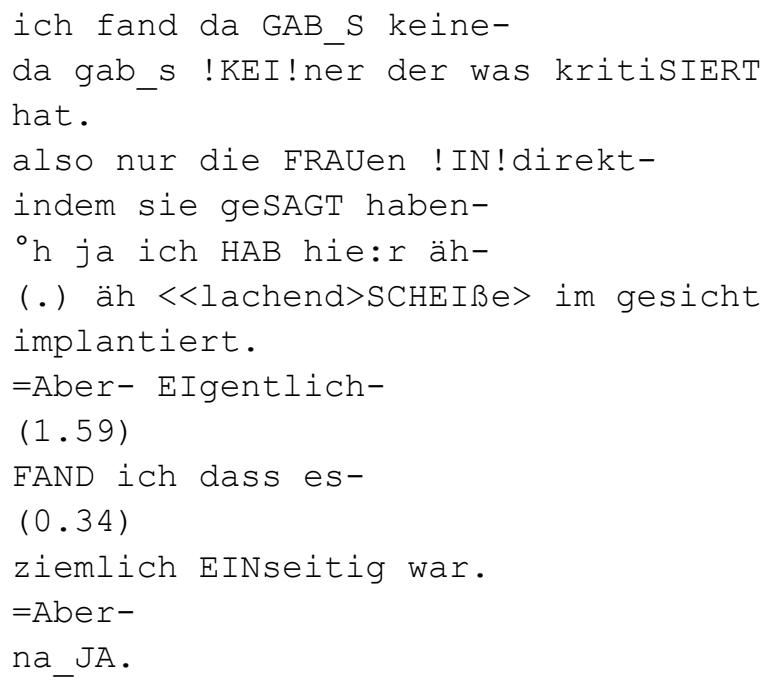

Irmgard (re-)initiiert die Rekonstruktion, indem sie in Form einer Frage und fragenden Antwort die Gesamtinszenierung rekonstruiert: „und? fandste war was NEUes? nee.=ne?“ (Z. 279-281). Zunächst bleibt der Referent ungenannt und die Sprecherin spezifiziert ihre Äußerung in Z. 282 in direktem Anschluss in Form einer Antwort: „von der AUSsage über!HAUPT! nich.“ Daraufhin beantwortet Cornelia Irmgards Frage, die sie als Einforderung nach dem Gesamteindruck während der Vorstellung behandelt: „ich FAND_S- mh NEE. (0.65) ((schmatzt)) ich fand_s jetz au nich so TOLL-IRgendwie-“ (Z. 283-287). Sie bringt diesen mit dreifacher Selbstreparatur und zwei Heckenausdrücken („au“ im Sinne von auch und „IRgendwie“) hervor. Nach diesem ersten Wahrnehmungsabgleich und einer Pause exemplifiziert Cornelia die Rekonstruktion des eigenen Erlebens der gesamten Vorstellung durch die Rekonstruktion ihres Eindrucks einer Gruppe von spezifischen Rollen und schauspielerischen Leistungen: „der DER. a DIEse. ts diese TSCHONheitschirurgen ham mich mega!AB!genervt- weil die die ganze zeit diese monoLOge gehalten haben-“ (Z. 189-292). Sie steigt in den reinszenierenden Darstellungsmodus ein, indem sie ihre emotionale Reaktion auf die Darstellung der Schönheitschirurgen durch den jugendsprachlichen, stark betonten und mehrfach gesteigerten (,mega“ und „!AB!“) Ausdruck „mega !AB!genervt-“ rekonstruiert. Irmgard rechtfertigt daraufhin die Darstellung der Schönheitschirurgen durch die deutende Rekonstruktion der Intention des Theaterregisseurs: „ts. es sollte halt die GEgenposition sein.=Aber- (0.41) in MEInen (augen.)“ (Z. 294-297). Im selben Redezug macht sie einen Versuch, diese Rechtfertigung in direktem Anschluss konzedierend durch eine individuelle 
Subjektivierung („Aber- (0.41) in MEInen (augen.)“ einzuschränken. Damit rekonstruiert sie ihre Wahrnehmung des Aufführungsaspekts. Daraufhin erfolgt der Höhepunkt der reinszenierenden Rekonstruktion in Form von Cornelias Aussage: „ja zu WAS? die GEgenposition- ich fand da GAB_S keine- da gab_s !KEI!ner der was kritiSIERT hat. also nur die FRAUen !IN!direkt-indem sie geSAGT haben- ${ }^{\circ}$ ja ich HAB hie:r äh- (.) äh <<lachend $>$ SCHEIße> im gesicht implantiert.“ (Z. 298-304). In dieser deutenden, reinszenierenden Rekonstruktion gibt die Sprecherin die Aussage des Stücks (in ihrer Umsetzung) wieder, welcher ihrer Meinung nach ein kontrastierender Aspekt („GEgenposition“) fehlt. Dazu stellt sie zunächst eine rhetorische Frage (,ja zu WAS? die GEgenposition“), die sie anschließend selbst beantwortet (,ich fand da GAB_S keine-“) und durch die Rekonstruktion ihrer Wahrnehmung eines Handlungsaspekts begründet: „ich fand da GAB_S keine-da gab_s !KEI!ner der was kritiSIERT hat.“ Diese Äußerung schränkt sie daraufhin konzedierend ein, indem sie einen weiteren spezifischen Handlungsaspekt rekonstruiert, der im (eingeschränkten: „nur [...] !IN!direkt“) Kontrast zu ihrer vorherigen Aussage steht: „also nur die FRAUen !IN!direkt- indem sie geSAGT haben- ${ }^{\circ} \mathrm{h}$ ja ich HAB hie:r äh- (.) äh $<<l a-$ chend $>$ SCHEIße $>$ im gesicht implantiert. " Cornelia exemplifiziert ihre Rekonstruktion der Stückaussage durch die Redewiedergabe: ,ja ich HAB hie:r äh- (.) äh $<<$ lachend $>$ SCHEIße > im gesicht implantiert.“ Im Sinne von Butterworth (2015) und Tannen (1989/2007) lässt sich diese Äußerung als Wiedergabe eines vollzogenen oder hypothetischen mündlichen kommunikativen Akts einordnen. Im Rahmen dieser Redewiedergabe klassifiziert Cornelia zunächst eine Gruppe von Rollen im Stück (,die FRAUen“) und führt explizit deren Rede als „fremde Stimme“ ein (Günthner 2002, 70): ,indem sie geSAGT haben-“. Diese zusammenfassende Klassifizierung sowie die auffällige Wortwahl (obszön: „SCHEIße“, technisch-medizinisch: „implantiert“) und der salopp-umgangssprachliche Stil (,ja ich HAB hie:r äh- (.) äh“) legen eine „Modifikation der ursprünglichen Aussage“ (Günthner 2002, 60) nahe. Statt eines wortwörtlichen Zitats der Aussage einer Schauspielerin scheint hier vielmehr eine zusammenfassend-deutende, hyperbolische Stilisierung der Sprecherinnengruppe vorzuliegen. Nach Günthner $^{62}(2002,75)$ werden „[b]estimmte Elemente der ,Original'-Äußerung [...] selektiert und in einem neuen Kontext so typisiert und verzerrt reproduziert, dass sie eine neue Bedeutung erlangen“. Konkret rekontextualisiert Cornelia die möglicherweise von den Schauspielerinnen getroffenen Aussagen auf eine hy-

62 Vgl. zur Polyphonie von Redewiedergaben auch Butterworth (2015); Buttny \& Cohen (2007); Clift (2007); Coulmas (1986); Couper-Kuhlen (2007); Günthner (2005); Holt (2007); Semino \& Short (2004); Tannen (1989/2007). 
perstilisierte, negativierte Art, durch die ihr Inhalt (negative Aspekte von Schönheitsoperationen) lächerlich gemacht wird und die Figuren karikiert werden (vgl. Günthner 2002, 75). Auf diese Weise vermischen sich die „Stimmen der Zitierenden und der zitierten Figur[en]“63 (Günthner 2002, 70) im Sinne einer Polyphonie der Redewiedergabe. Anschließend fährt die Sprecherin mit der Rekonstruktion ihres Eindrucks der Stückaussage fort: „=Aber-EIgentlich- (1.59) FAND ich dass es- (0.34) ziemlich EINseitig war. =Aber-na_JA.“ (Z. 305-311). Daraufhin entstehen eine zweisekündige Pause, sowie ein Themenwechsel (zu Fotos in Cornelias Handy). Irmgard nutzt keine Pause, um Cornelia zu widersprechen. Die Sprecherinnen behandeln Cornelias letzte Äußerung „=Aberna_JA.“ als thematischen Abschluss.

Resümierend veranschaulicht Ausschnitt 10, wie Reinszenierungen im Allgemeinen und Redewiedergaben im Speziellen als „typisches Muster von Rekonstruktionen in Foyergesprächen“ (Linz, Hrncal \& Schlinkmann 2017, 533) realisiert werden. Es wird eine gewisse Unschärfe bei der Einordnung von Redewiedergaben in diesem spezifischen Kontext als Wiedergabe von (vollzogenen) hypothetischen oder vergangenen kommunikativen Akten deutlich, die in der Polyphonie der Redewiedergabe begründet ist. Letztere äußert sich u.a. in der Hyperstilisierung der zitierten Figuren z.B. durch Wortwahl, Stil und Typisierung. Ähnlich der von Günthner (2002, 2005) festgestellten Mittel der Prosodie, der Stimmqualität und des Codeswitchings können auch diese Mittel der Hyperstilisierung im Rahmen von Redewiedergaben von den Sprechern als „indexikalische Zeichen“ (Günthner 2002, 60) zur Interpretation der Aussage behandelt werden. In diesem Kontext ermöglichen Redewiedergaben als „Ästhetisierungsphänomene [...] in der Alltagskommunikation“ Rückschlüsse über die „Normen des betreffenden sozio-kulturellen Milieus“ (Günthner 2002, 75-76). In Ausschnitt 10 gibt es im Rahmen dieser Beobachtung z.B. Hinweise auf die zugrunde liegende Annahme der Sprecherinnen, eine gesellschaftspolitische Theaterinszenierung solle in ihrer Intention konträre Positionen verhandeln.

\subsection{4 „jetz geht_s aber SCHON weiter.“64 - Ausstiege aus Rekonstruktionen}

Abschnitt 8.3.3 beschäftigte sich mit der Entfaltung von Rekonstruktionen im Laufe von Theaterpausengesprächen. Dabei ließen sich zwei Unterscheidungen

63 Die Stimmen stehen demnach in einem Verhältnis der „Interanimation“ (Günthner 2002, 70) und nach Goffman (1981a) ruft dies ein neues „Footing“ für die Interaktion hervor.

64 14-04-22 BrainAndBeauty Gr.2. 
feststellen: Einerseits bezüglich der Funktion mit Blick auf den Wissensstatus der Sprecher und andererseits in Bezug auf den Darstellungsmodus. So weisen Rekonstruktionen unterschiedliche Merkmale und Verfahren auf, abhängig davon, ob mindestens einer der Sprecher über einen Rekonstruktionsinhalt informiert wird (informierende Funktion) oder ob alle Sprecher den Inhalt kennen und ihn gemeinsam rekonstruieren (kommemorierende Funktion). Ebenfalls wurden Differenzen bezüglich einer berichtenden im Gegensatz zu einer reinszenierenden Darstellungsweise von Theaterrekonstruktionen exemplarisch aufgezeigt. Nicht zuletzt wurde der Spezialfall der für Theaterrekonstruktionen typischen reinszenierenden Redewiedergabe anhand eines Gesprächsbeispiels dargestellt. Anknüpfend an die diversen Möglichkeiten der Entfaltung von Theaterrekonstruktionen stellt sich die Frage, wie Theaterrekonstruktionen von den Sprecher beendet werden. Um dieser Frage nachzugehen, kehren wir zu dem Gespräch zwischen Cornelia und Irmgard zurück, aus dem bereits der letzte Ausschnitt (10) stammt. Ausschnitt 10 wird gefolgt von einem kurzen Themenwechsel zu zwei Fotos in Cornelias Handy. In direktem Anschluss daran ereignet sich folgender Ausschnitt:

Ausschnitt 11: ,jetz hat_s aber geKLINGelt.“65

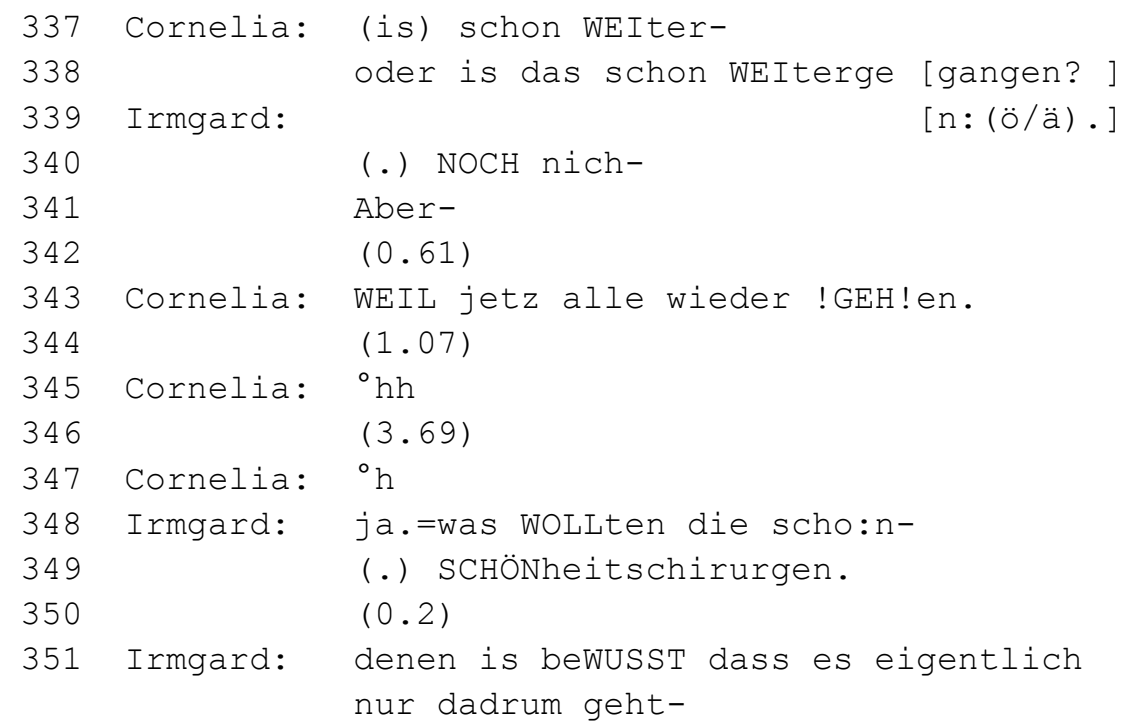

65 14-04-22 BrainAndBeauty Gr.2. 


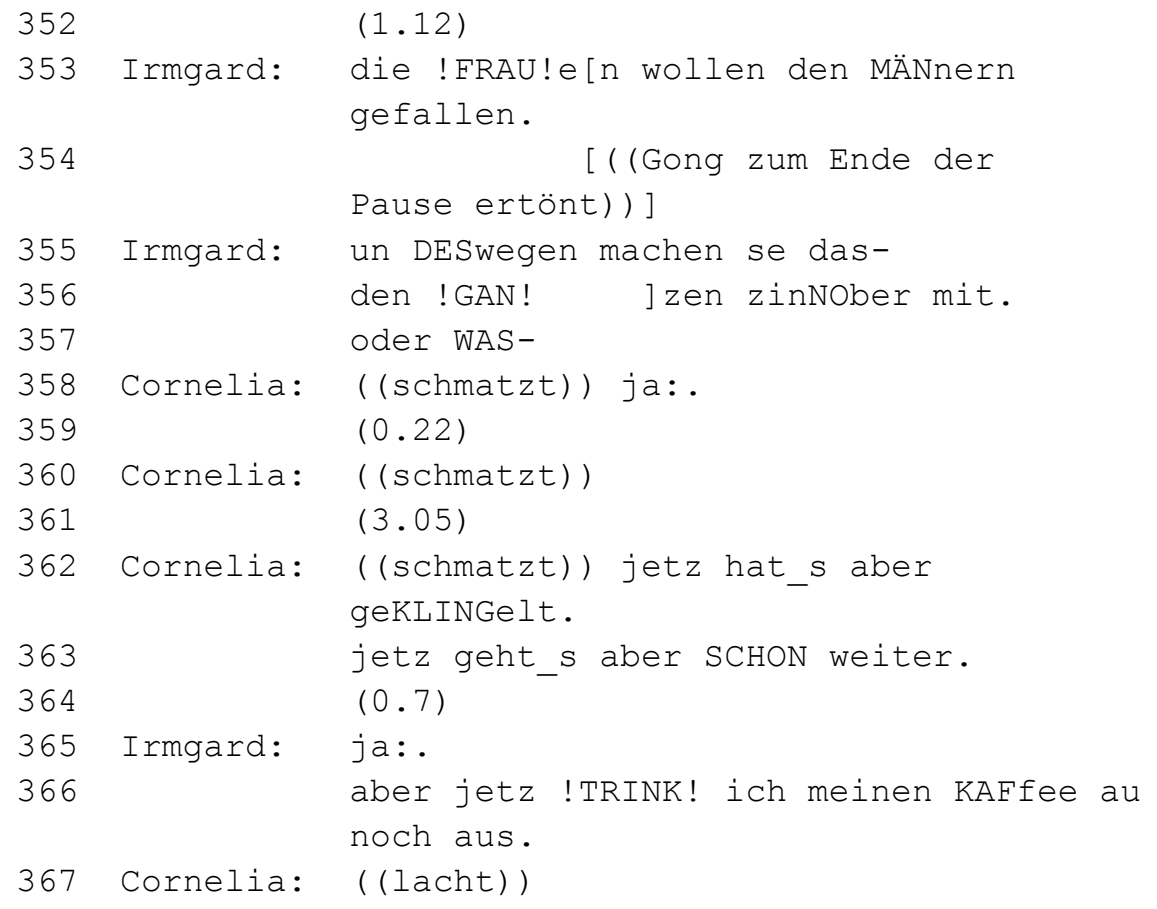

Zunächst verhandeln die Sprecherinnen in Zeile 337-343 die Frage, ob das Theaterstück „schon WEIterge[gangen?]“ (Z. 338) sei. Sie kommen aber zu keiner eindeutigen Antwort und es entstehen einige (gefüllte) Pausen (Z. 344-347). ${ }^{66}$ Daraufhin nimmt Irmgard die in Ausschnitt 11 unterbrochene Rekonstruktion der Stückintention wieder auf: ,ja.=was WOLLten die scho:n- (.) SCHÖNheitschirurgen. (0.2) denen is beWUSST dass es eigentlich nur dadrum geht- (1.12) die !FRAU!en wollen den MÄNnern gefallen. un DESwegen machen se das- den !GAN!zen zinNOber mit. oder WAS-“ (Z. 348-357). Irmgard rekonstruiert zunächst die Intention der Rolle der Schönheitschirurgen in Form einer syntaktischen Frage, die sie jedoch nicht fragend intoniert und daraufhin selbst beantwortet: „,ja.=was WOLLten die scho:n- (.) SCHÖNheitschirurgen.“ Mit „die [...] SCHÖNheitschirurgen." referiert sie dabei auf die bereits in Ausschnitt 11 als Gruppe klassifizierte Rolle der im Stück dargestellten Schönheitschirurgen. In ihrer Antwort vergegenwärtigt sie ihre Interpretation der Darstellung der

66 Die Zeilen 337-347 geben im Sinne einer Präsequenz oder Vorankündigung Hinweise auf die Bereitschaft der Sprecherinnen, aus der Rekonstruktion auszusteigen (vgl. die gefüllten Pausen in Z. 344-347). 
Schönheitschirurgen: „denen is beWUSST dass es eigentlich nur dadrum geht(1.12) die !FRAU!en wollen den MÄNnern gefallen. un DESwegen machen se dasden !GAN!zen zinNOber mit. oder WAS-“. Dazu rekonstruiert sie den Gedankengang der Chirurgen (,denen“), indem sie einen hypothetisch vollzogenen mentalen kommunikativen Akt wiedergibt (vgl. Butterworth 2015; Tannen 1989/2007): „die !FRAU!en wollen den MÄNnern gefallen. un DESwegen machen se das- den !GAN!zen zinNOber mit.“ Dabei ist das Bezugsobjekt zu „denen“ u.a. durch den Wechsel ins Präsens (,is“) nicht eindeutig. Imrmgard changiert in der Rekonstruktion zwischen den Ebenen der Theaterinszenierung und allgemeinen Feststellungen über Schönheitschirurgen und Frauen in der gesellschaftlichen Realität (vgl. Präsens: „wollen“, „machen“; verallgemeinernde Klassifizierungen: „die !FRAU!en“ und „den MÄNnern“). ${ }^{67}$ Darüber hinaus wird in dieser Redewiedergabe durch den umgangssprachlichen abwertenden Ausdruck „den !GAN!zen zinNOber“ als negative Perspektivierung die Stimme der Sprecherin im Sinne einer Polyphonie evident. Durch das Frageanhängsel „oder WAS-“ (Z. 357) fordert Irmgard schließlich eine Partizipation Cornelias an der Rekonstruktion ein. Cornelia behandelt Irmgards Äußerung inklusive uneindeutiger Referenzen, changierender Bezugsebenen und einer perspektivierenden Redewiedergabe als unproblematisch und ratifiziert die Rekonstruktion in Zeile 358 durch „((schmatzt)) ja:.“. Während Irmgards Redezug ertönt der Gong zum Ende der Pause (Z. 354) und im Anschluss an Cornelias Ratifizierung entstehen einige (gefüllte) Pausen (Z. 359-362). Daraufhin kommentiert Cornelia das akustische Signal zum Pausenende (,jetz hat_s aber geKLINGelt. jetz geht_s aber SCHON weiter.“, Z. 362-363), was wiederum von Irmgard ratifiziert wird (,ja:.“, Z. 365). Nach dieser äußeren Einflussnahme auf das Gespräch initiiert Cornelia an dieser Stelle einen Themenwechsel und die Sprecherinnen behandeln die Rekonstruktion somit als abgeschlossen. Irmgard bestätigt den gemeinsamen Ausstieg aus der Rekonstruktion nochmals durch die Fokussierung auf die Organisation der Pausenbeendigung: „aber jetz !TRINK! ich meinen KAFfee au noch aus.“ (Z. 366), woraufhin Cornelia lacht. Im anschließenden letzten Teil des Pausengesprächs begeben sich die beiden Sprecherinnen zu ihren Plätzen zurück und besprechen dabei die Mitnahme von Getränken in den Theatersaal und das Aufsuchen ihrer Plätze.

Ausschnitt 11 illustriert die Tendenz der Theaterbesucher(innen), äußere Einflüsse, die das Zu-Ende-Gehen der Pause mit herstellen, zum Anlass zu nehmen, ihre Rekonstruktion(en) zu beenden. Mögliche Beispiele sind der Pausengong oder der Beginn des zweiten Teils des Theaterstücks oder des Publi-

67 Vgl. übertragender Kontext in Abschnitt 8.3.2.3. 
kumsgesprächs. Der Ausstieg erfolgt dabei, indem die Sprecher sich das Ende wechselseitig anzeigen und/oder zu einem anderen Thema wechseln. Das Gesprächskorpus deutet darauf hin, dass die Pausengespräche bis zu diesem Ausstieg in einem Modus der Rekonstruktion stattfinden, in den die Sprecher immer wieder einsteigen. Diese Wiedereinstiege erfolgen z.B. nach längeren Pausen ( $Z$. 344-347) oder nach Exkursen zu anderen nicht-rekonstruktiven Aktivitäten wie der Klärung organisatorischer Fragen (WC-Besuch, Essen und Trinken, Abschätzung der Länge der Pause etc.) oder Inhalten, die in keiner offensichtlichen (thematischen) Verbindung zur Theaterinszenierung stehen (Renovierung des eigenen Bads, Babysitter der Kinder, gemeinsamer Restaurantbesuch etc.). Schließlich fällt im Datenkorpus die Tendenz der Sprecher auf, von Rekonstruktionen des Theaterereignisses und anderer Medienereignisse überzugehen $\mathrm{zu}$ (rekonstruierenden) Übertragungen der thematisierten Rekonstruktionsinhalte auf die gesellschaftliche Realität bzw. die eigene Lebenswelt (vgl. Abschnitt 8.3.2.4) oder zu eigenständigen Ereignisrekonstruktionen. ${ }^{68}$ Nicht zuletzt steht Ausschnitt 11 exemplarisch für das sich im Datenkorpus abzeichnende Muster, erst mit Gesprächsende aus dem rekonstruktiven Modus auszusteigen.

\subsection{Zusammenfassung der Ergebnisse und Ausblick}

Der vorliegende Beitrag führte zunächst in die der Analyse zugrunde liegenden Konzepte der kommunikativen Gattung und des kommunikativen Haushalts ein. Anschließend wurden auf der Basis konversations- und gattungsanalytischer Untersuchungen einige für die Analyse des Datenkorpus relevante rekonstruktive Verfahren vorgestellt sowie ein Augenmerk auf verschiedene Kontexte von Rekonstruktionen gelegt. Im Anschluss wurden 11 exemplarische Ausschnitte aus dem Datenkorpus im Hinblick auf die darin vorkommenden Rekonstruktionen analysiert. Die Untersuchungen der Rekonstruktionen zielten auf Muster in Bezug auf Subtypen und Inhalte rekonstruktiver Verfahren, Einstiege in Rekonstruktionen mit Fokus auf ihre kontextuelle Einbettung, Entfaltungen von Rekonstruktionen im Hinblick auf Funktion und Darstellungsmodus und Ausstiege aus Rekonstruktionen.

Die Sprecher(innen) thematisieren innerhalb der Rekonstruktionen in den untersuchten Pausengesprächen vor allem drei inhaltlich und formal vonei-

68 Der Ausstieg aus Rekonstruktionen vor solchen Exkursen und der Übergang zu Übertragungen und Ereignisrekonstruktionen kann hier aus Platzgründen nicht weiter ausgeführt werden. 
nander abgrenzbare Bereiche: Einerseits das Erlebnis der Theaterinszenierung selbst, andererseits andere Medienereignisse und nicht zuletzt Aspekte der Welt außerhalb des Theaters (vgl. Abschnitt 8.3.1). Die Vergegenwärtigung der Theaterinszenierung und anderer Medienereignisse erfolgt in Form verschiedener rekonstruktiver Verfahren und Subtypen, die sich in Bezug auf ihren Inhalt, ihre Sprecherbeteiligung, ihre Einbettung in das Gespräch, ihren Umfang und ihre sprachlich-kommunikativen Merkmale voneinander abgrenzen: Angelehnt an die Unterscheidung zwischen Medienrekonstruktionen und Medienverweisen (vgl. Ulmer \& Bergmann 1993 und Keppler 1995) wurde im spezifischen Kontext von Theaterpausengesprächen die Unterscheidung zwischen Theaterrekonstruktionen („es is halt überHAUPT nich konsistent.“) und rekonstruierenden Theaterverweisen (,dann kommt aber einer in SOcken daher-“), sowie rekonstruierenden Medienverweisen (,früher GAB_S wenigstens noch- $n$ Obertitel-in der Oper-") herausgearbeitet. Bezüglich der spezifischen Merkmale der drei Rekonstruktionstypen zeigten die Gesprächsausschnitte 1 und 2 hauptsächlich, dass Theaterrekonstruktionen umfangreicher als Verweise sind, über einen gewissen Gesprächsabschnitt von mehreren Sprecher(inne)n als alleiniges Thema behandelt werden und einen hohen Geselligkeitswert aufweisen (vgl. Verwendung von Reinszenierungen, Übertreibungen, parodistischen Elementen und emotiven Ausdrücken). Dahingegen werden die kurzen rekonstruierenden Verweise in einen übergeordneten thematischen Gesprächskontext eingebettet (z.B. eine Argumentation). Ergänzend zu diesen Erkenntnissen illustriert das Gesprächsmaterial, dass sich Theaterverweise in Pausengesprächen durch ihre vagen Bezugnahmen und die fehlende Nennung der Wissensquelle von Medienverweisen unterscheiden. Außerdem werden die Verschachtelung von Rekonstruktionstypen und -themen und ihre fließenden Übergänge deutlich. Die Sprecher betten rekonstruktive Verweise, reinszenierende Redewiedergaben und untergeordnete Rekonstruktionen von Einzelaspekten in einen übergeordneten rekonstruktiven Zusammenhang ein, so dass die gesamte übergeordnete, zusammenhängende kommunikative Einheit in einem Modus der Rekonstruktion erfolgt.

Die Untersuchung der Einstiege in Rekonstruktionen belegt zum einen die Relevanz von Rekonstruktionen in Theaterpausengesprächen, z.B. anhand der antizipierenden Reaktion auf abgebrochene Fragen in Form von Rekonstruktionen oder anhand der Häufigkeit von Rekonstruktionseinstiegen am unmittelbaren Gesprächsbeginn (vgl. Abschnitt 8.3.2). Zum zweiten konnten drei typische Rekonstruktionskontexte festgehalten werden, in welche die Sprecher(innen) Rekonstruktionen bereits während des Einstiegs sprachlich-kommunikativ einbetten: Zunächst ein bewertender und ein deutender Kontext, die auch 
Hausendorf \& Müller (2016a) für die Ausstellungskommunikation konstatieren. In Ergänzung ist das Übertragen als zusätzliche für Theaterpausengespräche relevante Kategorie festzuhalten. Im Datenkorpus konnte eine Tendenz der Sprecher konstatiert werden, von Rekonstruktionen des Theaterereignisses und anderer Medienereignisse überzugehen $\mathrm{zu}$ Übertragungen der thematisierten Rekonstruktionsinhalte auf die gesellschaftliche Realität bzw. die eigene Lebenswelt. Mit Fokus auf die charakteristischen rekonstruktiven Verfahren und sprachlichen Mittel, die in den verschiedenen Kontexten zur Anwendung kommen, ist festzuhalten, dass die Sprecher(innen) im bewertenden Kontext zur Einbettung z.B. verba sentiendi oder evaluierende Adjektive verwenden, wohingegen der deutende Kontext von einer Redewiedergabe, einem Medienverweis, einer Typisierung und einem hypothetisch-fragenden Unterton geprägt wird. In Abgrenzung dazu kennzeichnen das Changieren zwischen den Bezugsebenen (der Inszenierung, der eigenen Deutung und der gesellschaftlichen Realität) und eine teilweise unausgeglichene und tentative Gesprächsbeteiligung den Kontext des Übertragens. Abweichend vom Bewerten und Deuten in der Ausstellungskommunikation gibt es Hinweise darauf, dass der deutende Kontext in Theaterpausengesprächen ebenso relevant gesetzt wird wie der bewertende. Außerdem bestätigen die Daten die Tendenz, die Keppler (1995) ebenfalls im Rahmen von Familientischgesprächen feststellt, dass die Sprecher(innen) die gemeinsame kommunikative Initiierung einer reibungslosen Rekonstruktion relevanter setzen als den Inhalt der Rekonstruktion (vgl. Ausschnitt 3). Nicht zuletzt lässt sich festhalten, dass die Sprecher(innen) die kontextuelle Einbettung der Rekonstruktionen ständig verhandeln und fließend zwischen den Kontexten wechseln (vgl. Ausschnitt 3, 4 und 5).

Bezüglich der weiteren Entfaltung von Rekonstruktionen können angelehnt an Ulmer \& Bergmann (1993) zwei verschiedene Funktionen von Rekonstruktionen bezüglich des Wissensstatus der Sprecher(innen) festgehalten werden: Einerseits die informierende Funktion und andererseits die kommemorierende (vgl. Abschnitt 8.3.3). Wie Rekonstruktionen anderer Medienereignisse (vgl. Abschnitt 8.3.3) werden informierende Rekonstruktionen und Verweise von einer vorgeschalteten expliziten Wissensabklärung und Positionierung als Erzähler oder Zuhörer, von einer anfänglichen Erzählaufforderung und von Beendigungsverfahren im Sinne der wechselseitigen Kommentierung des Rekonstruktionsgegenstandes geprägt (vgl. Ausschnitt 6). Im Kontrast dazu zeichnet sich die kommemorierende Funktion von Theaterrekonstruktionen und -verweisen durch die selektive und fragmentarische Rekonstruktion von einzelnen besonders relevanten (z.B. interessanten, amüsanten, ärgerlichen) Aspekten sowie durch durchgängige bewertende und interpretierende Kommentare und kleine 
Belehrungen aus (vgl. Keppler 1995; Ausschnitt 7). Ein weiteres Ergebnis für sowohl informierende als auch kommemorierende Theaterrekonstruktionen und -verweise richtet sich auf die Frage, ob alle Sprecher(innen) das gleiche Medienereignis, auf das sie sich beziehen, erlebt haben. Bezüglich dieser Frage erfolgt im Rahmen beider Funktionen ein ständiger laufender Wahrnehmungsabgleich und ein ständiges Aushandeln der (nicht-)wissenden Positionen. Einerseits setzen die Sprecher(innen) ein gewisses geteiltes Wissen über das Theaterereignis voraus, so dass z.B. auch in der informierenden Funktion keine chronologische, vollständige Schilderung des Rekonstruktionsaspekts stattfindet. Andererseits gleichen sie permanent kommunikativ ab, was sie wahrgenommen haben und inwieweit ihre Wahrnehmungen kongruent sind. Zudem setzen die Sprecher(innen) auch in den untersuchten kommemorierenden und informierenden Rekonstruktionen reinszenierende Verfahren (z.B. das Verstellen der Stimme und Redewiedergaben) und das Changieren zwischen verschiedenen Bezugsebenen relevant.

Neben den unterschiedlichen Funktionen von Rekonstruktionen, die sich die Sprecher(innen) in ihrem Verlauf wechselseitig aufzeigen, wurden am Datenmaterial zwei Darstellungsmodi deutlich: der berichtende und der reinszenierende (vgl. Keppler 1995; Kotthoff 2011; Ulmer \& Bergmann 1993). Kurz gefasst stimmen die Ergebnisse bezüglich der berichtenden Darstellungsweise in großen Teilen mit den von Kotthoff (2011) festgehaltenen Eigenschaften des Berichtens überein. So findet sich im Gespräch (vgl. Ausschnitt 8) kaum eine Dramatisierungsstrategie oder Detaillierung, sondern eine relativ sachliche, faktische Darstellung, die in einer Quintessenz endet. Zusätzlich zu diesen Ergebnissen äußert Finn eine rekonstruierende Redewiedergabe, die von den Beteiligten aber weniger als Dramatisierung, sondern vielmehr als Beleg für den Wahrheitsanspruch behandelt wird.

Im Kontrast dazu steht der reinszenierende Darstellungsmodus, der durch dramatisierende Geräuschimitationen, Singen und Redewiedergaben einzelner Inszenierungsdetails charakterisiert ist (vgl. Ausschnitt 9). Die Sprecher(innen) behandeln diese Reinszenierungen als Belege oder Illustrationen von bewertenden Rekonstruktionen (vgl. Couper-Kuhlen 2007), und sie behandeln sie als Elemente der Gesprächserhaltung, Erheiterung und Unterhaltung. Diesen Sinn verdeutlichen u.a. lachendes Goutieren sowie die Serialität von Reinszenierungen (vgl. Keppler 1995; Günthner 2002; 2005).

In der Analyse der Ausschnitte 1-9 wurde die Relevanz von Redewiedergaben als typisches Muster von Rekonstruktionen in Theaterpausengesprächen evident - unabhängig vom Kontext, der Funktion und dem Darstellungsmodus der Rekonstruktionen (vgl. Linz, Hrncal \& Schlinkmann 2016). Darüber hinaus 
geht aus Ausschnitt 10 als Ergebnis hervor, dass ebensolche Redewiedergaben von den Sprecher(inne)n nicht eindeutig als Wiedergabe von vollzogenen oder hypothetischen kommunikativen Akten eingeordnet werden. Vielmehr spielen sie mit der Polyphonie von Redewiedergaben, in der sich z.B. durch die Hyperstilisierung der zitierten Figuren sowohl die Sprecherstimme als auch die Stimme der zitierten Figur ausdrücken. So können Redewiedergaben als indexikalische Ästhetisierungsphänomene Rückschlüsse über die Normen und Werte des jeweiligen soziokulturellen Milieus ermöglichen.

In Bezug auf Ausstiege aus Rekonstruktionen zeigen die Analysen des Datenkorpus, dass die Beteiligten in der Mehrheit der Gespräche äußere Einflüsse, die das Ende der Pause mit herstellen (wie den Pausengong oder den Beginn des zweiten Teils), zum Anlass nehmen, aus den Rekonstruktionen auszusteigen. Dazu verbalisieren sie entweder das Pausenende und/oder wechseln zu einem nicht-rekonstruktiven Thema (z.B. dem Aufsuchen der Sitzplätze). In diesem Sinne bildet das Datenkorpus die Tendenz ab, erst am Pausenende aus den (Teil)Rekonstruktionen auszusteigen. Auch nach Exkursen in andere nichtrekonstruktive Themen im Laufe der Pausengespräche erfolgt in der Mehrheit der Gespräche teils mehrmals ein Wiedereinstieg in Rekonstruktionen. Dies illustriert den im Hintergrund über weite Strecken mitlaufenden Zugzwang zur Rekonstruktion in Theaterpausengesprächen.

Bezüglich der Frage, ob sich im Datenkorpus rekonstruktive Gattungen auffinden lassen, stellen die genannten Muster und Tendenzen zumindest exemplarisch Hinweise auf gattungsartige Verfestigungen dar. Vor allem die Subtypen der Theaterrekonstruktion, des rekonstruierenden Theaterverweises und des rekonstruierenden Medienverweises bergen aufgrund ihrer komplexen Merkmalskombinationen und der Häufigkeit ihres Auftretens das Potenzial (kleiner) kommunikativer Gattungen. Allerdings bedürfen alle Muster einer weiteren Überprüfung hinsichtlich ihres Verfestigungsgrads anhand einer größeren Datenmenge sowie hinsichtlich der Kombination einer größeren Anzahl von Merkmalen auf verschiedenen gattungsanalytischen Ebenen.

Anknüpfend an die in diesem Beitrag dargestellten Ergebnisse stellen sich einige Fragen an Theaterpausengespräche und speziell an die darin enthaltenen Rekonstruktionen, welche noch einer Beantwortung bedürfen:

- Sind die herausgearbeiteten Merkmalskombinationen so stark verfestigt und so komplex, dass sie als (kleine) kommunikative Gattungen charakterisiert werden können?

- Welchen Einfluss haben die sozialen Beziehungen der Sprecher(innen) auf die Pausengespräche und Rekonstruktionen? 
- Inwieweit unterscheiden sich die Gespräche und rekonstruktiven Verfahren in Abhängigkeit vom jeweiligen Stück, das besucht wurde?

- Wie gestalten die Sprecher(innen) Rekonstruktionen von Inhalten der Welt außerhalb des Theaters (z.B. Ereignisrekonstruktionen oder Alltagserzählungen)?

- In welchem Verhältnis stehen der fachliche Austausch über Theater als Kunst (Kunstkommunikation), die vergnügliche, unterhaltsame Geselligkeit von Pausengesprächen und die soziale Positionierung der Sprecher(innen) (z.B. durch Membership Categorization Devices; Schegloff 2007)? Und welche Rolle spielen Rekonstruktionen dabei? 